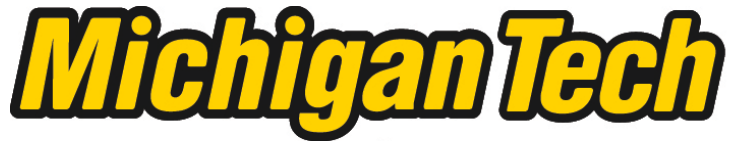 \\ Michigan Technological University Create the Future Digital Commons @ Michigan Tech
}

2015

NON-PULSITILE SHEAR DRIVEN ANNULAR FLOW-BOILING INVESTIGATIONS

Timothy M. Frasier

Michigan Technological University

Follow this and additional works at: https://digitalcommons.mtu.edu/etds

Part of the Engineering Commons

Copyright 2015 Timothy M. Frasier

\section{Recommended Citation}

Frasier, Timothy M., "NON-PULSITILE SHEAR DRIVEN ANNULAR FLOW-BOILING INVESTIGATIONS", Master's Thesis, Michigan Technological University, 2015.

https://doi.org/10.37099/mtu.dc.etds/980

Follow this and additional works at: https://digitalcommons.mtu.edu/etds

Part of the Engineering Commons 


\title{
NON-PULSITILE SHEAR DRIVEN ANNULAR FLOW-BOILING
} INVESTIGATIONS

\author{
By \\ Timothy M. Frasier
}

\begin{abstract}
A THESIS
Submitted in partial fulfillment of the requirements for the degree of MASTER OF SCIENCE

In Engineering Mechanics
\end{abstract}

MICHIGAN TECHNOLOGICAL UNIVERSITY

2015

(C) 2015 Timothy M. Frasier 
This thesis has been approved in partial fulfillment of the requirements for the Degree of MASTER OF SCIENCE in Engineering Mechanics.

Department of Mechanical Engineering-Engineering Mechanics

Thesis Advisor: Dr. Amitabh Narain

Committee Member: Dr. Scott A Miers

Committee Member: Dr. Allan Struthers

Department Chair: William W. Predebon 
To my family, friends and colleagues who have given support and motivation. 


\section{Table of Contents}

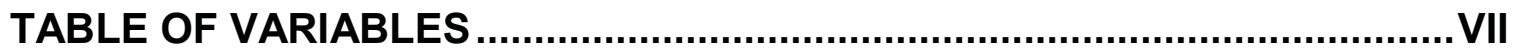

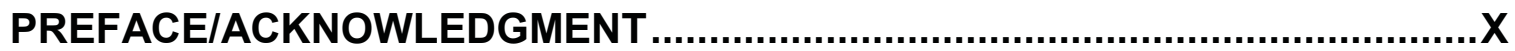

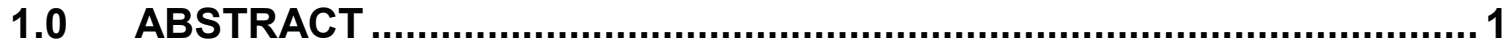

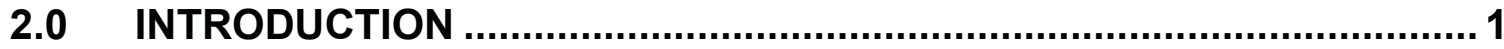

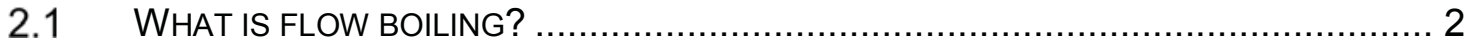

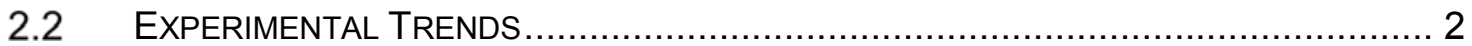

2.3 ACHIEVING HIGH HEAT FLUX IN MICROCHANNEL / MINI-CHANNEL ...................... 3

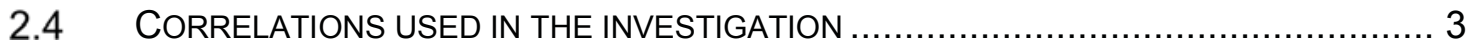

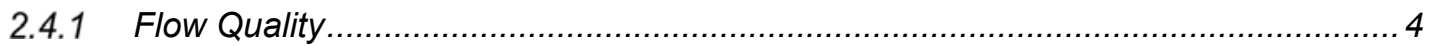

2.4.2 Heat Transfer Coefficient (HTC) Correlations ..................................................... 5

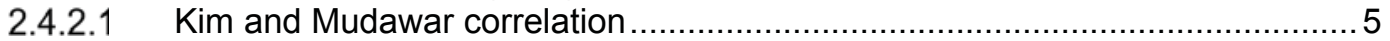

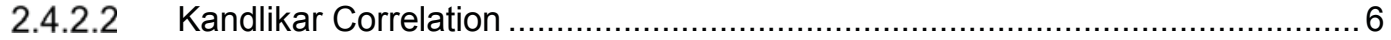

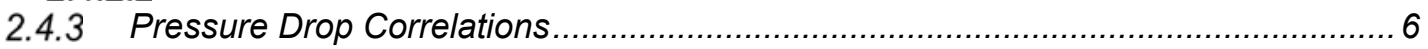

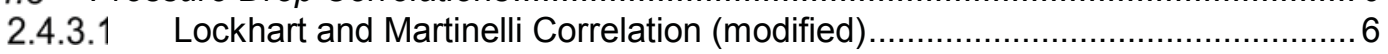

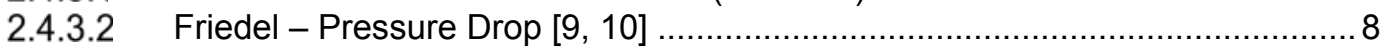

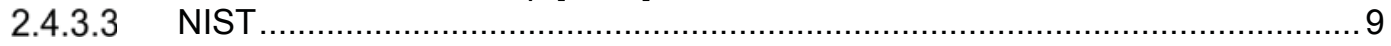

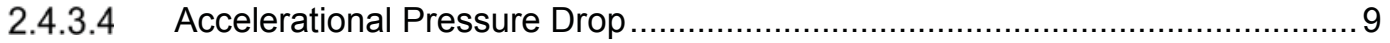

2.4.3.5 Gravitational Pressure Drop ………...................................................... 9

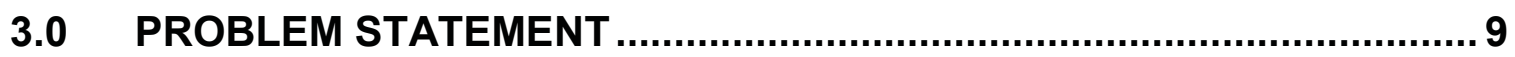

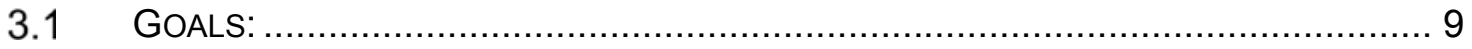

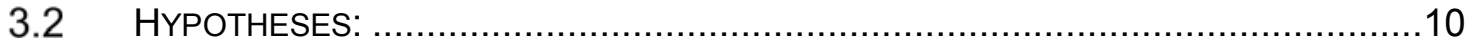

4.0 EXPERIMENTAL METHODS ........................................................ 11

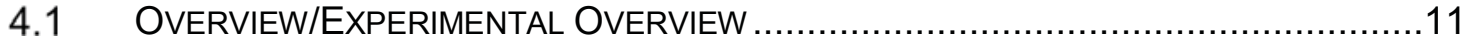

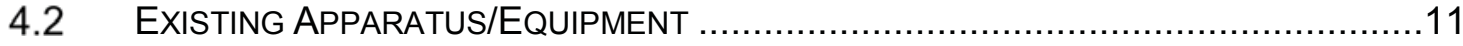

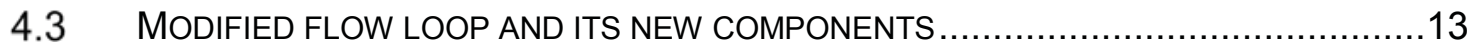

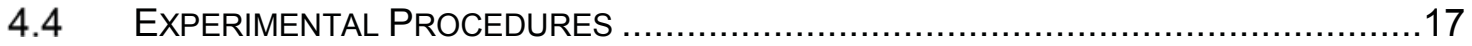

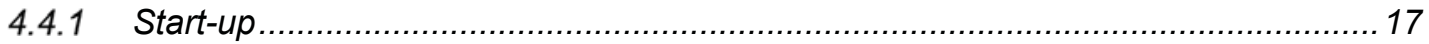

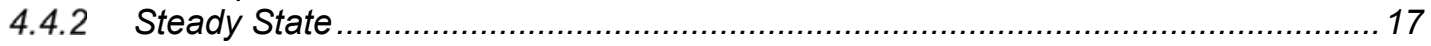

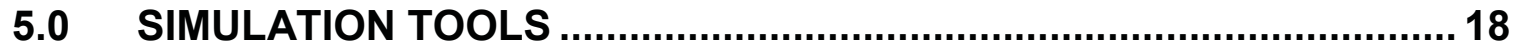

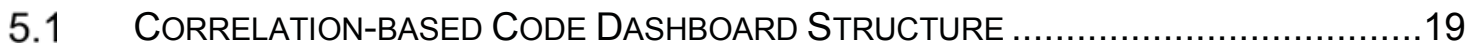

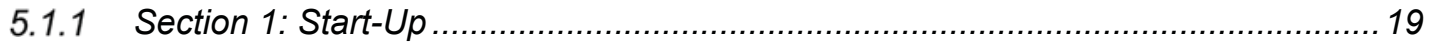

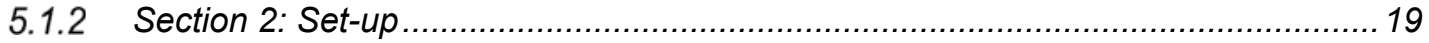

5.1.3 Section 3: Define Geometric Properties......................................................... 20

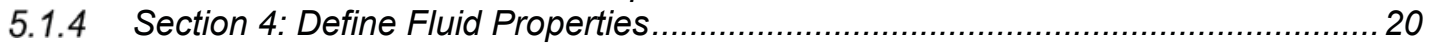

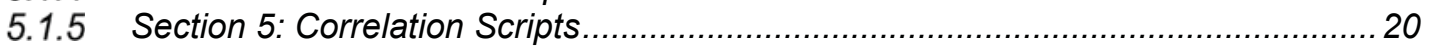

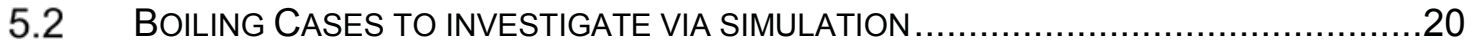

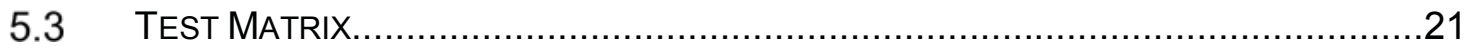

5.4 SET-UP OF EXPERIMENTAL COMPARISONS TO PREVIOUS EXPERIMENTS $\ldots \ldots \ldots \ldots \ldots .22$

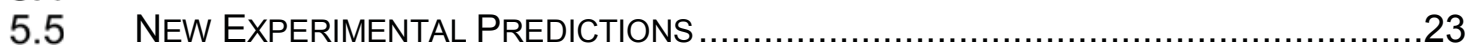

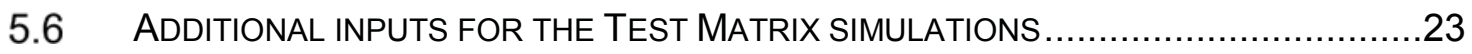

6.0 RESULTS (DATA AND OBSERVATIONS) …..................................... 24

6.1 SIMULATION OF N-IF CASES AND COMPARISON TO EXPERIMENTAL DATA .............24 


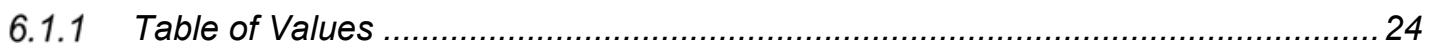

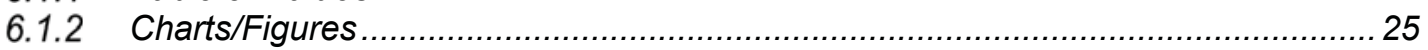

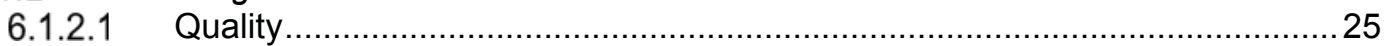

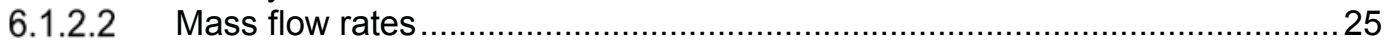

6.1.2.3 HTC

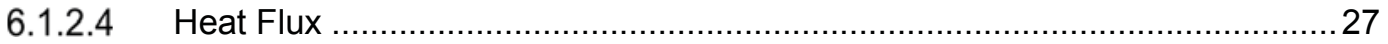

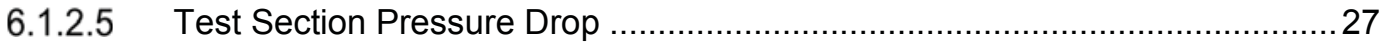

6.2 Simulation PREDICTIONS FOR THE NEW TEST SECTION LENGTH (N-IF) .............29

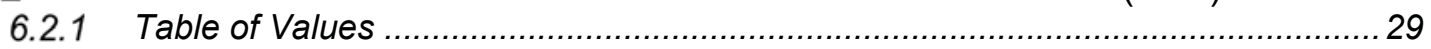

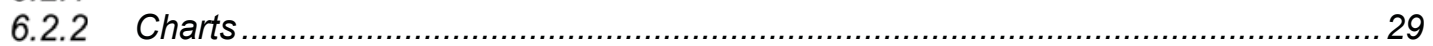

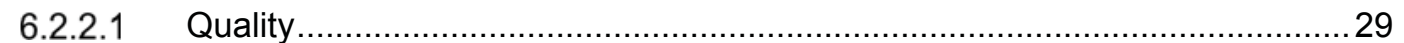

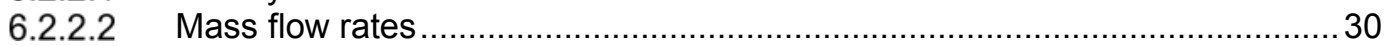

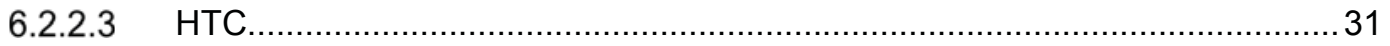

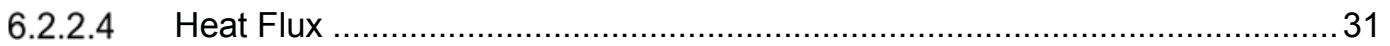

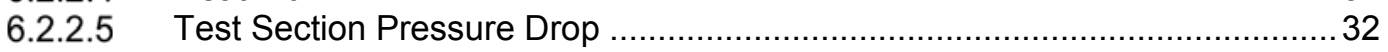

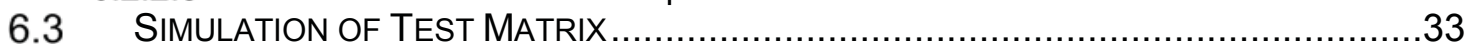

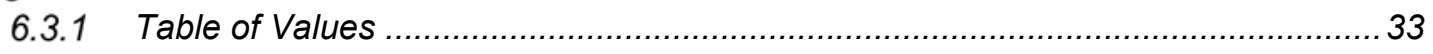

7.0 DISCUSSIONS ........................................................................... 34

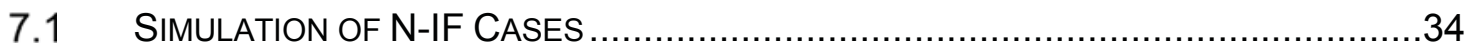

7.1.1 Case 4

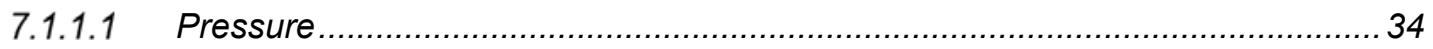

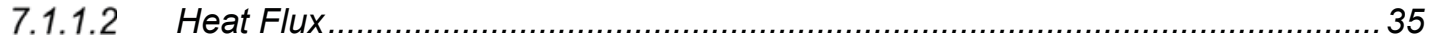

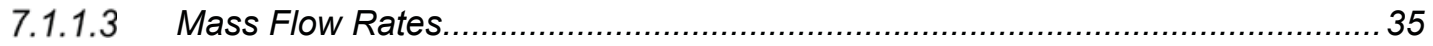

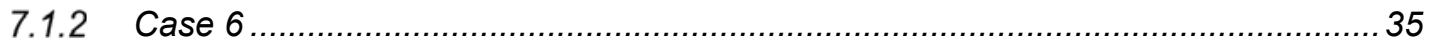

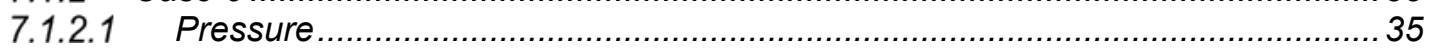

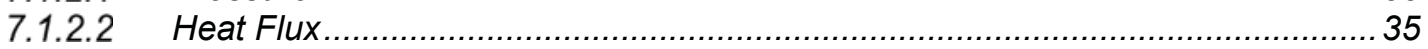

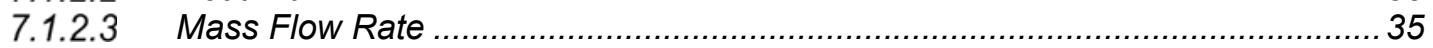

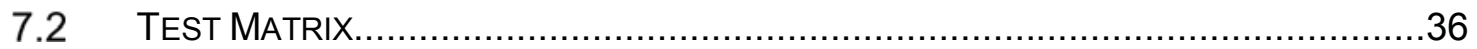

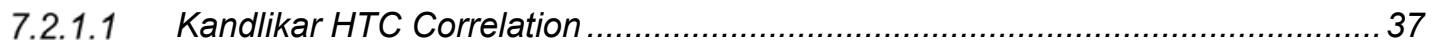

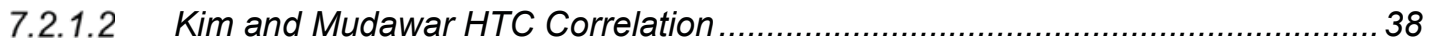

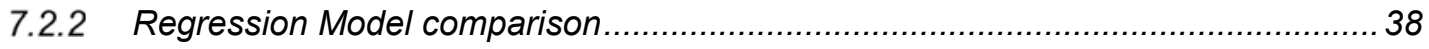

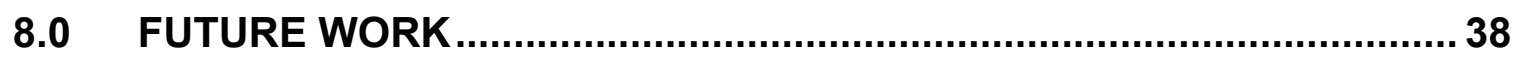

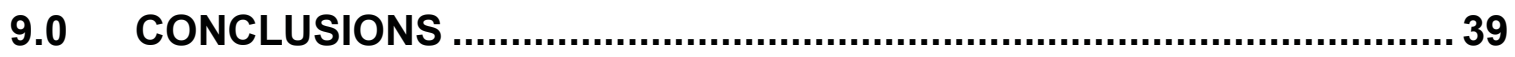

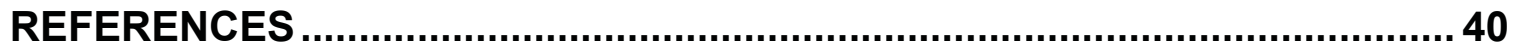

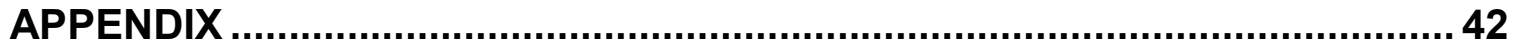

APPENDIX A - Flow QUALITY DIFFERENTIAL EQUATION DERIVATION ..........................43

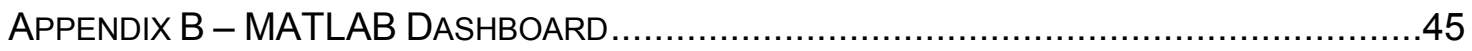

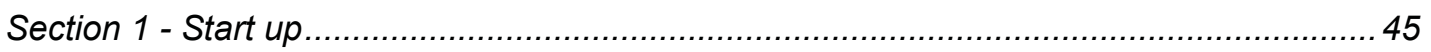

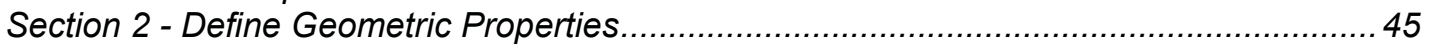

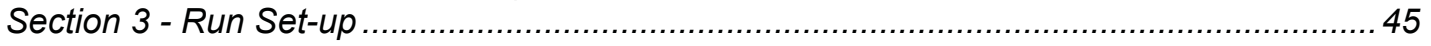

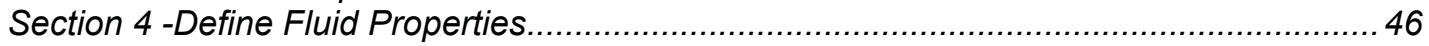

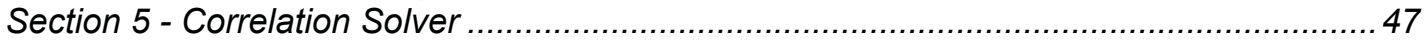

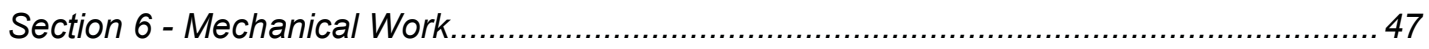

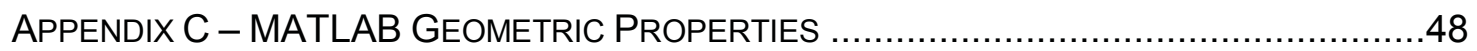

APPENDIX D - MATLAB FLUID PROPERTIES .................................................. 49

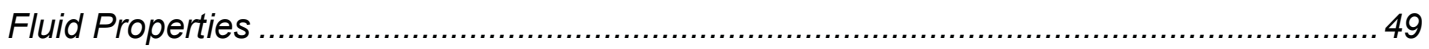

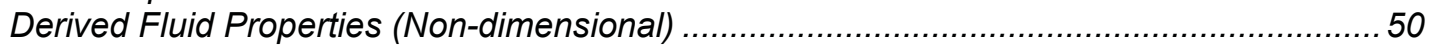

APPENDIX E - MATLAB KANDLIKAR CORRELATION SCRIPT ................................... 51

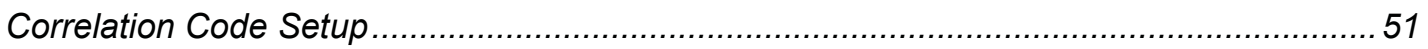


Kandlikar Correlation

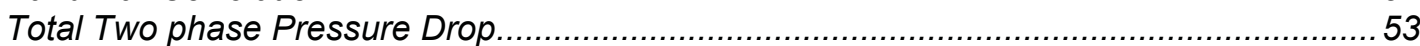

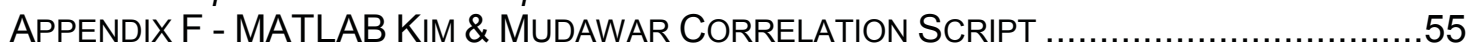

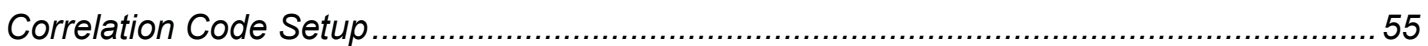

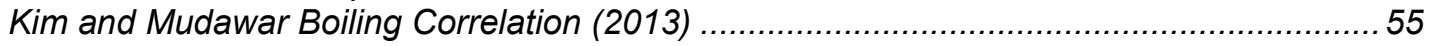

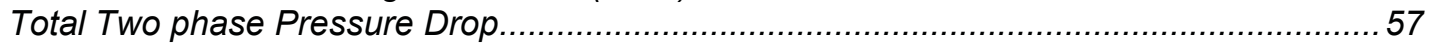

APPENDIX G - MATLAB KANDLIKAR MYODEFUN FOR LAMINAR REYNOLDS NUMBER .......58

APPENDIX H - MATLAB KANDLIKAR MYODEFUN FOR TURBULENT REYNOLDS NUMBER ....58

APPENDIX I - MATLAB KIM \& MUDAWAR MYODEFUN .........................................59

APPENDIX J - MATLAB LOCKHART-MARTINELLI PRESSURE DROP ............................60

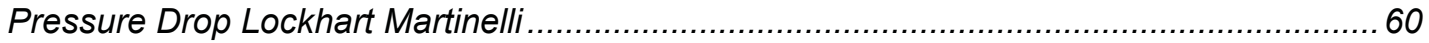

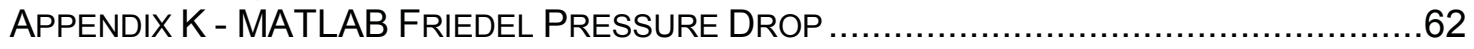

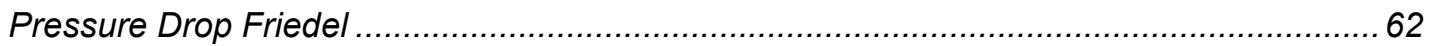

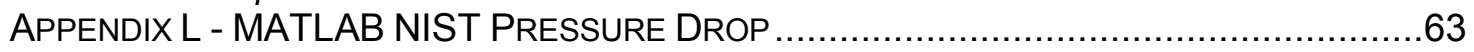

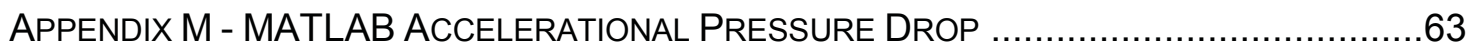

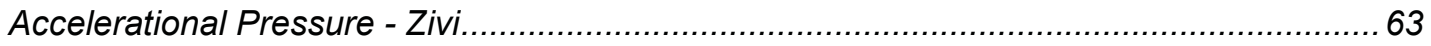

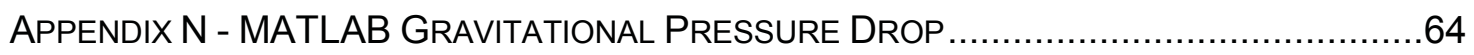

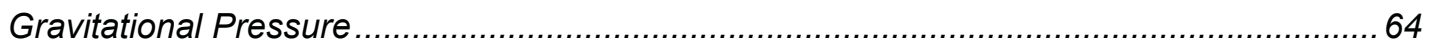

APPENDIX O - SIMULATION OF EXPERIMENTAL COMPARISONS FOR H-IF CASES ...............64

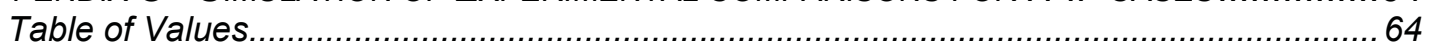

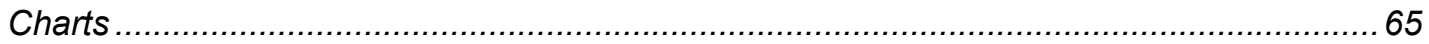

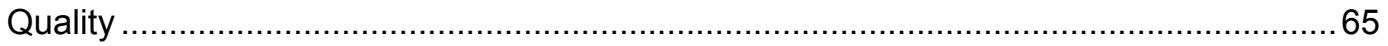

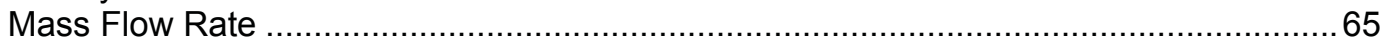

HTC

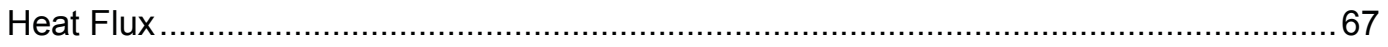

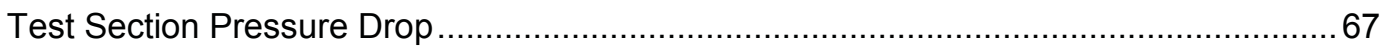

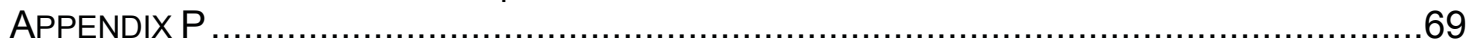

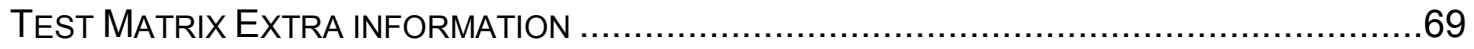

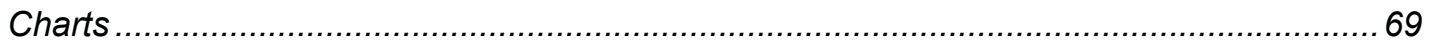

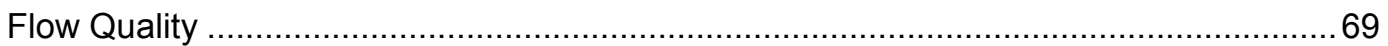

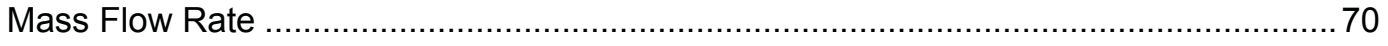

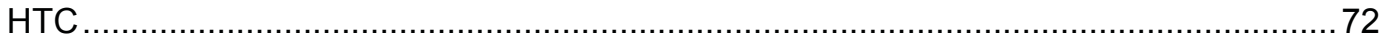

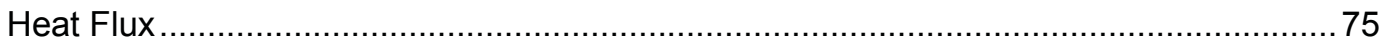

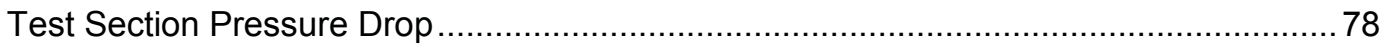




\section{Table of Variables}

\section{Variables:}

$\mathrm{X}(z)-$ Flow Quality as function of distance from testsection inlet $z-$ downstream distance from the inlet of the test section

$$
\begin{aligned}
& N u_{z}-\text { local Nusselt Number } \\
& \text { Ja - Jakob Numer } \\
& \text { Pr - Prantdl Number } \\
& \mu-\text { Dynamic viscosity }[\mathrm{Pa}-\mathrm{s}] \\
& \text { Re - Reynolds Number } \\
& D_{h}-\text { Hydraulic Diameter }[m] \\
& k \text { - Thermal Conductivity }[\mathrm{W} / \mathrm{mK}] \\
& h_{z}-\text { local heat transfer coefficent }(H T C)\left[W / m^{2} K\right] \\
& \text { Bo - Boiling Number } \\
& P_{H}-\text { Heated Perimeter }[\mathrm{m}] \\
& P_{W}-\text { Wetted Perimeter }[\mathrm{m}] \\
& \text { We - Weber Number } \\
& \chi(\text { chi })-\text { Lockhart Martinelli parameter } \\
& \rho-\text { Density }\left[\mathrm{kg} / \mathrm{m}^{3}\right] \\
& G-\text { Mass Flux }\left[\mathrm{kg} /\left(\mathrm{m}^{2} \mathrm{~s}\right)\right] \\
& \text { Co - Convective Number } \\
& \text { Fr - Froude Number } \\
& f_{2}(F r)-\text { Function of Froude Number }
\end{aligned}
$$

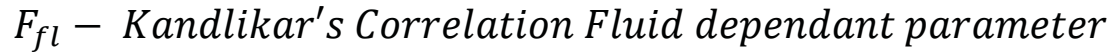

$$
\begin{aligned}
& P-\text { Pressure }[\mathrm{Pa}]
\end{aligned}
$$




$$
\begin{gathered}
P_{r}-\text { Reduced Pressure } \\
\varphi^{2}-\text { Two Phase multiplier } \\
C-\text { Chisholm Parameter } \\
f-\text { Fannie friction factor } \\
v-\text { specific volume }\left[\mathrm{m}^{3} / \mathrm{kg}\right] \\
\text { Su-Suratman number }
\end{gathered}
$$

Subscripts

$$
\begin{gathered}
f-\text { liquid phase } \\
g \text {-gas/vapor phase } \\
\text { GO-Gas only } \\
\text { LO - Liquid only }
\end{gathered}
$$$$
40-40 \mathrm{~cm} \text { location within the test section }
$$

Definitions

$$
\begin{gathered}
R e_{g}=\frac{G \mathrm{X}(\mathrm{z}) D_{h}}{\mu_{g}} \\
R e_{f}=\frac{G(1-\mathrm{X}(\mathrm{z})) D_{h}}{\mu_{f}} \\
R e_{G O}=\frac{G D_{h}}{\mu_{g}} \\
R e_{L O}=\frac{G D_{h}}{\mu_{f}} \\
\Delta P=P_{\text {inlet }}-P_{\text {outlet }}
\end{gathered}
$$

Abbreviations:

$$
\begin{gathered}
\text { HTC - Heat Transfer coefficient } \\
\text { N-IF - Non Imposed Fluctuations } \\
\text { KM - Kima \& Mudawar }
\end{gathered}
$$




$$
\begin{gathered}
\text { Kand - Kandliakr } \\
\text { FR - Friedel }
\end{gathered}
$$

$$
\text { LM - Lockhart and Martinelli }
$$

NIST - National Institute of Standards and Technology

$$
\begin{gathered}
\mathrm{cb} \text { - convective boiling } \\
\mathrm{nb} \text { - nucleate boiling } \\
\text { tp - two-phase }
\end{gathered}
$$




\section{Preface/Acknowledgment}

The simulation tool described in section 6 was written with the assistance of Sharayu Bhasme and Kaustubh Kale, who are members of Dr. Narain's simulation team. Section 6 was also written with both these students' input as the code was developed with the intention of being modular - to easily switch correlations, fluid and geometric properties.

I also wish to acknowledge experimental works done by Michael T Kivisalu (MTK) and Patcharapol Gorgitrattanagul (PG). I have highlighted portions of this thesis which relate to flow loop building work of MTK and PG.

With regard to "correlation" based simulations, I have reviewed related water (as a working fluid) based simulation results of Kaustubh Kale and Sharayu Bhasme. The focus of this thesis is to present expected - but approximate - "correlation" based simulations results for the planned and forthcoming FC-72 experiments dealing with innovative flow boiler operations.

Hardware costs of my experimental work was covered by NSF-GrantCBET-1402702 (PI: A. Narain).

I would like to thank the MEEM department for the GTA support over the year of my graduate study.

I would also like to thank my advisor, Amitabh Narain for guiding and supporting me over the years. You lead by example and demonstrate what can be done with hard work and determination. 


\subsection{Abstract}

The main goal of this correlations-based modeling investigation is to undertake a preemptive analysis on expected measurement values (of selected flow variables) that may be realized during the implementation/completion of the ongoing experimental endeavors dealing with non-pulsatile steady operations of the innovative flow boiler. The correlation models do not accurately predict the heat transfer coefficients or pressure drops due to the assumptions lumped into the development of the correlations. At the conclusion of the investigation, a tool was created that provides rough order of magnitude estimates of pressure drop and local heat transfer rates. The approach is also recommended for finding or developing HTC correlations that have better compatibility with experimental results to be obtained for innovative boiler operations eliminating to the significant differences seen in the predictions between experimental and modeling approaches.

\subsection{Introduction}

Advances in power generation, electronics and military applications all require innovative approaches to reject heat which stems from increased power requirements and decreasing package volumes of the devices to be cooled. Current systems typically utilize the sensible energy of single phase fluid flows (liquid or vapor) to remove heat from critical components. However, many researchers have turned to two-phase heat exchange because of the potentially higher heat flux capabilities associated with the latent heat of evaporation in flow boiling. To better achieve the heat rejection requirements of the future, it is well know that this latent heat utilization is a promising proposition.

The challenges that appear while using two phase systems are related to inefficient flow regimes that appear in flow boiling -examples are bubbly, plug-slug, mist, etc. As the fluid progresses through the different regimes in a small hydraulic diameter tube, there are accompanying changes in driving forces that directly affect the local heat transfer rates and surface heat fluxes.

The close to boiling-surface portions of annular flow boiling regimes, bubble and plug-slug, may still be dominated by nucleate boiling. Nucleation has two distinct sub regimes, isolated bubbles and jets [1]. The isolated bubbles are formed at nucleation sites and eventually separate from the heating surface. This separation induces fluid mixing as higher temperature fluid from the bottom rises and lower temperature fluid sinks to the heating surface. This induced mixing phenomenon leads to a substantial increase in the heat transfer rates and surface heat flux. 
Most thermal management systems operate with nucleate boiling being the dominant mode of heat transfer. Nucleate boiling is often seen in pool boiling applications, such as boiling a pot of water where bubbles are formed and are typically brought upwards due to buoyant forces.

The later downstream and thinner portions of annual and annular wavy regimes are dominated by convective boiling under suppressed nucleation. Convective boiling consist of an annular liquid film and a relatively fast moving vapor flow - characterized by flow quality X $\equiv \dot{M}_{g}(z) / \dot{M}_{\text {total }}$ where $\dot{M}_{g}(z)$ is the vapor mass flow rate at a distance $z$ from the inlet and $\dot{M}_{\text {Total }}$ is the total mass flow rate $(\mathrm{kg} / \mathrm{s})$ - contained within a pipe or channel (e.g. $0.6 \leq \mathrm{X} \leq 1)$. The relatively fast moving vapor creates a shear stress at the liquid/vapor interface. This shearing creates a thinner film across the test section and allows the heat to be easily transferred from the heat source to the liquid, then transferred across the liquid/vapor interface to be rejected.

\subsection{What is flow boiling?}

Boiling is the transition between a fluid's saturated liquid state to a saturated vapor state. The interest of flow boiling research is to utilize the large energy absorption potential at small temperature differences that is available for phase change flows. This energy absorption plays a factor in the overall heat transfer rates that can be utilized to obtain an increase in heat removal within flow boilers designed for appropriate applications.

Although flow boiling shows promise, it does not come without some potential issues. Now the heat extraction system has to handle both a vapor and a liquid - which means that more equipment overall is required over some conventional single phase systems. There is also the issue of utilizing the annular/stratified regions of the flow, since regions like plug and slug actually diminish the heat transfer rates. (See Figure 1 in section 2.3)

\subsection{Experimental Trends}

There have been many works investigating how vapor quality affects the local heat transfer coefficient. As indicated in the Figure 1 below, at lower flow qualities, in the bubbly or pre-bubbly nucleate boing regimes, there is a regime that allows for large heat removal rates through unhindered nucleate boiling. However, further downstream in the plug-slug zone, there is a decrease in bubble removal and heat removal rates. This decrease in heat transfer coefficient is a result of inefficient plug-slug regimes taking over the earlier nucleate boiling regime. After the inefficient convective plug/slug regimes passes, a new regime takes over with efficient convective annular boiling - with or without suppressed nucleate boiling. This annular regime provides a range of flow qualities that provide an opportunity - with or without pulsations [2] - to efficiently remove large amounts of heat at small excess temperatures.. 


\subsection{Achieving high heat flux in microchannel / mini-channel}

Previous literature in flow boiling all seem to develop heat transfer coefficient correlations as the working fluid travels through the different flow regimes. Almost all of their flow boiling experiments and correlations start with all liquid at the inlet and end with all vapor at the outlet.

This research is an extension of previous work [2] that demonstrated use of pulsations and recirculation loops (for both liquid and vapor flow streams in the boiler) can lead to wavy annular flows time averaged heat flux values even in the absence of nucleate boiling. These proposed changes, outlined in [2], ensure realization of annular flow regimes that are thermally and hydrodynamically efficient over the entire length of the test section

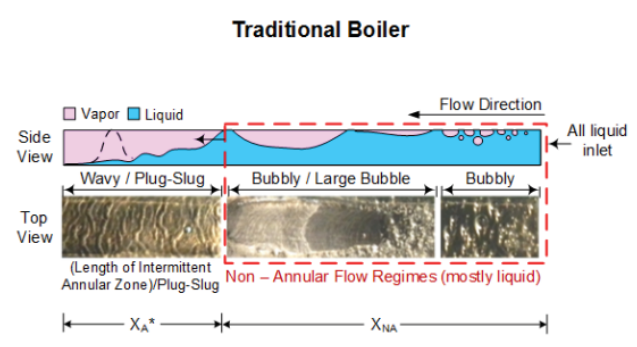

(a)

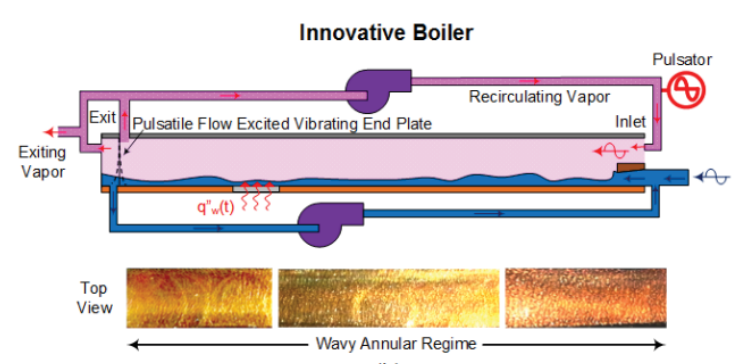

(b)

Figure 1: Comparison of Traditional Boiler and Innovative Boiler with their respective flow regimes

\subsection{Correlations used in the investigation}

Given that heat transfer enhancement and prediction is still an emerging field of research, it is often difficult or close to impossible to find an existing correlation that correctly accounts for every parameter that significantly affects the correlation - such as fluid properties, mass flux, hydraulic diameters, flow orientations with respect to gravity vector, etc.

This study presents an approach for using and assessing existing correlations through the use of the following:

- An ordinary differential equation where the solution represents flow quality as a function of non-dimensional distance, $z$, from the inlet (or any point where flow quality is known).

- Any existing local heat transfer coefficient correlations - e.g. either Kim and Mudawar's universal approach or Kandlikar's approach.

- Frictional Pressure drop through a modified Lockhart-Martinelli correlation, or the Friedel correlation, or NIST correlation.

- Accelerational pressure drop, e.g. Zivi correlation. 
- Gravitational pressure drop through the expressed correlation given within Kim and Mudawar's universal approach.

\subsubsection{Flow Quality}

The derived differential equation given below allows the computation of flow quality, once a Nusselt number is found from a suitable heat transfer coefficient correlations. The differential equation solves for flow quality as a function of non-dimensional distance, $z_{-} n d \equiv z / D \_h$, from the test section inlet. The equation is listed below and its derivation, from mass and energy balance, can be found in Appendix A.

$$
\begin{aligned}
& \frac{d X\left(z_{n d}\right)}{d z_{n d}}=\left(N u_{z}\right)_{\text {correlation }} \times \frac{J a_{f}}{P r_{f}} \times \frac{\mu_{f}}{\mu_{g}} \times \frac{1}{R e_{\text {inlet }(G)}}, z_{n d} \geq 0 \text { and prescribed } X(0)=X_{0} \\
& \left(N u_{z}\right)_{\text {Correlation }}=\left.h_{z}\right|_{\text {correlation }}(X(z)) \times \frac{D_{h}}{k_{f}}
\end{aligned}
$$

This equation is solved through MATLAB, using any appropriate ODE solver. In this approach, once the flow quality $X(0 \leq X \leq 1)$ is found for any discrete value of $Z_{n d}$, the effective two phase heat transfer coefficient, heatflux, etc. are easily computed. A function file is used for each correlation and includes a set of equations required to solve the ODE in equation (1), more details can be found in section 5 . 


\subsubsection{Heat Transfer Coefficient (HTC) Correlations}

\subsubsection{Kim and Mudawar correlation}

One method used to calculate the flow-physics is through use of a heat transfer coefficient correlation provided by Kim and Mudawar [3]. Kim and Mudawar provide a universal correlation for pre-dry out saturated flow boiling heat transfer in mini/micro-channels in both single- and multichannel configurations. They are partially defined in equations $3,4 \& 5$ below.

$$
\begin{aligned}
& h_{t p}=\left(h_{n b}^{2}+h_{c b}^{2}\right)^{0.5} \\
& h_{n b}=\left[2345\left(B o \frac{P_{H}}{P_{F}}\right)^{0.7} \operatorname{Pr}^{0.38}(1-X)^{-0.51}\right]\left(0.023 \operatorname{Re}_{f}^{0.8} \operatorname{Pr}_{f}^{0.4} \frac{k_{f}}{D_{h}}\right) \\
& h_{c b}=\left[5.2\left(B o \frac{P_{H}}{P_{F}}\right)^{0.8} W e_{f o}^{-0.54}+3.5\left(\frac{1}{\chi_{t t}}\right)^{0.94}\left(\frac{\rho_{g}}{\rho_{f}}\right)^{0.25}\right]\left(0.023 \operatorname{Re}_{f}^{0.8} \operatorname{Pr}_{f}^{0.4} \frac{k_{f}}{D_{h}}\right)
\end{aligned}
$$

The detailed definition of terms in equations (3)-(5) are given in [3].

This correlation was created for the following flow conditions:

- Working Fluid: FC72, R11, R113, R123, R1234yf, R1234ze, R134a, R152, R22, R236fa, R32, R404A, R407C, R410A, R417A, $\mathrm{CO}_{2}$, and water

- Hydraulic Diameter: $0.19<D_{h}<6.5 \mathrm{~mm}$

- Mass velocity: $19<G<1608 \mathrm{~kg} / \mathrm{m}^{2} \mathrm{~s}$

- Liquid only Reynolds number: $57<R e_{f o}=G D_{h} / \mu_{f}<49820$

- Flow Quality: $0<X<1$

- $\quad$ Reduced Pressure: $0.005<P_{r}<0.69$

Each of the terms, $h_{t p}, h_{n b}$ and $h_{c b}$ are calculated independently, after the flow quality $X(z)$ solution has been obtained, and are investigated further to understand the effects of the correlation-dependent determination of flow quality $X(z)$. It should be noted that, because of our limited order of magnitude interests in the predicted values, this thesis will still use this correlation even though that the hydraulic diameter used in the planned experiments is to be $8 \mathrm{~mm}$. The effect of this discrepancy will most likely be included in any errors in predictions since this correlation is fitted over all flow boiling regimes and not just specific to the annular convective regimes. 


\subsubsection{Kandlikar Correlation}

The Kandlikar correlation that is used is from the 2004 paper [4], which was a revision from a 1990 proposed correlation [5]. This revision adds the vapor mass fraction (flow quality) into the correlation.

$$
\begin{aligned}
& h_{T P}=\text { larger of }\left\{\begin{array}{l}
h_{T P, N B D} \\
h_{T P, C B D}
\end{array}\right. \\
& h_{T P, N B D}=0.6683 C \mathrm{Co}^{-0.2}(1-\mathrm{X})^{0.8} f_{2}(F r) h_{L O}+1058.0 B o^{0.7}(1-X)^{0.8} F_{f l} h_{L O} \\
& h_{T P, C B D}=1.136 C o^{-0.9}(1-X)^{0.8} f_{2}(F r) h_{L O}+667.2 B o^{0.7}(1-X)^{0.8} F_{f l} h_{L O}
\end{aligned}
$$

The details of the above correlation is given [4]. The correlation proposed in 2004 has one equation for the heat transfer coefficient for the convective boiling dominate regime and another for the nucleate boiling as demonstrated. The effective two phase flow is then the maximum of the two coefficients.

The other term that Kandlikar uses is liquid only heat transfer coefficient, $h_{L O}$, which will be determined either by a constant for laminar flow $(\operatorname{Re}<1600)$ or the Dittus -Boelter correlation for turbulent flow $(\operatorname{Re}>$ 3000 ). And it is by linear interpolation between equation 10 and 11 if 1600 $<\operatorname{Re}<3000$. The Constant term in equation 10 is determined by the channels geometry and wall thermal boundary condition. For the purpose of this thesis, the value of $C$ was taken to be 5.60 from [1], although it is understood that the fully developed criteria may not be met, but only order of magnitude approximations are being made here.

$h_{L O}=$ Constant $\times \frac{k_{f}}{D_{h}}$

$h_{L O}=0.023 \operatorname{Re}_{D}^{0.8} \operatorname{Pr}^{0.4} \times \frac{k_{f}}{D_{h}}$

Care is to be taken when using the equation supplied by Kandlikar due to the terms of $f_{2}(F r)$ and $F_{f l}$. Since we will be assuming the Froude number to have little effect in the horizontal flow cases investigated the term $f_{2}(F r)$ will have the value of 1 , as proposed by Kandlikar [4]. The $F_{f l}$ term is a fluid dependent parameter that was introduced to improve the correlation for better capturing of the nucleate boiling affect. In this investigation, the refrigerant FC-72 will be used, which is known to have properties similar to $\mathrm{R}-113$. Due to this similarity a value of 1.3 will be used for the $F_{f l}$ term, as suggested in Table 3 of [5].

\subsubsection{Pressure Drop Correlations}

\subsubsection{Lockhart and Martinelli Correlation (modified)}

This two-phase correlation is a model where component terms treat the liquid and vapor flow to be made up of two independent streams, idealizing 
each phase to be traveling at a constant velocity independent of each other. The Lockhart-Martinelli correlation does this with the help of two parameters $\varphi_{l}$ and $\varphi_{g}$. These two parameters are defined as the ratio of the two phase frictional pressure gradient, $\left(\frac{d P}{d z}\right)_{f}$ or $\left(\frac{d P}{d z}\right)_{g}$, which would exist if the liquid/vapor flow was assumed alone. The two-phase frictional pressure gradient, $\left(\frac{d P}{d z}\right)_{F}$, is given by:

$\left(\frac{d P}{d z}\right)_{F}=\left(\frac{d P}{d z}\right)_{f} \varphi_{f}^{2}=\left(\frac{d P}{d z}\right)_{g} \varphi_{g}^{2}$

$\varphi_{f}^{2}=1+\frac{c}{x}+\frac{1}{\chi^{2}}$

$\chi^{2}=\frac{(d P / d z)_{f}}{(d P / d z)_{g}}$

$-\left(\frac{d P}{d z}\right)_{f}=\frac{2 f_{f} v_{f} G^{2}(1-\mathrm{X})^{2}}{D_{h}}$

$-\left(\frac{d P}{d z}\right)_{g}=\frac{2 f_{g} v_{g} G^{2} \mathrm{X}^{2}}{D_{h}}$

The Lockhart and Martinelli correlation was published as curves on a $\varphi$ versus Martinelli parameter $(\chi)$, although charts are difficult to use in calculations. This investigation has adapted the usage of functions that replace the Chisholm parameter, C, supplied by Kim and Mudawar [6], instead of using the constants supplied by Chishom [7].

$$
\begin{aligned}
& C=16 R e_{f o}^{0.03} S u_{g o}^{0.1}\left(\frac{\rho_{f}}{\rho_{g}}\right)^{0.35} \text { for } R e_{f} \geq 2000 \text { and } R e_{g} \geq 2000 \\
& C=\left(8.7 \times 10^{-4}\right) R e_{f o}^{0.17} S u_{g o}^{0.5}\left(\frac{\rho_{f}}{\rho_{g}}\right)^{0.14} \text { for } \operatorname{Re}_{f} \geq 2000 \text { and } R e_{g}<2000 \\
& C=0.0015 R e_{f o}^{0.59} S u_{g o}^{0.19}\left(\frac{\rho_{f}}{\rho_{g}}\right)^{0.36} \text { for } \operatorname{Re}_{f}<2000 \text { and } R e_{g} \geq 2000 \\
& C=\left(3.5 \times 10^{-5}\right) R e_{f o}^{0.44} S u_{g o}^{0.5}\left(\frac{\rho_{f}}{\rho_{g}}\right)^{0.48} \text { for } \operatorname{Re}_{f}<2000 \text { and } \operatorname{Re}_{g}<2000
\end{aligned}
$$

This correlation was originally developed, with the help of data obtained from iso-thermal two phase adiabatic flow experiments, for the purpose of providing frictional pressure drop estimates. When this correlation was developed in 1949 the authors suggested that this correlation could be extended and utilized for the following objectives: 1) Prediction of pressure drop during evaporation or condensation, 2) Prediction of gas-lift pump behavior, 3) Prediction of the heat transfer conductance during force convection boiling or condensation. 
The experiments conducted to achieve this correlation followed the following assumptions [8]: 1) Static pressure for the liquid phase must be equal to the static pressure drop for the vapor phase regardless of the flow pattern, as long as radial static pressure difference does not exist. 2) The volume occupied by the liquid plus the volume occupied by the vapor at any instant in time, must be equal to the total volume of the pipe (i.e. incompressibility of each phase).

The f parameter in equations $15 \& 16$ is the Fanning friction factor, which represents non-dimensional value of interfacial shear stress.

$$
\begin{aligned}
& f_{k}=16 R e_{k}^{-1} \text { for } R e_{k}<2000 \\
& f_{k}=0.079 R e_{k}^{-0.25} \text { for } 2000 \leq R e_{k} \leq 20,000 \\
& f_{k}=0.046 R e_{k}^{-0.2} \text { for } R e_{k} \geq 20,000
\end{aligned}
$$

- with the subscript $k$ denotes $f$ or $g$ as liquid phase or vapor phase respectively.

\subsubsection{Friedel - Pressure Drop [9, 10]}

The Friedel correlation is another model based on terms that employ assumptions of single-phase flows moving through the entire tube. These terms are $\varphi_{l o}$ and $\varphi_{g o}$. These two parameters are defined as the ratio of the two phase frictional pressure gradient that would exist if the two phase mixture is assumed to be all liquid or vapor. The Friedel pressure drop correlation is widely accepted due to the correlation being developed through the use of 25,000 experimental data points. [11]

$$
\begin{aligned}
& \left(\frac{d P}{d z}\right)_{F}=\left(\frac{d P}{d z}\right)_{f o} \varphi_{f o}^{2}=\left(\frac{d P}{d z}\right)_{f o} \varphi_{g o}^{2} \\
& \varphi_{f o}^{2}=(1-\mathrm{X})^{2}+\mathrm{X}^{2}\left(\frac{v_{g}}{v_{f}}\right)\left(\frac{f_{g o}}{f_{f o}}\right) \ldots \\
& +3.24 \mathrm{X}^{0.74}(1-\mathrm{X})^{0.224}\left(\frac{v_{g}}{v_{f}}\right)^{0.91}\left(\frac{\mu_{g}}{\mu_{f}}\right)^{0.19}\left(1-\frac{\mu_{g}}{\mu_{f}}\right)^{0.7}\left(F r_{t p}\right)^{-0.045}\left(W e_{t p}\right)^{-0.035}
\end{aligned}
$$




\subsubsection{NIST}

The correlation presented by NIST [12] is an effort to provide heat exchanger designers with a pressure drop correlation for two phase flow within smooth and micro-fin tubes with pure refrigerator and refrigerant/lubrication mixtures as working fluids. The presented correlation for pure refrigerants, equation 26, implements a modified Pierre (1964) correlation by using the hydraulic diameter and including the specific volume of the liquid.

$$
\begin{aligned}
& \Delta \boldsymbol{P}_{\text {tp }}=\Delta \boldsymbol{P}_{\text {friction }}+\Delta \boldsymbol{P}_{\text {acceleration }}=G^{2}\left(\frac{f_{N} L\left(v_{\text {out }}+v_{\text {in }}\right)}{D_{h}}+\left(v_{\text {out }}-v_{\text {in }}\right)\right) \\
& \boldsymbol{f}_{N}=0.0050 \boldsymbol{R e}_{f o}^{-0.0951} K_{f}^{0.1554} \\
& K_{f}=\frac{\Delta x h_{f g}}{L g}
\end{aligned}
$$

The authors then compared the predicted values with different data and observed no more than $30 \%$ deviation from the mean for all ranges and refrigerants of both smooth and micro-fin tubes.

\subsubsection{Accelerational Pressure Drop}

The accelerational pressure drop component can be expressed as shown in equation (26), the recommendation from Kim and Mudawar [10]. The void fraction, $\alpha$, is expressed in terms of flow quality, $\mathrm{X}$, and is determined through the Zivi's correlation, instead of the homogenous equilibrium.

$$
\begin{aligned}
& \left(\frac{d P}{d z}\right)_{A}=-G^{2}\left(\frac{d}{d z}\left[\frac{v_{g} \mathrm{X}^{2}}{\alpha}+\frac{v_{f}(1-\mathrm{X})^{2}}{(1-\alpha)}\right]\right) \\
& \alpha=\left[1+\left(\frac{1-\mathrm{X}}{\mathrm{X}}\right)\left(\frac{\rho_{g}}{\rho_{f}}\right)^{\frac{2}{3}}\right]^{-1}
\end{aligned}
$$

\subsubsection{Gravitational Pressure Drop}

The correlation used for gravitational pressure drop component is expressed as given in equation 30, again by Kim and Mudawar [10]. Where the void fraction, $\alpha$, is related to flow quality, $\mathrm{X}$, through equation (29).

$\left(\frac{d P}{d z}\right)_{G}=-\left[\alpha \rho_{g}+(1-\alpha) \rho_{f}\right] g \sin (\theta)$

\subsection{Problem Statement}

\subsection{Goals:}

The main goal of this correlations-based modeling is to undertake a preemptive analysis on expected measurement values (of selected flow variables) that may be realized during the implementation/completion of the ongoing experimental endeavors dealing with non-pulsatile steady 
operations of the innovative flow boiler operations described in [2]. This work will also help in ensuring that the "range choices" for various selected instruments is correct and, when experimental and more exact simulation results have been obtained, one has the confidence that comes from seeing "order of magnitude" mutual consistencies among values assessed estimated by very different approaches. The correlations based simulation tool is expected to become a part of a foundational toolset that will also be used by subsequent generation of students under Dr. Narain.

A secondary goal is to provide the procedure of calculation as an input for the experimental doctoral student so they can better interpret their results. The student can also plan on code modifications of using other existing heat transfer coefficient and pressure difference correlations, including the annular suppressed nucleation flow boiling model developed by the MTU simulation group.

In addition this work will also further advance the development of models for "pulsatile" cases, once the experimental results are obtained and processed.

A successful completion of this thesis will include development of a MATLAB tool that uses modular MATLAB .m files for fluid and geometric properties and correlations. This tool should also be able to predict previous experimental values/trends with an order of magnitude estimation/calculation of the parameters of interest.

\subsection{Hypotheses:}

The correlation models will not accurately predict the heat transfer coefficients or pressure drops due to the assumptions lumped into the development of the correlation. Although, it is expected that general trends and order of magnitude estimation can be achieved. Typically correlations are only as good as the experimental data bank and the non-dimensional analyses used to develop them. The phase-change flows' HTC correlations are affected by:

i. Range of fluids (and associated properties and non-dimensional numbers' ranges)

ii. Range of inlet pressure, with $P \ll P_{c r}$ and $P \sim P_{c r}$ exhibiting very different behavior

iii. Range of mass flux, $G$

iv. Test geometry (circular, rectangular, triangular) and hydraulic diameter, $D_{h}$, ranges

v. Method of heating/cooling used

vi. Range on flow regimes encounter by the flow

vii. Orientation of the test section with respect to the gravity vector 
A clear understanding of the above facts can lead to better design choice of a suitable HTC correlation (whether it is chosen from an existing one or is experimentally developed for a specific purpose).

\subsection{Experimental Methods}

\subsection{Overview/Experimental Overview}

The ongoing investigations are to use various experimental measurements that are to be acquired during the experiments (with FC-72 as working fluid) dealing with innovative flow boiler operations [1]. These experiments are primarily concerned with flow visualization and measurements at the inlet, outlet, and the interior of the test-section (which models innovative flow boiler operations). Measurements such as pressure drops, mass flow rates, heat flux values (time-varying or steady) at certain test-section locations, etc. are to be obtained and are to be compared with science-based or correlations-based simulations results. This section's write-up first describes the earlier experimental set-up flow-loop's basic structure [2] and then describes the modifications that have since been made - over the last one year - for the proposed investigations.

\subsection{Existing Apparatus/Equipment}

The original flow boiling loop shown here is originally described in [2]. The list below are the components used in the flow loop for the boiling experiments. The original experimental flow loop shown in Figure 2 depicts the various equipment used to collect and run the experiment. Figure 2 shows a system schematic of the experiment.

- Test Section

- Pool Boiler

- Peristaltic/Displacement pumps

- Magnetically-Coupled Compressor

- LabVIEW DAQ

- Absolute Pressure Transducer

- Differential Pressure Transducer

- Coriolis flow meters

- Vapor pulsator

- Auxiliary condenser

Test Section:

The test section has a stainless steel plate that has a machined plastic channel fastened atop. The stainless steel is heated via reverse thermal electric coolers. The plastic channel is machined to have a channel width and height of $15 \mathrm{~mm}$ and $2 \mathrm{~mm}$, respectively. The previous experiments in 
[2] had a channel length on $1 \mathrm{~m}$, but the new forthcoming experiments to be investigated will have a channel length of $0.5 \mathrm{~m}$.

Pool Boiler:

The Pool boiler is used to initially supply the system with a vapor of the working fluid. After start up conditions have been met and the system reaches a quasi-steady (approximately stead-in-the-mean) conditions within the test section, the pool boiler will be taken out of the system loop via the shutting off of suitable ball-valves.

Peristaltic/Displacement pumps:

The pumps within the system are controlled through actuating milli-Amp signals (via pulse-width management) into the pump that moves the liquid through the liquid lines in its vicinity.

Magnetic-coupling driven oil-free RPM Controlled Compressor:

The compressor is used to move partial amounts of vapor from the exit of the test section to the inlet. The control of the compressors RPM is used to assist in controlling the vapor mass flow rate for recirculated vapor.

LabVIEW DAQ:

LabVIEW is used to assist with data collection and controlling various equipment's within the setup for the flow boiling experiments.

Absolute Pressure Transducer (APT):

Various APTs are used in the flow loop to electronically record the pressure at various points within the flow loop. Their placement is not seen in Figure 2, but a couple of locations are: the pool boiler pressure, the inlet pressure at the test section, inlet to auxiliary condenser, exit of the visualization chamber.

Differential Pressure Transducer (DPT):

Two DPTs are used across the test section to measure and record the mean and dynamic pressure difference across the test section lengths of 0 to 40 $\mathrm{cm}$ and 40 to $90 \mathrm{~cm}$.

Coriolis flow meters:

Two Coriolis flow meters are used to measure the mass flow rates of the liquid and vapor flows introduced at the innovative flow-boiler test section's inlet. The flow meters' readings are also used to assist in the feedback control of pumps and compressors - to suitably direct [2] attainment of approximate steady flow conditions.

Vapor pulsator:

The Vapor pulsator in Figure 2 is a modified pump that has its inlet and outlets linked together. This configuration causes a push and push motion 
within the vapor line connecting the pulsator to the system loop. This pulsator imposes pressure fluctuations within the vapor, providing a pulsatile motion to the working mixture within the test section. More details of the operation of the vapor pulsator can be found in Michael Kivisalu Thesis [13].

Auxiliary condenser:

The Auxiliary condenser in Figure 1 is a vertical tube-in-tube heat exchanger that condenses, in its inner tube, part of the vapor (the portion that is not recirculated) created in the test section. The outer tube is cooled by a water-flow arrangement (not shown in Figs. 1-2), where flow-rate and temperature can be independently controlled.

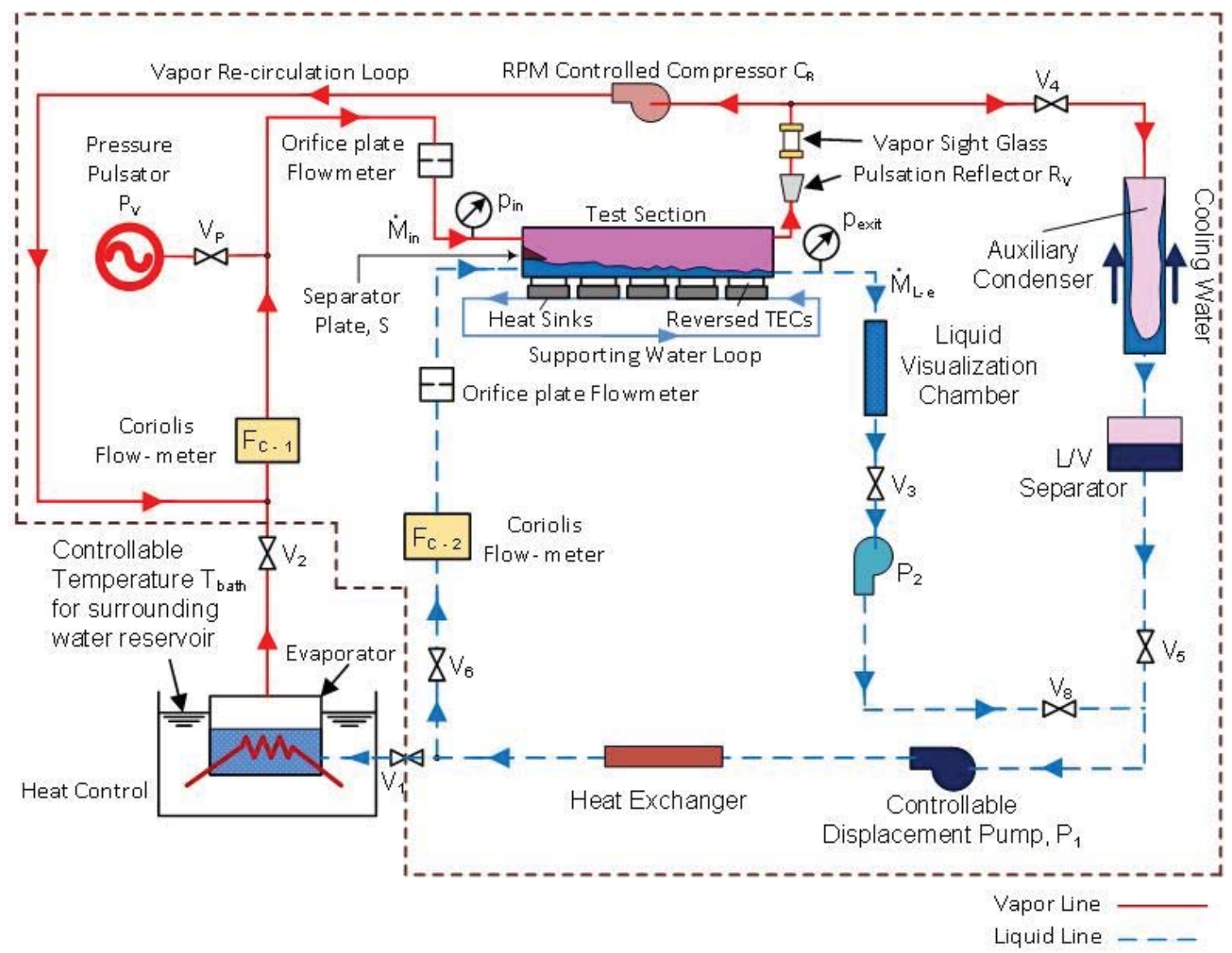

Figure 2: Original flow loop structure used in previous experiments

\subsection{Modified flow loop and its new components}

For the modified flow loop, see Figure 4 below, we added/relocated the following components:

- Shorter Test Section 
- Heat Exchanger

- Liquid Pulsator

- Liquid exit fitting and visualization chamber

- Liquid Pulsation damper

- Turbine flow meter

Shorter New Test-section

The new test-section is rebuilt and instrumented along lines of the testsection described earlier in section 1.2. However, to avoid complete boil-off (necessary for the proposed innovative flow-boilers [1]) for a larger number of test-runs and to allow measurements in the overall heat-transfer rate enhancements between non-pulsatile and pulsatile realizations of a testrun, the new test-section (see Figure 3 below) is shorter (it has a width of $15 \mathrm{~mm}$, height of $2 \mathrm{~mm}$, and length of $0.5 \mathrm{~m}$ ) and it has only one differentialpressure measurement (between inlet and $40 \mathrm{~cm}$ location). It continues to have a dynamic heat-flux measurement capability at $x=40 \mathrm{~cm}$ location.

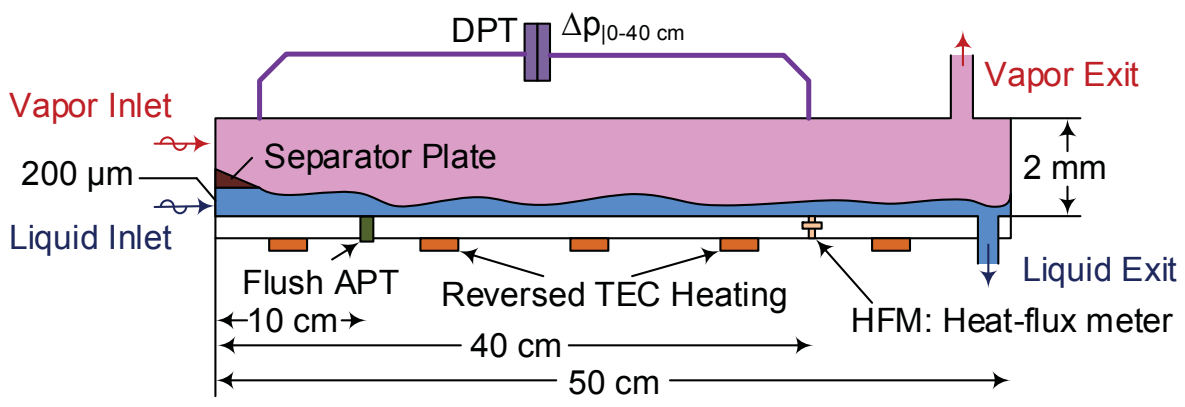

Figure 3: schematic of the new test section

Heat Exchanger:

The heat exchanger in Figureure 2 has been moved, modified, and inserted prior to the liquid test section inlet and before the liquid pulsator, see Figure 4. This modification was done to supply a liquid, as it enters the test-section that has a temperature much closer to the saturation temperature. This is important because many innovative vapor compression cycle designs being recommended by our group cannot allow significant sub-cooling.

Liquid Pulsator:

The liquid pulsator has been inserted immediately after the liquid Coriolis flow meter and right before the test section inlet in Figureure 4. The new "liquid pulsator" serves a similar purpose to the vapor pulsator in Figureure 2 , except that the device's resonant frequency (same as that of the vapor pulsator) is expected to significantly decrease the total pulsatile energy (from both the pulsators) needed for high heat-flux performance of the innovative flow-boiler ([1]) during pulsatile operations. This device is central to expanding and increasing the benefits of our current findings [1] with regard to ways of enhancing heat transfer rates in pulsatile thin liquid film 
flow boiling - particularly during suppressed nucleation mode of operation involving a wetting or highly wetting heat-exchange surface.

Exit-fitting and Visualization Chamber:

A new exit fitting has been designed and is to be positioned at the 50 centimeter length location of the test section in Figure 3. This new test section liquid exit fitting is designed so, if needed, a suitable resonant naturally vibrating end-plate can be incorporated - for further reductions in the total pulsatile energy consumed. This is for future experimental work dealing with this facility.

Pulsation Damper:

The pulsation damper shown in Figure 4 has been inserted immediately after the liquid line displacement pump. The displacement pump is a peristaltic pump that moves liquid - and its principle of operation is based on periodic squeezing of a flexible tube. This pump induces pulsations within the liquid line - and was providing useful fixed frequency pulsations in the earlier Figure 2 flow-loop based innovative operations [1] for a given liquid flow rate at the test-section inlet. The very same pulsations are now unwanted in the new operations - because we do not want these liquid pump induced pulsations to interfere with more controllable (both in frequency and amplitude) pulsations from the new liquid pulsator. The damper is therefore inserted to stifle the peristaltic pump generated pulsations.

Turbine Flow meter:

The turbine flow meter has been inserted - after the liquid exits a filter located after the visualization chamber and the pump shown in the liquid line (following the test-section exit) of Figure 4. The turbine flow meter has been calibrated to measure liquid flow rates (around a range of liquid temperatures in the vicinity of certain expected liquid saturation temperatures of interest). 


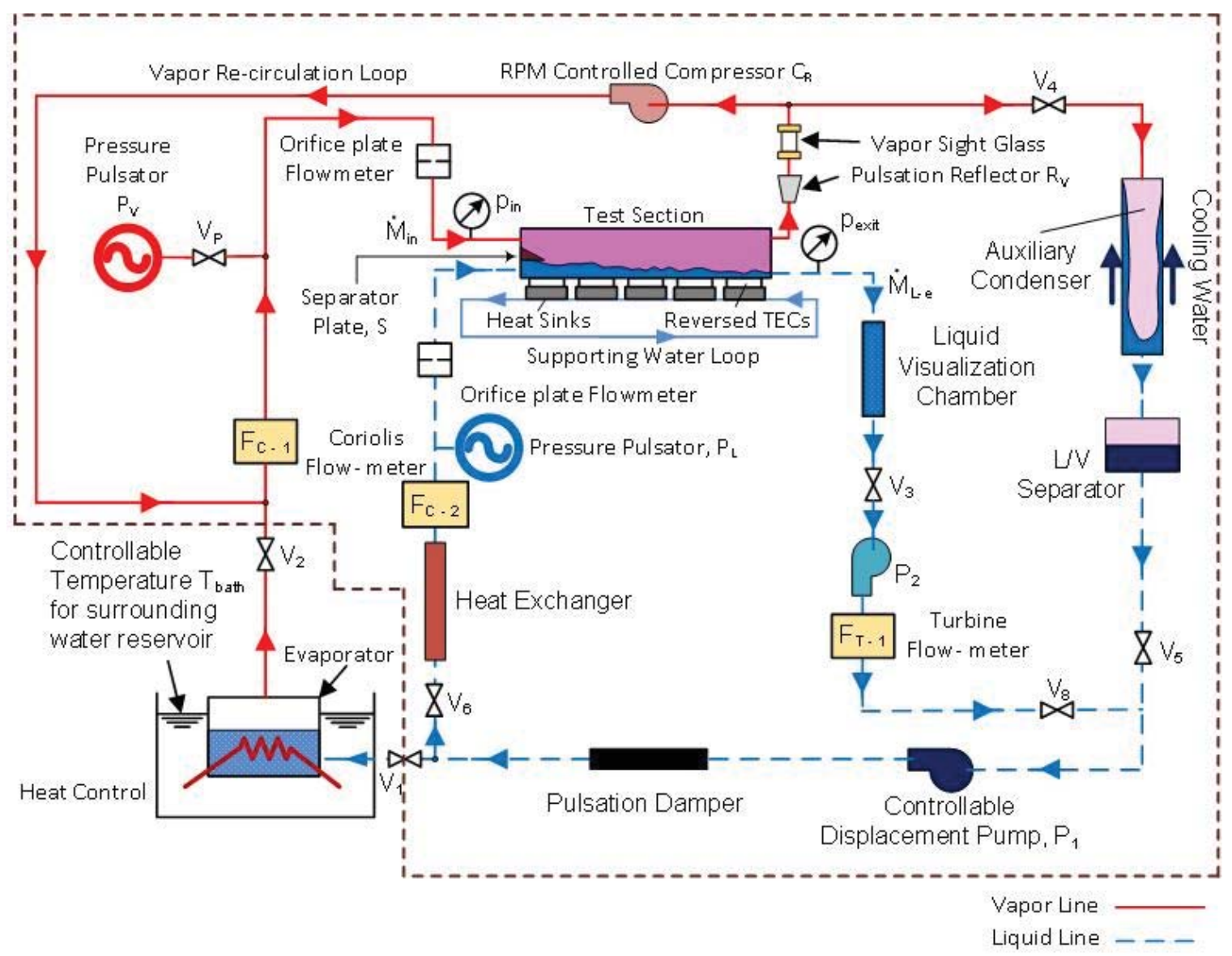

Figure 4: Modified Flow loop structure for innovative boiling experiments 


\subsection{Experimental Procedures}

\subsubsection{Start-up}

Start-up of the experiment consist of filling and leveling the pool boiler, subpump, and auxiliary condenser reservoir with distilled water. The system is filled with 1 liter of FC-72 at atmospheric pressure within the pool boiler. A vacuum purge is then initiated for 2 hours to evacuate the system of any air or previously used FC-72. After the vacuum purge is completed the system is separated/closed-off from the line containing the purge vacuum pump, the pool boiler heaters are then activated. The heaters are controlled via a PID temperature controller that has been previously implemented in the earlier experimental investigations. Once the pool boiler has reached a desired temperature and pressure, the pool boiler is then opened and connected to the rest of the system up until the experiment is ready to shift to innovative flow-boiler operation mode described in [2]. The vapor is run through the test section and then divided, at test-section exit, through the RPM controlled compressor and the auxiliary condenser shown in Figs. 2 and 4. The vapor passing through the RPM controlled compressor is recirculated through the test-section to control the inlet quality and to achieve annular flow over the entire flow-boiler. The vapor sent through the auxiliary condenser is sent back, in liquid form, to the test section inlet as the flow-boiler's working liquid - to be boiled-off. Once the test section inlet conditions such as: pressure, liquid temperature, liquid and vapor flow rates, etc. meet desired values associated with boiling-surface's steady heat-load, the pool boiler is disconnected from the flow loop and the remaining flow loop operates in a steady-in-the-mean way.

\subsubsection{Steady State}

Steady state operations include two variations: one without externally imposed pulsations (i.e. liquid-vapor pulsators are still), and another with externally imposed pulsations (i.e. liquid-vapor pulsators are active). The newer more controllable pulsatile flows are to be achieved with both the liquid and vapor FC-72 pulsators being resonantly active. The intent of investigating pulsatile flows is to investigate energy-efficient ways of realizing the high heat flux operations indicated in previous experiments [2]. The pulsatile flows are intended to create standing waves on thin film thickness liquid film flows - with "sticking" troughs [2] that are known to create higher heat flux removal capabilities - over the entire test section. 


\subsection{Simulation tools}

The reader is referred to Appendices $B-N$ if one would like to review the MATLAB script while reading this section.

MATLAB was the primary tool for the simulations. Making use of several correlations allows for the determination of the following variables: heat transfer coefficient, pressure drop, flow quality, $\mathrm{X}$, as function of distance " $z$ " from the inlet of the test section.

The objective of the simulation is to provide flow conditions of non-pulsatile cases - so that experimental operators can get a sense of order of magnitude of flow variables during experiment runs at steady state.

The general procedure of the analysis is as follows (also see Figure 5 below).

1. Define the initial values of total mass flow rate, inlet flow quality and specify the geometry and fluid properties.

2. Use a MATLAB ODE solver to numerically solve for flow quality, $X(z)$, equation 1 , to yield qualities as a function of distance $z$.

3. Evaluate the heat transfer coefficients (HTC) from the solution of flow quality, X(z). Pay attention to special needs of each HTC.

a. For example, with the Kandlikar correlation a check of Reynolds numbers is required to be sure that the correct Nusselt number correlation is used.

4. Solve for the heat flux variations as a function of distance $z$ and report their values along with $\mathrm{HTC}$ and temperature difference $(\Delta \mathrm{T})$ values as a function of distance, $\mathrm{z}$.

5. Use the flow quality, $X(\mathrm{z})$, predictions to provide a pressure drop estimate as a function of $z$ along the test section. Use existing correlations for the three different components of pressure drop: frictional, accelerational, and gravitational.

6. Save the results and possibly loop through different flow quality solutions if multiple HTC correlations are inputted.

Again it is restated that this MATLAB tool was developed with the assistance of Sharayu Bhasme and Kaustubh Kale, who are members of Dr. Narain's simulation team. 


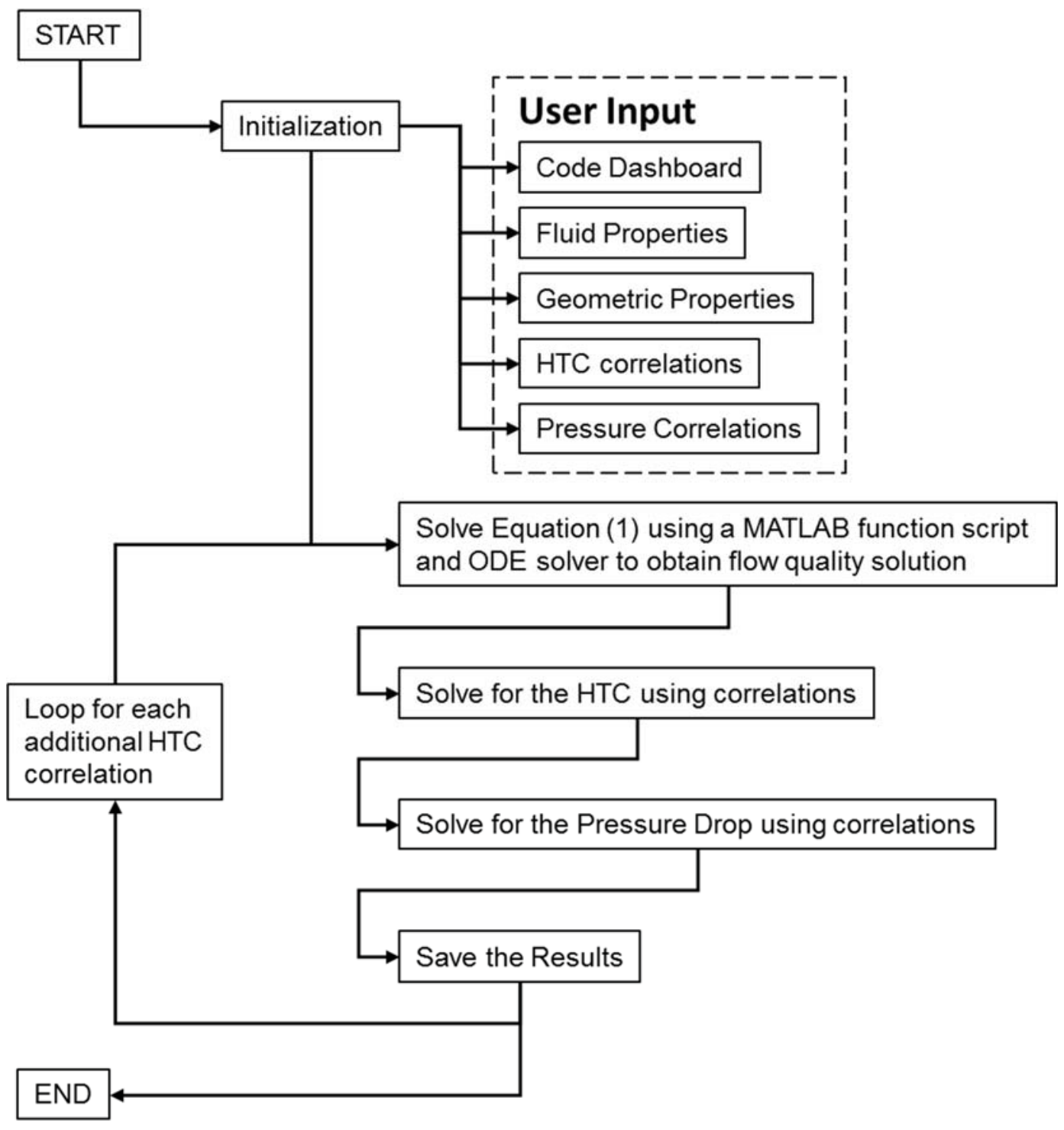

Figure 5: Flow chart of Modular code scheme

\subsection{Correlation-based Code Dashboard Structure}

This sections provides a deeper look into the structure of the code.

\subsubsection{Section 1: Start-Up}

The first section clears all variables in the workspace, closes all Figures currently open, sets the integer format to be long and clears command window. The fluid properties, geometric properties structures and the figure counter are defined as a global variable.

\subsubsection{Section 2: Set-up}

The second section is composed of 4 sub-sections. 
Section 2-A sets up information for saving Figures and .mat files for easily simulating multiple iterations.

Section 2-B is used to define the parameters of average heat flux, inlet flow quality, total mass flow rate of two phase mixture, mass flow rates of inlet liquid and vapor. The values will most likely by supplied via a PhD committed student after running an in-house 1-D engineering code.

Section 2-C is used to define the method of heating (MoH) as either constant wall temperature or as constant heat flux. If the constant wall temperature is chosen all that is required is the temperature difference between wall temperature and the fluid saturated temperature. If the constant heat flux method of heating is chosen then an array of temperature difference is required.

Section 2-D is used to define the axial gravity of the system, with 0 indicating a horizontal test section and 9.8 being a vertical test section.

\subsubsection{Section 3: Define Geometric Properties}

Section 3 simply asks for the user to input what kind of geometry the user wishes to model. This section then calls a separate script that will initialize geometric properties. The user supplies a string and the geometric properties are selected through an IF/ELSEIF structure, which allows for future expansions of different geometries.

\subsubsection{Section 4: Define Fluid Properties}

Similar to the Geometric properties in section 3, in Section 4 the user supplies a string for a fluid of interest and the fluid properties are initialized via an IF/ELSEIF within a separate script. This structure allows for a variety of fluids to be added without much difficulty.

\subsubsection{Section 5: Correlation Scripts}

Section 5 adds your correlation code to MATLABs current working directory, runs your correlation script and then saves your workspace. Future users must use the same variable structure as what is defined through the dashboard in any future correlation scripts. It is noted that the pressure drop correlations will be called within the HTC correlation script instead of the dashboard.

\subsection{Boiling Cases to investigate via simulation}

This study will investigate the predictive capability of the correlation based simulation tool and use the results to provide predictions to the future experiments. The boiling cases that were investigated and report in [2] are tabulate in table 1 below. Boiling cases 4 and 6 (B4 and B6) are cases of non-imposed fluctuation (N-IF), which did not make use of the vapor 
pulsator. Boiling cases 3 and 5 (B3 and B5) are cases of high-imposed fluctuation (H-IF), which did make use of the vapor pulsator.

The two different types of cases will be investigated in how the results from the different correlations used compare with the measured values presented in table 1, below.

Table 1: Cases that are investigated from the Experimental results for innovative boilers [11]

\begin{tabular}{|c|c|c|c|c|c|c|c|}
\hline Run & Type & $\begin{array}{c}\text { Inlet Pressure } \\
{[\mathbf{k P a}]}\end{array}$ & $\dot{\boldsymbol{M}}_{\mathbf{L}_{\text {in }}}[\mathbf{g} / \mathbf{s}]$ & $\dot{\boldsymbol{M}}_{\boldsymbol{V}_{\text {in }}}[\mathbf{g} / \mathbf{s}]$ & $\begin{array}{c}\Delta \mathbf{T} \\
{[\mathbf{K}]}\end{array}$ & $\begin{array}{c}\mathbf{q}^{\mathbf{4 0}} \\
{\left[\mathbf{W} / \mathbf{m}^{\wedge} \mathbf{2}\right]}\end{array}$ & $\begin{array}{c}\Delta \mathbf{P} \\
{[\mathbf{k P a}]}\end{array}$ \\
\hline B4 & $\mathrm{N}-\mathrm{IF}$ & 120.03 & 1.699 & 2.525 & 9.59 & 2060 & 6.89 \\
\hline B6 & $\mathrm{N}-\mathrm{IF}$ & 120.2 & 1.000 & 2.015 & 10.01 & 770 & 4.08 \\
\hline B3 & $\mathrm{H}-\mathrm{IF}$ & 120.31 & 1.700 & 2.540 & 9.57 & 4890 & 6.38 \\
\hline B5 & $\mathrm{H}-\mathrm{IF}$ & 119.74 & 1.000 & 2.025 & 10.87 & 1560 & 4.15 \\
\hline
\end{tabular}

\section{$5.3 \quad$ Test Matrix}

When considering at the experimental data collected via Kivasalu [2], a range of experimental conditions were used. Table 2, below depicts the different run conditions used in a simulation to provide the simulation team with a data base of results.

There are four input parameters for different variations of the runs indicated in Table-1. These are: Inlet Flow Quality $\left(\dot{\mathrm{M}}_{\mathrm{V} \text {-in }} / \dot{\mathrm{M}}_{\text {Total }}\right)$, Excess Average Boiling-surface Temperature $\Delta \mathrm{T}$, Inlet Pressure (for the test-section), Total steady flow rate $\left(\dot{\mathrm{M}}_{\text {Total }}=\dot{\mathrm{M}}_{\mathrm{V} \text {-in }}+\dot{\mathrm{M}}_{\mathrm{L} \text {-in }}\right)$.

Table 2: Input parameters used for the 18 different simulations

\begin{tabular}{|c|c|c|c|c|}
\hline Simulation & Inlet Flow Quality & $\Delta \mathrm{T}\left[{ }^{\circ} \mathrm{C}\right]$ & Inlet Pressure $[\mathrm{kPa}]$ & $\dot{m}_{T}[\mathrm{~g} / \mathrm{s}]$ \\
\hline 1 & 0.3 & 5 & 120 & 3 \\
\hline 2 & 0.3 & 5 & 135 & 4 \\
\hline 3 & 0.3 & 5 & 150 & 5 \\
\hline 4 & 0.3 & 10 & 120 & 3 \\
\hline 5 & 0.3 & 10 & 135 & 4 \\
\hline 6 & 0.3 & 10 & 150 & 5 \\
\hline 7 & 0.3 & 15 & 120 & 4 \\
\hline 8 & 0.3 & 15 & 135 & 5 \\
\hline 9 & 0.3 & 5 & 150 & 3 \\
\hline 10 & 0.4 & 5 & 120 & 5 \\
\hline 11 & 0.4 & 10 & 135 & 3 \\
\hline 12 & 0.4 & 10 & 150 & 4 \\
\hline 13 & 0.4 & 10 & 120 & 4 \\
\hline 14 & 0.4 & 15 & 135 & 3 \\
\hline 15 & 0.4 & 15 & 150 & 5 \\
\hline 16 & 0.4 & 15 & 120 & 3 \\
\hline 17 & 0.4 & & 135 & 4 \\
\hline 18 & 0.4 & 150 & \\
\hline
\end{tabular}




\subsection{Set-up of experimental comparisons to previous experiments}

The tables below show that input definitions that are used within this investigation. Please note that temperature difference and average heat flux were supplied via the results of a separate 1-D code, ran by a PhD student.

The geometric properties are physically defined from manufactured or designed equipment. Fluid properties are found using EES, with a special consideration of the liquid and vapor viscosities being taken to be equivalent to those of R-113 at the same pressure and temperature.

Table 3: Correlation Input Parameters for the experimental boiling case comparisons

\begin{tabular}{|c|c|c|c|c|c|c|}
\hline \multicolumn{7}{|c|}{ Code Dashboard inputs } \\
\hline Run & Type & Inlet Pressure [kPa] & $\Delta \mathrm{T}\left[{ }^{\circ} \mathrm{C}\right]$ & $q_{A V G}$ & Inlet flow Quality & $\dot{m}_{T}[\mathrm{~g} / \mathrm{s}]$ \\
\hline B4 & $\mathrm{N}-\mathrm{IF}$ & \multirow{4}{*}{120} & \multirow{4}{*}{10} & \multirow{4}{*}{900} & 0.4022 & 4.224 \\
\hline B6 & $\mathrm{N}-\mathrm{IF}$ & & & & 0.3316 & 3.015 \\
\hline B3 & $\mathrm{H}-\mathrm{IF}$ & & & & 0.4010 & 4.24 \\
\hline B5 & $\mathrm{H}-\mathrm{IF}$ & & & & 0.3306 & 3.025 \\
\hline
\end{tabular}

Table 4: Geometric Properties from previous experiments

\begin{tabular}{|c|c|c|c|}
\hline \multicolumn{4}{|c|}{ Geometric properties of Channel } \\
\hline Height $[\mathrm{mm}]$ & Width $[\mathrm{mm}]$ & Length $[\mathrm{mm}]$ & Hydraulic Diameter [mm] \\
\hline 2 & 15 & 1000 & 8 \\
\hline
\end{tabular}

Table 5: FC-72 Fluid Properties at 120kPa

\begin{tabular}{|c|c|c|}
\hline Inlet Pressure [kPa] & Liquid Density $\left[\mathrm{kg} / \mathrm{m}^{3}\right]$ & Vapor Density $\left[\mathrm{kg} / \mathrm{m}^{3}\right]$ \\
\hline 120 & 1609.63 & 15.87 \\
\hline $\begin{array}{l}\text { Liquid thermal conductivity } \\
\qquad[\mathrm{W} / \mathrm{m}-\mathrm{K}]\end{array}$ & Heat of vaporization $[\mathrm{J} / \mathrm{kg}]$ & Saturation temperature $\left[{ }^{\circ} \mathrm{C}\right]$ \\
\hline $5.153 \mathrm{e}-2$ & 82,949 & 62 \\
\hline $\begin{array}{l}\text { Liquid dynamic viscosity } \\
{[\mathrm{Pa}-\mathrm{s}]}\end{array}$ & $\begin{array}{c}\text { Vapor dynamic viscosity } \\
{[\mathrm{Pa}-\mathrm{s}]}\end{array}$ & $\begin{array}{c}\text { Specific heat } \\
{[\mathrm{J} / \mathrm{kg}-\mathrm{K}]}\end{array}$ \\
\hline $4.77 \mathrm{e}-4$ & $1.112 \mathrm{e}-5$ & 1106.75 \\
\hline Surface Tension [N/m] & Critical pressure [kPa] & Liquid Prandtl Number \\
\hline $7.816 \mathrm{e}-3$ & 1834 & 10.2535 \\
\hline
\end{tabular}




\subsection{New Experimental Predictions}

With a new test section channel length of $0.5 \mathrm{~m}$, this simulation code will be used to provide the experimental team will predicted values of Measures such as pressure drops, Mass flow rates and heat flux at $40 \mathrm{~cm}$. All inputs are the same as the previous section 5.2, except that the geometric channel length is changed to $500 \mathrm{~mm}$.

\subsection{Additional inputs for the Test Matrix simulations}

Table 6: FC-72 Fluid Properties at 135kPa

\begin{tabular}{|c|c|c|}
\hline Inlet Pressure [kPa] & Liquid Density $\left[\mathrm{kg} / \mathrm{m}^{3}\right]$ & Vapor Density $\left[\mathrm{kg} / \mathrm{m}^{3}\right]$ \\
\hline 135 & 1602.45 & 17.75 \\
\hline $\begin{array}{l}\text { Liquid thermal conductivity } \\
{[\mathrm{W} / \mathrm{m}-\mathrm{K}]}\end{array}$ & Heat of vaporization $[\mathrm{J} / \mathrm{kg}]$ & Saturation temperature $\left[{ }^{\circ} \mathrm{C}\right]$ \\
\hline $5.111 \mathrm{e}-2$ & $81,888.8$ & 65.6 \\
\hline $\begin{array}{l}\text { Liquid dynamic viscosity } \\
{[\mathrm{Pa}-\mathrm{s}]}\end{array}$ & $\begin{array}{c}\text { Vapor dynamic viscosity } \\
{[\mathrm{Pa}-\mathrm{s}]}\end{array}$ & $\begin{array}{l}\text { Specific heat } \\
{[\mathrm{J} / \mathrm{kg}-\mathrm{K}]}\end{array}$ \\
\hline $4.554 \mathrm{e}-4$ & $1.13 e-5$ & 1112.31 \\
\hline Surface Tension $[\mathrm{N} / \mathrm{m}]$ & Critical pressure [kPa] & Liquid Prandtl Number \\
\hline $7.515 \mathrm{e}-3$ & 1834 & 9.9109 \\
\hline
\end{tabular}

Table 7: FC-72 Fluid Properties at $150 \mathrm{kPa}$

\begin{tabular}{|c|c|c|}
\hline Inlet Pressure [kPa] & Liquid Density $\left[\mathrm{kg} / \mathrm{m}^{3}\right]$ & Vapor Density $\left[\mathrm{kg} / \mathrm{m}^{3}\right]$ \\
\hline 150 & 1595.50 & 19.64 \\
\hline $\begin{array}{l}\text { Liquid thermal conductivity } \\
{[\mathrm{W} / \mathrm{m}-\mathrm{K}]}\end{array}$ & Heat of vaporization [J/kg] & Saturation temperature $\left[{ }^{\circ} \mathrm{C}\right]$ \\
\hline $5.072 \mathrm{e}-2$ & $80,905.7$ & 68.9 \\
\hline $\begin{array}{l}\text { Liquid dynamic viscosity } \\
{[\mathrm{Pa}-\mathrm{s}]}\end{array}$ & $\begin{array}{c}\text { Vapor dynamic viscosity } \\
{[\mathrm{Pa}-\mathrm{s}]}\end{array}$ & $\begin{array}{l}\text { Specific heat } \\
{[\mathrm{J} / \mathrm{kg}-\mathrm{K}]}\end{array}$ \\
\hline $4.363 e-4$ & $1.114 \mathrm{e}-5$ & 1117.41 \\
\hline Surface Tension [N/m] & Critical pressure [kPa] & Liquid Prandtl Number \\
\hline $7.241 \mathrm{e}-3$ & 1834 & 9.612 \\
\hline
\end{tabular}




\subsection{Results (data and observations)}

This section is dedicated to tables and Figures of results see section 7 for a discussion on the results presented here. The values represented within the prediction sections have been truncated, via the ceiling for positive numbers and the floor function for negative numbers, to the nearest whole number as the investigation is only interested in providing order of magnitude estimations.

\subsection{Simulation of N-IF cases and comparison to Experimental data}

\subsubsection{Table of Values}

Table 8 is separated into three sections: prediction results from Kandlikar, prediction results from Kim \& Mudawar, and corresponding experimental results [2]. Please note that the error associated with the experimental measure is kept from [2].

The fact that Kim and Mudawar as well as Kandlikar correlations' pressuredrop and heat-flux values are very different - except for order of magnitude - than the experiment's is understandable. This is because the experiments are primarily in annular (close to suppressed nucleation) regime whereas correlations try to fit data covering all the regimes (from inlet to dry-out in Figure 1a).

Table 8: Comparison of simulation and experimental results for the N-IF cases

\begin{tabular}{|c|c|c|c|c|c|c|c|c|}
\hline \multirow{3}{*}{ \&్ } & \multirow{3}{*}{$\begin{array}{c}\dot{M}_{L_{\text {out }}}[\mathrm{g} / \mathrm{s}] \\
\text { Kand }\end{array}$} & \multirow{3}{*}{$\frac{\dot{M}_{V_{\text {out }}}[\mathrm{g} / \mathrm{s}]}{\text { Kand }}$} & \multirow{2}{*}{\multicolumn{3}{|c|}{$\frac{q_{40}^{\prime \prime}\left[W / m^{\wedge} 2\right]}{\text { Kand }}$}} & \multicolumn{3}{|c|}{$\Delta \boldsymbol{P}_{\text {Total }}[\mathrm{kPa}]$} \\
\hline & & & & & & \multicolumn{3}{|c|}{ Kand } \\
\hline & & & $\mathbf{c b}$ & nb & tp & $\mathbf{F R}$ & LM & NIST \\
\hline 4 & 2 & 2 & 6522 & 2127 & 6522 & -2 & -2 & -2 \\
\hline 6 & 2 & 1 & 5224 & 2203.842 & 5224 & -1 & -1 & -1 \\
\hline \multirow{3}{*}{ 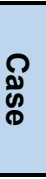 } & $\dot{M}_{L_{\text {out }}}[\mathrm{g} / \mathrm{s}]$ & $\dot{M}_{V_{\text {out }}}[\mathrm{g} / \mathrm{s}]$ & & $40[\mathrm{~W} / \mathrm{m}$ & & & tal $[k$ & \\
\hline & \multirow{2}{*}{ KM } & \multirow{2}{*}{ KM } & \multicolumn{3}{|c|}{ KM } & \multicolumn{3}{|c|}{ KM } \\
\hline & & & $\mathrm{cb}$ & $\mathrm{nb}$ & tp & FR & LM & NIST \\
\hline 4 & 1 & 4 & 8422 & 1649 & 8583 & -2 & -2 & -3 \\
\hline 6 & 1 & 3 & 6074 & 1658. & 6297 & -1 & -1 & -2 \\
\hline \multirow{2}{*}{ 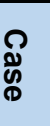 } & $\dot{M}_{L_{\text {out }}}[\mathrm{g} / \mathrm{s}]$ & $\dot{M}_{V_{\text {out }}}[\mathrm{g} / \mathrm{s}]$ & \multicolumn{3}{|c|}{$q_{40}^{\prime \prime}\left[W / m^{\wedge} 2\right]( \pm 0.15)$} & \multicolumn{3}{|c|}{$\Delta P_{\text {Total }}[\mathrm{kPa}]( \pm .05+6 \%)$} \\
\hline & \multicolumn{8}{|c|}{ Experimental Measures } \\
\hline 4 & Not Available & Not Available & \multicolumn{3}{|c|}{2060.00} & \multicolumn{3}{|c|}{-6.89} \\
\hline 6 & Not Available & Not Available & \multicolumn{3}{|c|}{770.00} & \multicolumn{3}{|c|}{-4.08} \\
\hline
\end{tabular}




\subsubsection{Charts/Figures}

\subsubsection{Quality}

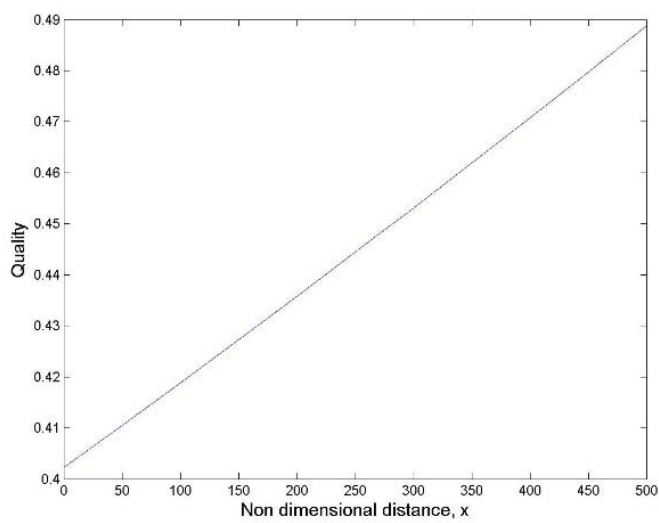

Figure 6: Case 4 Kandlikar

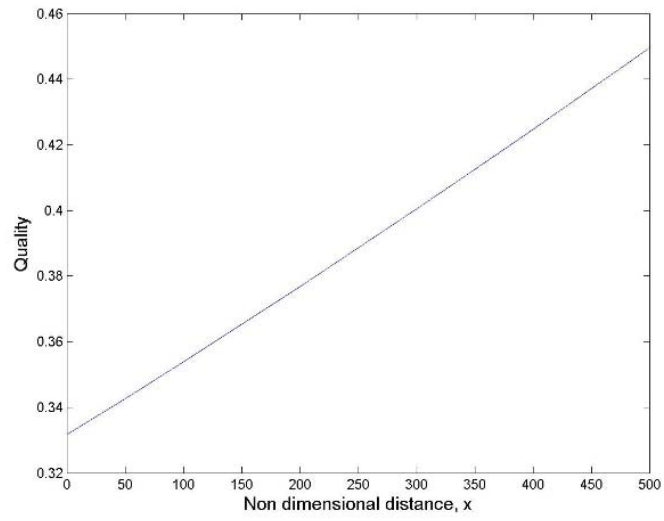

Figure 8: Case 6 Kandlikar

\subsubsection{2 $\quad$ Mass flow rates}

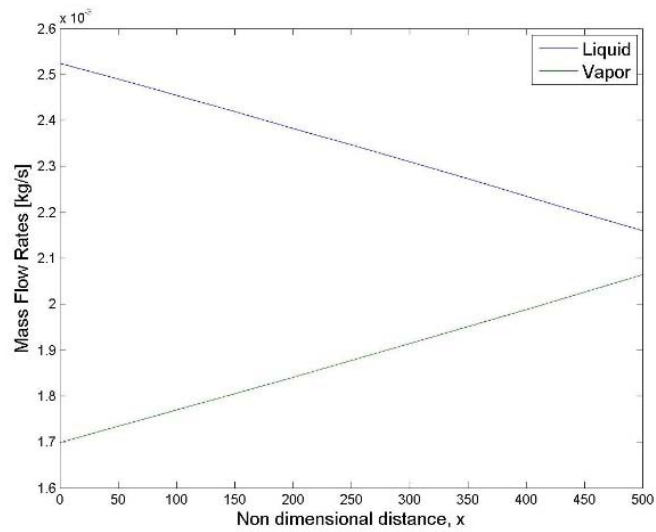

Figure 10: case 4 Kandlikar

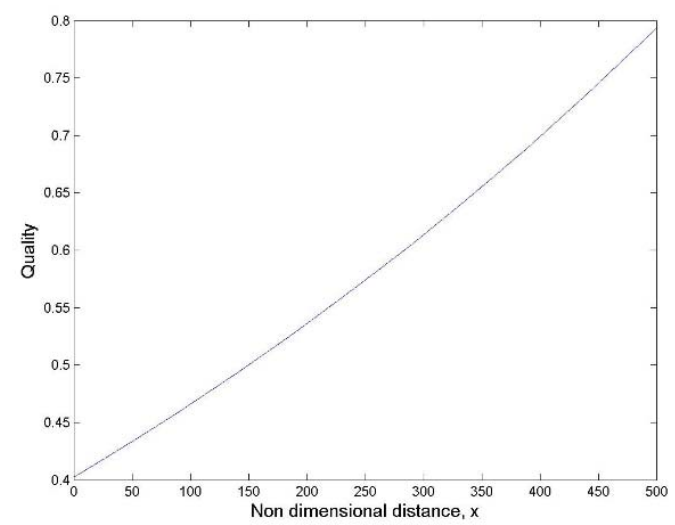

Figure 7: Case $4 \mathrm{Kim}$ and Mudawar

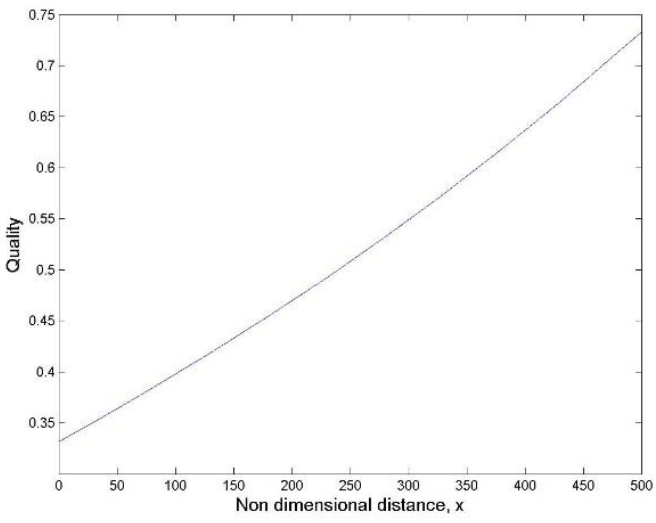

Figure 9: Case 6 Kim \& Mudawar

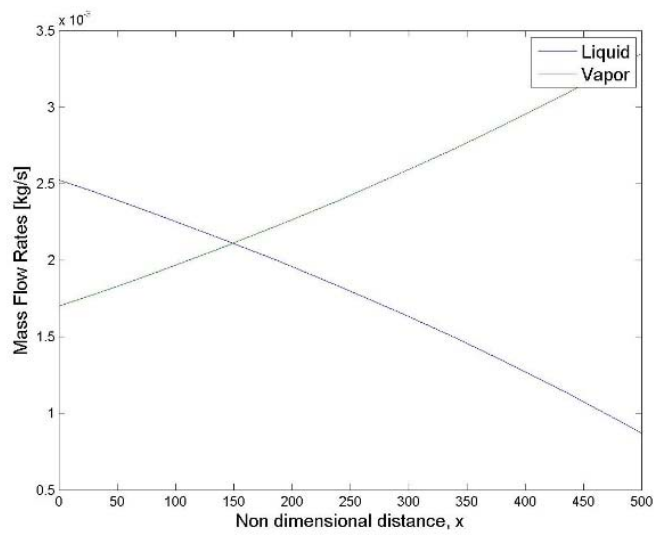

Figure 11: Case 4 Kim \& Mudawar 


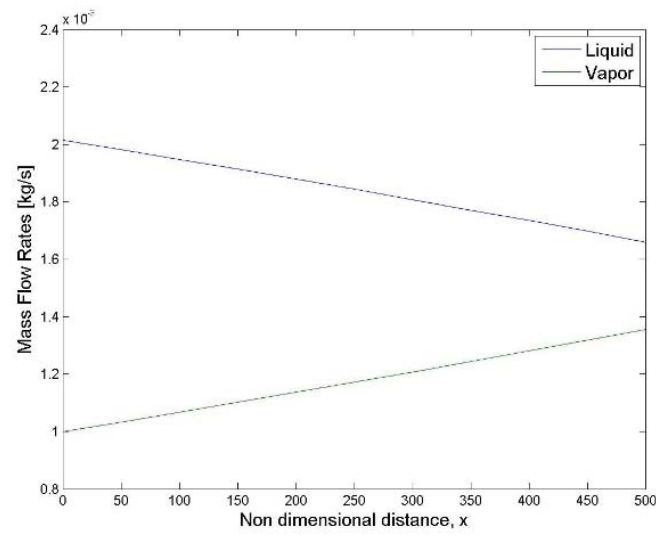

Figure 12: case 6 Kandlikar

\subsubsection{3 $\underline{\text { HTC }}$}

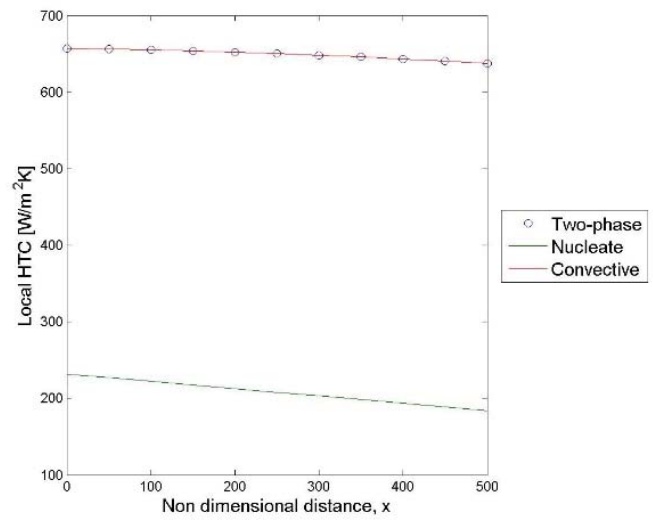

Figure 14: Case 4 Kandlikar

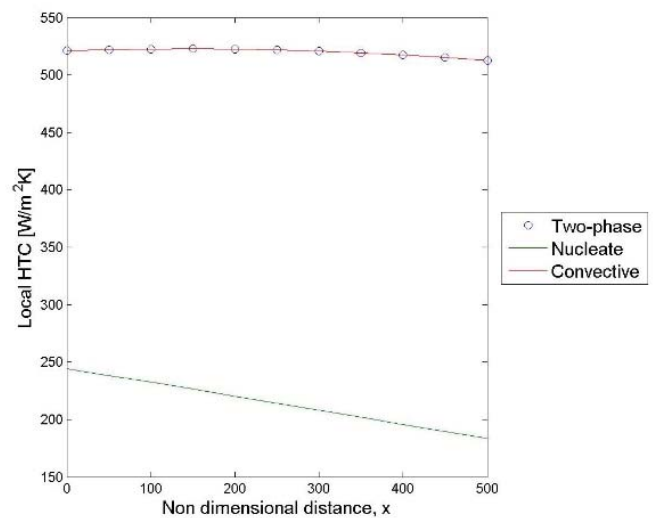

Figure 16: Case 6 Kandlikar

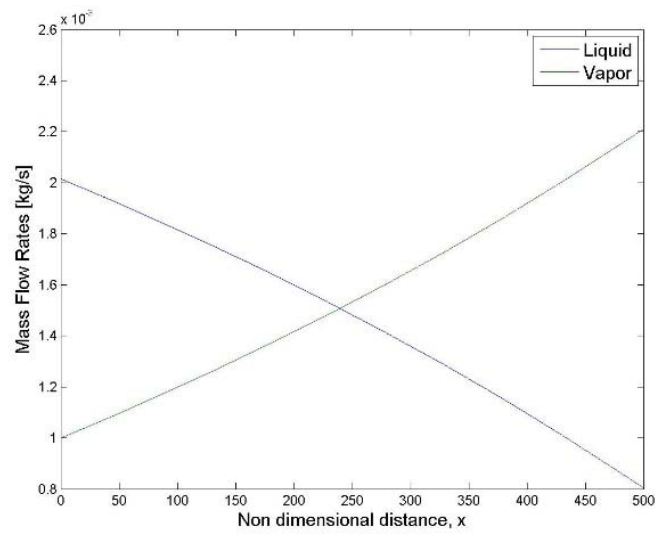

Figure 13: Case 6 Kim \& Mudawar

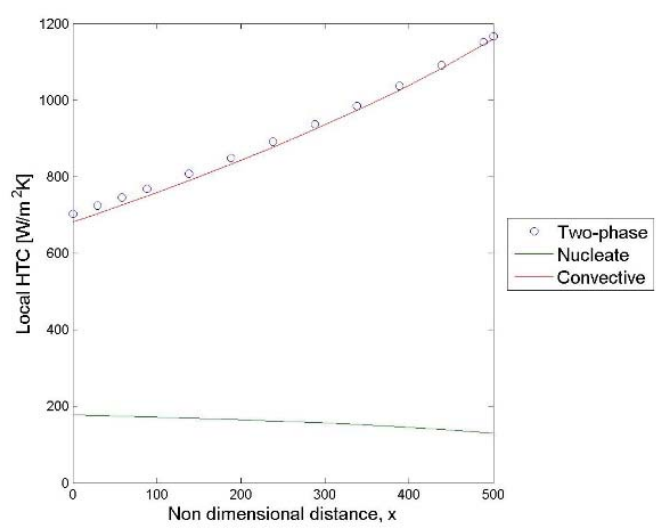

Figure 15: Case 4 Kim \& Mudawar

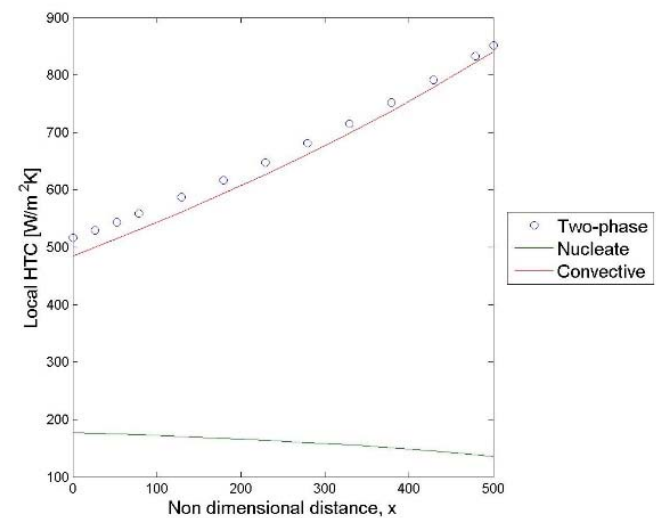

Figure 17: Case $6 \mathrm{Kim}$ and Mudawar 


\subsubsection{Heat Flux}

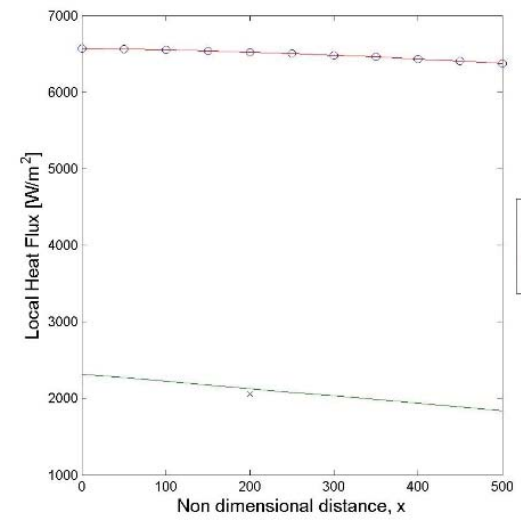

Figure 18: Case 4 Kandlikar

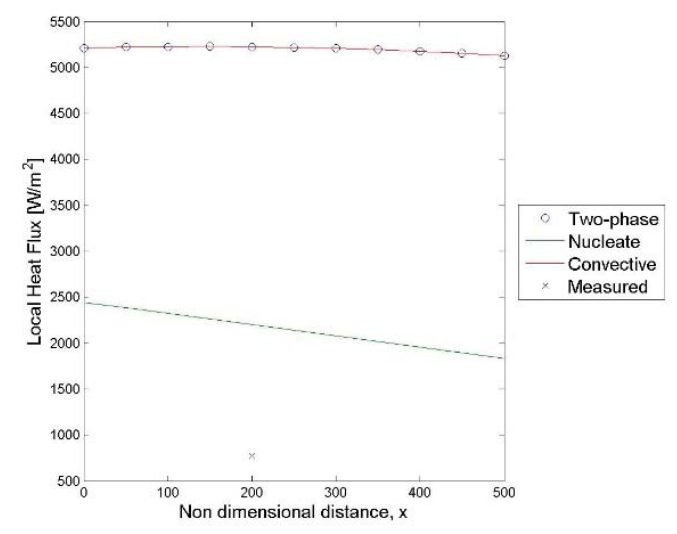

Figure 20: Case 6 Kandlikar

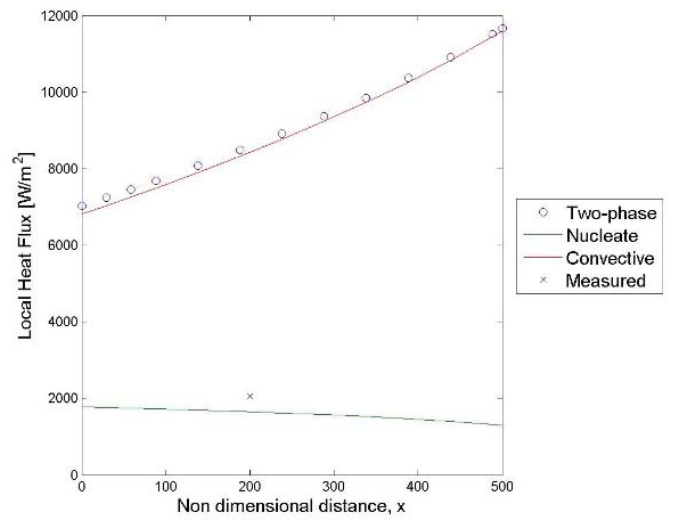

Figure 19: Case 4 Kim \& Mudawar

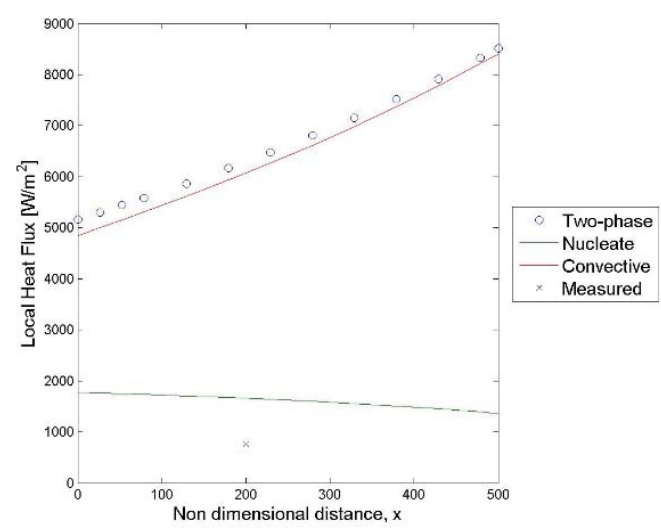

Figure 21: Case 6 Kim \& Mudawar

\subsubsection{5 $\quad$ Test Section Pressure Drop}

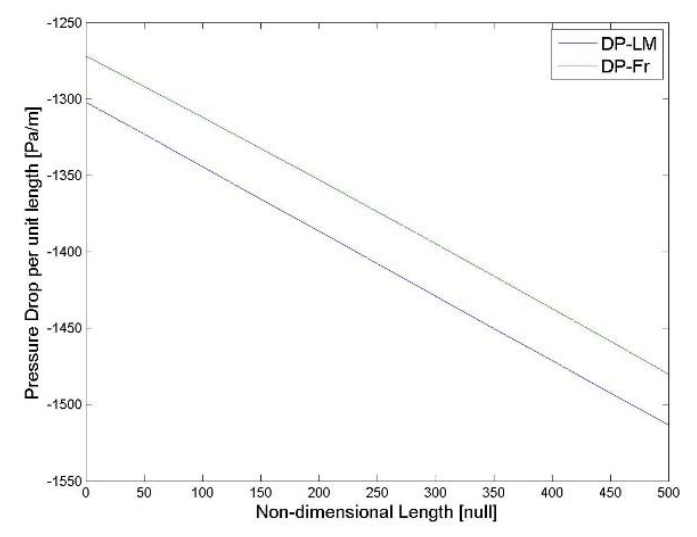

Figure 22: Case 4 Kandlikar

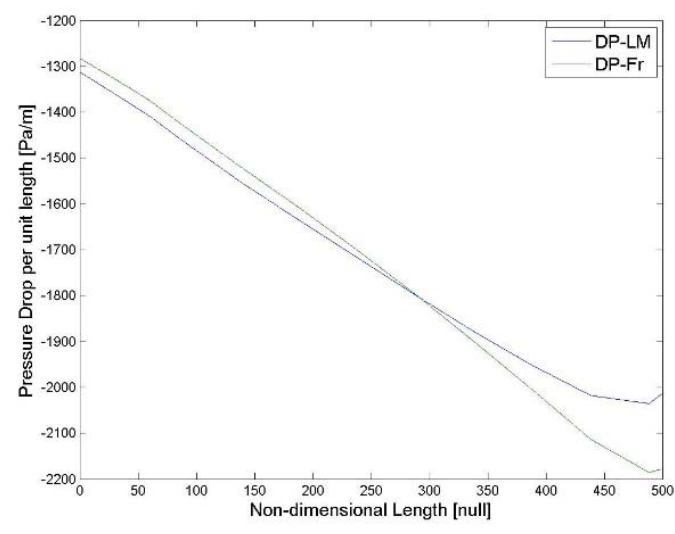

Figure 23: Case 4 Kim \& Mudawar 


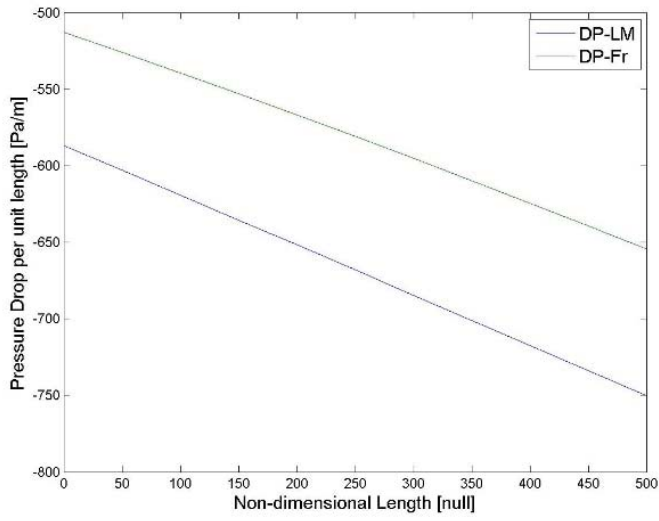

Figure 24: Case 6 Kandlikar

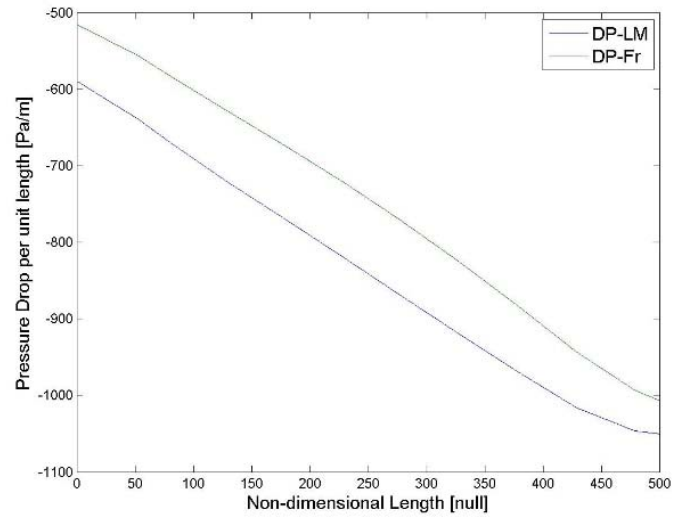

Figure 25: Case 6 Kim \& Mudawar 


\subsection{Simulation Predictions for the new test section length (N-IF)}

\subsubsection{Table of Values}

Table 9: Simulation Predictions for the new experimental runs with the shorter test section

\begin{tabular}{|c|c|c|c|c|c|c|c|c|}
\hline \multirow{3}{*}{ 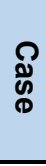 } & $\dot{M}_{L_{\text {out }}}[\mathrm{g} / \mathrm{s}]$ & $\dot{M}_{V_{\text {out }}}[\mathrm{g} / \mathrm{s}]$ & & ${ }_{0}[\mathrm{~W} / \mathrm{n}$ & & & otal [ & \\
\hline & \multirow{2}{*}{ Kand } & \multirow{2}{*}{ Kand } & \multicolumn{3}{|c|}{ Kand } & \multicolumn{3}{|c|}{ Kand } \\
\hline & & & cb & nb & tp & Fr & LM & NIST \\
\hline 4 & 3 & 2 & 6194 & 1612 & 6194 & -1 & -1 & -1 \\
\hline 6 & 2 & 2 & 4848 & 1623 & 4848 & -1 & -1 & -1 \\
\hline \multirow{3}{*}{$\begin{array}{l}\text { 尺 } \\
\text { ஸी } \\
\text { ه }\end{array}$} & $\dot{M}_{L_{\text {out }}}[\mathrm{g} / \mathrm{s}]$ & $\dot{M}_{V_{\text {out }}}[\mathrm{g} / \mathrm{s}]$ & & ${ }_{0}[\mathrm{~W} / \mathrm{n}$ & & & otal [ & \\
\hline & \multirow{2}{*}{ KM } & \multirow{2}{*}{ KM } & \multicolumn{3}{|c|}{ KM } & \multicolumn{3}{|c|}{ KM } \\
\hline & & & cb & nb & tp & $\mathrm{Fr}$ & LM & NIST \\
\hline 4 & 2 & 3 & 8348 & 1018 & 8410 & -1 & -1 & -1 \\
\hline 6 & 2 & 2 & 5979 & 1025 & 6067 & -1 & -1 & -1 \\
\hline
\end{tabular}

\subsubsection{Charts}

\subsubsection{Quality}

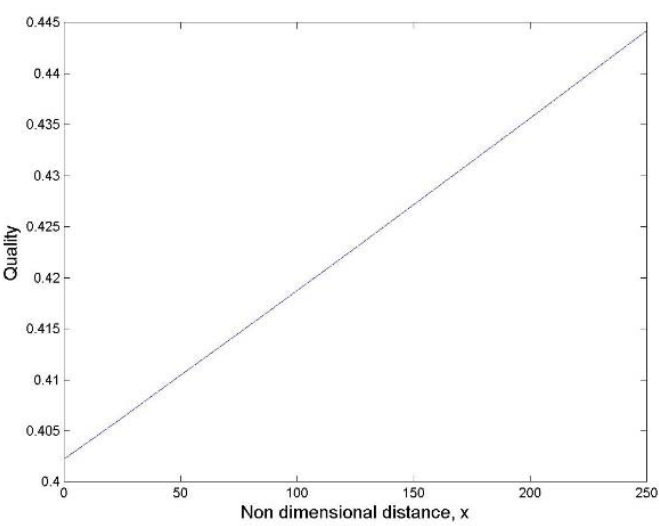

Figure 26: Case 4 Kandlikar

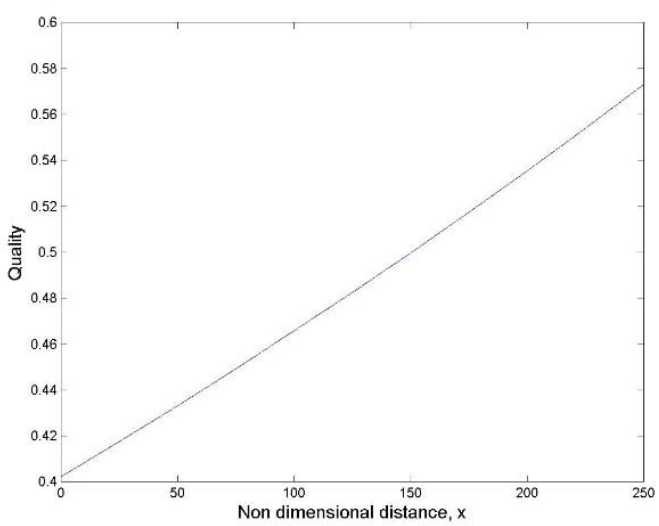

Figure 27: Case $4 \mathrm{Kim}$ and Mudawar 


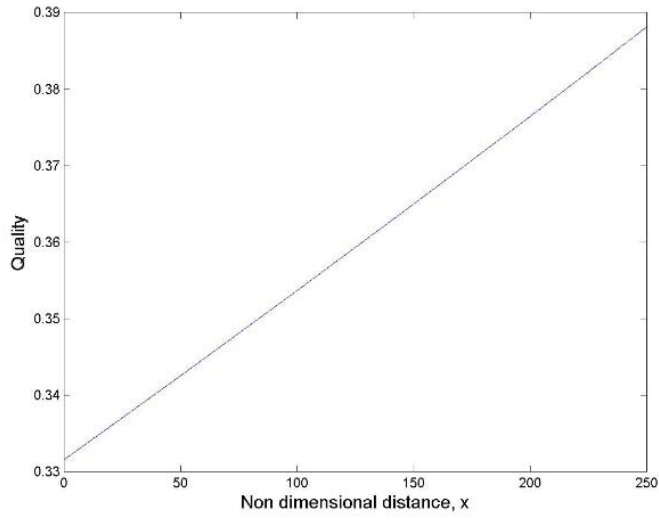

Figure 28: Case 6 Kandlikar

\subsubsection{Mass flow rates}

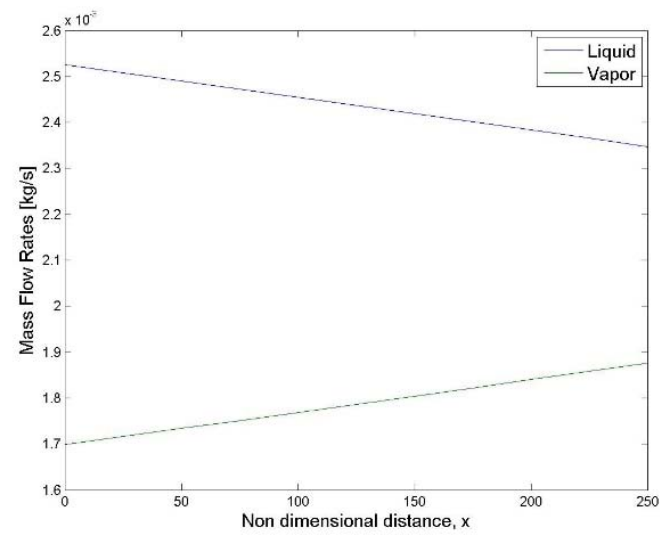

Figure 30: case 4 Kandlikar

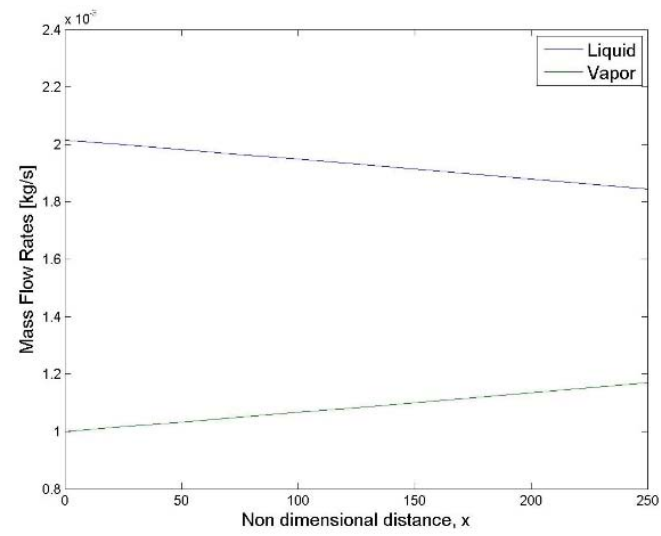

Figure 32: case 6 Kandlikar

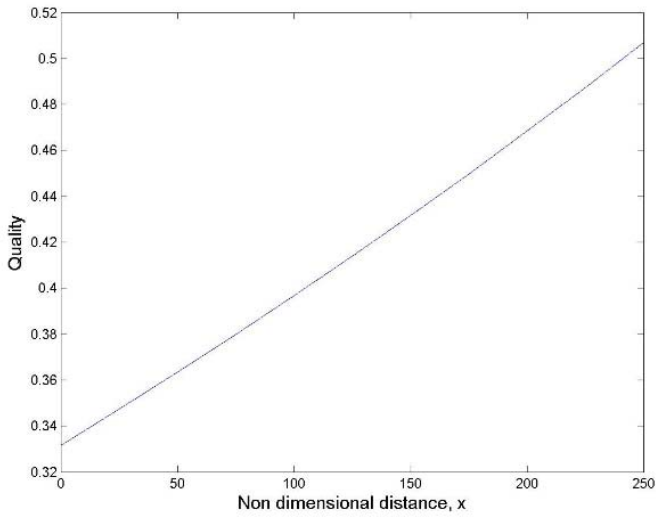

Figure 29: Case 6 Kim \& Mudawar

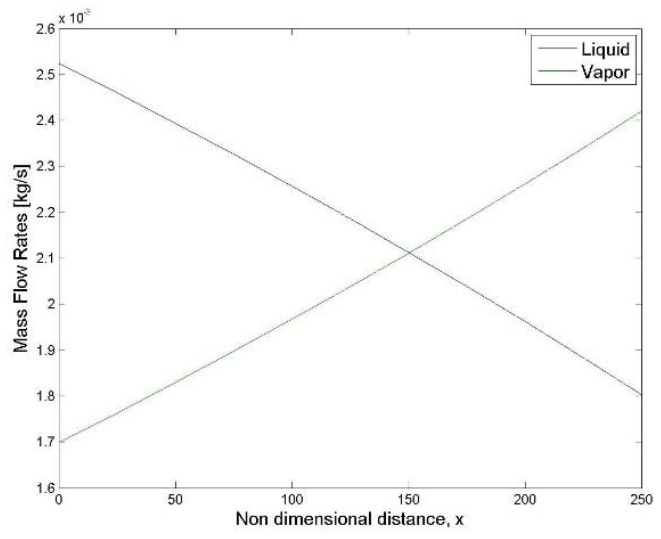

Figure 31: Case 4 Kim \& Mudawar

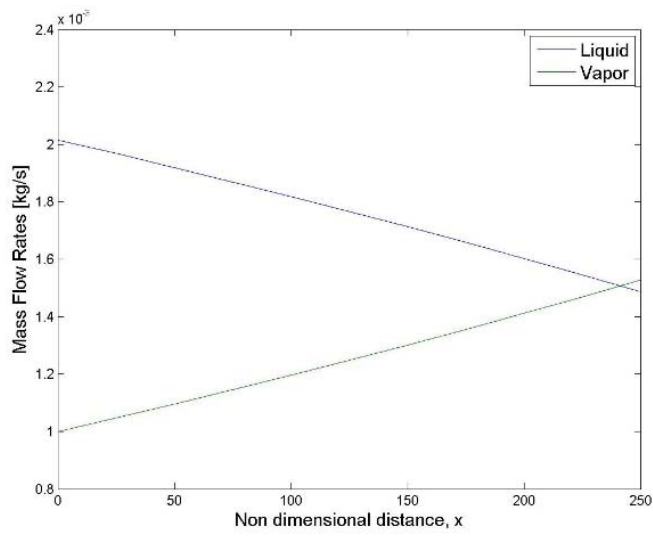

Figure 33: Case 6 Kim \& Mudawar 


\subsubsection{3 $\underline{\mathrm{HTC}}$}

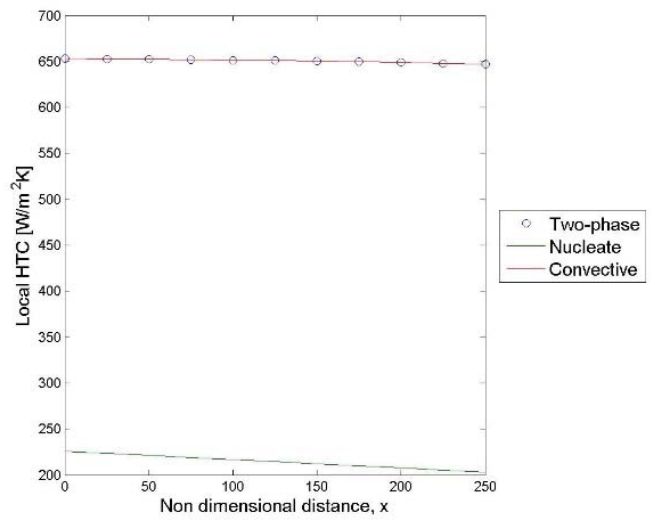

Figure 34: Case 4 Kandlikar

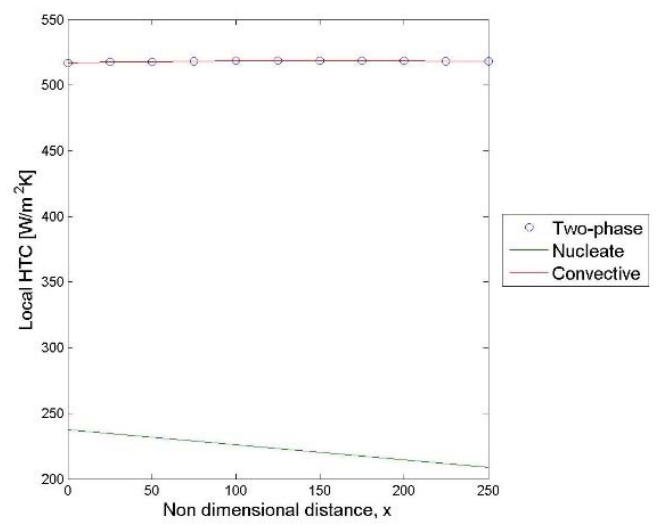

Figure 36: Case 6 Kandlikar

\subsubsection{Heat Flux}

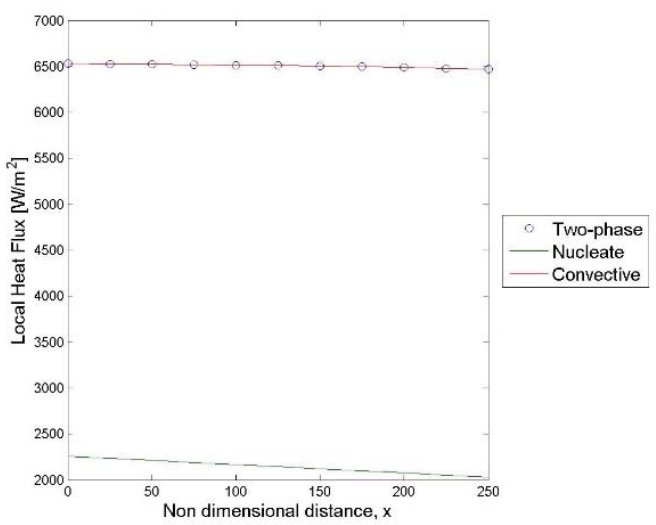

Figure 38: Case 4 Kandlikar

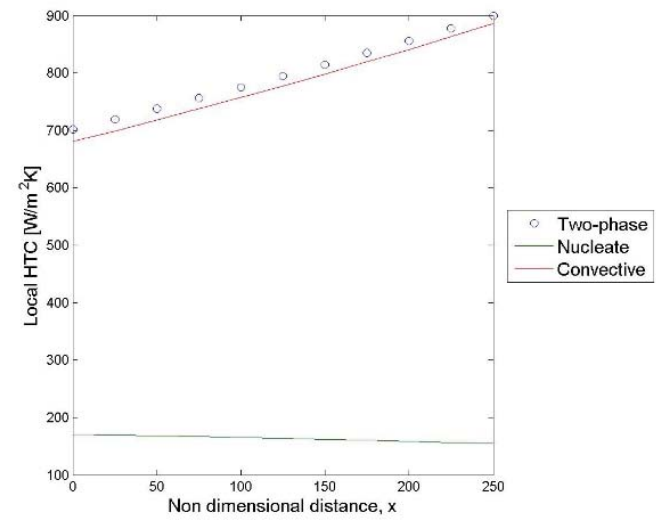

Figure 35: Case 4 Kim \& Mudawar

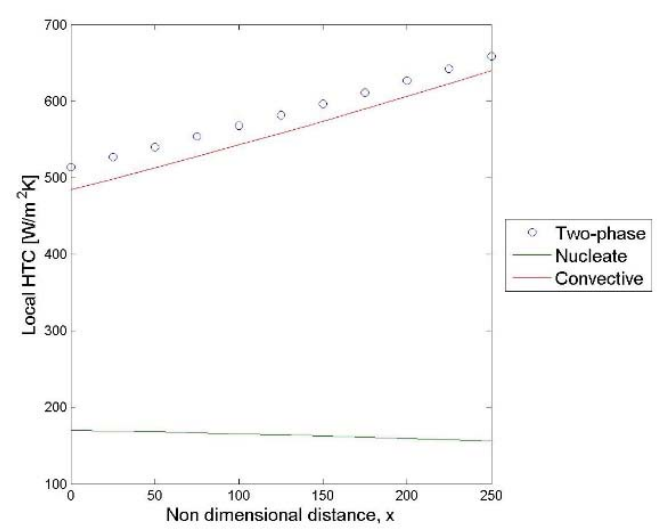

Figure 37: Case $6 \mathrm{Kim}$ and Mudawar

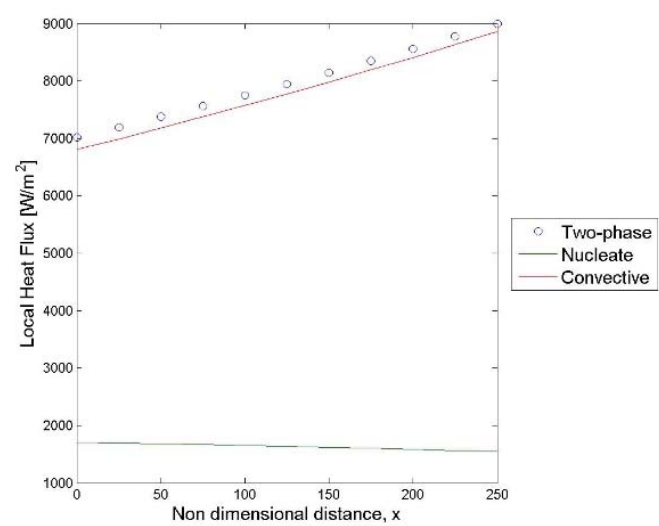

Figure 39: Case 4 Kim \& Mudawar 


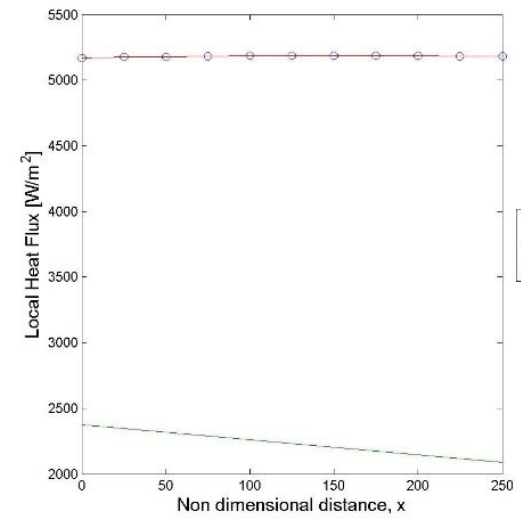

Figure 40: Case 6 Kandlikar

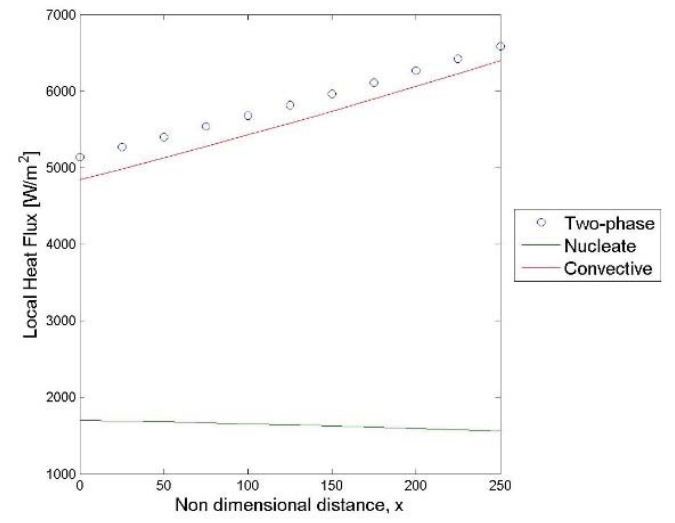

Figure 41: Case 6 Kim \& Mudawar

\subsubsection{5 $\quad$ Test Section Pressure Drop}

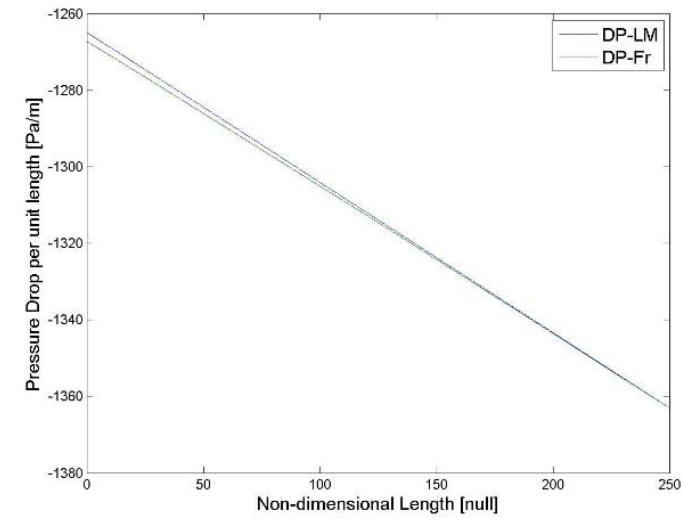

Figure 42: Case 4 Kandlikar

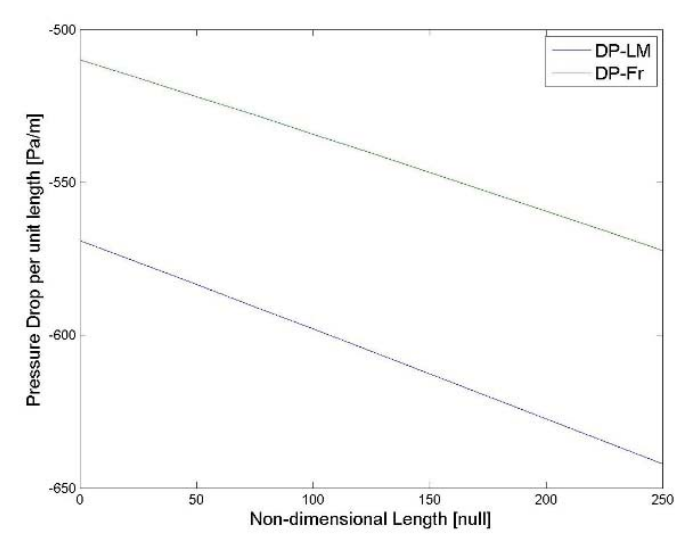

Figure 44: Case 6 Kandlikar

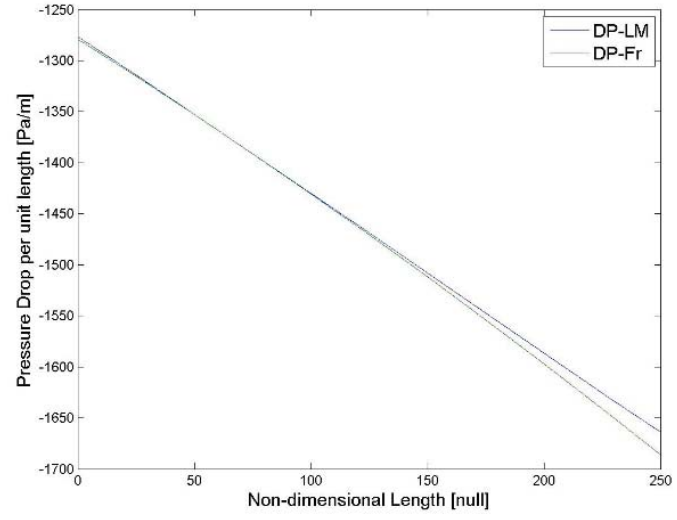

Figure 43: Case 4 Kim \& Mudawar

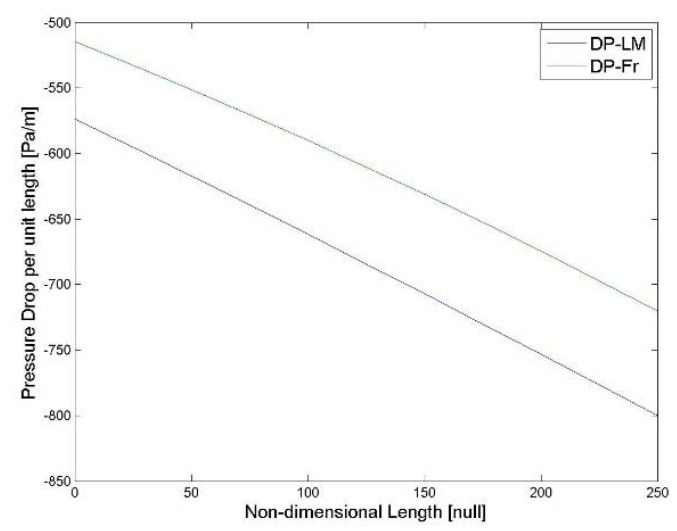

Figure 45: Case 6 Kim \& Mudawar 


\subsection{Simulation of Test Matrix}

\subsubsection{Table of Values}

Table 10: Results of test matrix via the Kandlikar HTC correlation

\begin{tabular}{|c|c|c|c|c|c|c|c|c|}
\hline \multirow{3}{*}{ Exp } & $\dot{M}_{L_{o u t}}[\mathrm{~g} / \mathrm{s}]$ & $\dot{M}_{V_{\text {out }}}[\mathrm{g} / \mathrm{s}]$ & & ${ }_{0}[\mathrm{~W} / \mathrm{m}$ & & & otal [ & \\
\hline & \multirow{2}{*}{ Kand } & \multirow{2}{*}{ Kand } & \multicolumn{3}{|c|}{ Kand } & \multicolumn{3}{|c|}{ Kand } \\
\hline & & & $\mathrm{cb}$ & $\mathrm{nb}$ & tp & $\mathrm{Fr}$ & LM & NIST \\
\hline 1 & 3 & 1 & 2593 & 1247 & 2593 & -1 & -1 & -1 \\
\hline 2 & 3 & 1 & 3052 & 1411 & 3052 & -1 & -1 & -1 \\
\hline 3 & 4 & 1 & 3459 & 1559 & 3459 & -1 & -1 & -1 \\
\hline 4 & 2 & 1 & 5205 & 2376 & 5205 & -1 & -1 & -1 \\
\hline 5 & 3 & 1 & 6132 & 2732 & 6132 & -1 & -1 & -1 \\
\hline 6 & 4 & 1 & 6947 & 3045 & 6947 & -1 & -1 & -1 \\
\hline 7 & 3 & 1 & 9470 & 3876 & 9470 & -1 & -1 & -1 \\
\hline 8 & 4 & 1 & 10713 & 4376 & 10713 & -1 & -1 & -1 \\
\hline 9 & 2 & 1 & 7467 & 3544 & 7467 & -1 & -1 & -1 \\
\hline 10 & 3 & 1 & 3694 & 1196 & 3694 & -1 & -1 & -1 \\
\hline 11 & 2 & 1 & 2514 & 1000 & 2514 & -1 & -1 & -1 \\
\hline 12 & 3 & 1 & 2995 & 1136 & 2995 & -1 & -1 & -1 \\
\hline 13 & 3 & 1 & 6277 & 2089 & 6277 & -1 & -1 & -1 \\
\hline 14 & 3 & 1 & 7162 & 2355 & 7162 & -1 & -1 & -1 \\
\hline 15 & 2 & 1 & 4867 & 1916 & 4867 & -1 & -1 & -1 \\
\hline 16 & 3 & 1 & 11014 & 3338 & 11014 & -1 & -1 & -1 \\
\hline 17 & 2 & 1 & 7372 & 2628 & 7372 & -1 & -1 & -1 \\
\hline 18 & 3 & 1 & 8882 & 3121 & 8882 & -1 & -1 & -1 \\
\hline
\end{tabular}


Table 11: Results of test matrix via the Kim \& Mudawar HTC correlation

\begin{tabular}{|c|c|c|c|c|c|c|c|c|}
\hline \multirow{3}{*}{ Exp } & $\dot{M}_{L_{\text {out }}}[\mathrm{g} / \mathrm{s}]$ & $\dot{M}_{V_{\text {out }}}[\mathrm{g} / \mathrm{s}]$ & & ${ }_{0}[\mathrm{~W} / \mathrm{m}$ & & & tal $[\mathrm{k}$ & \\
\hline & \multirow{2}{*}{ KM } & \multirow{2}{*}{ KM } & \multicolumn{3}{|c|}{ KM } & \multicolumn{3}{|c|}{ KM } \\
\hline & & & cb & $\mathrm{nb}$ & tp & $\mathrm{Fr}$ & LM & NIST \\
\hline 1 & 2 & 1 & 2554 & 875 & 2700 & -1 & -1 & -1 \\
\hline 2 & 3 & 1 & 2998 & 968 & 3150 & -1 & -1 & -1 \\
\hline 3 & 4 & 1 & 3417 & 1057 & 3577 & -1 & -1 & -1 \\
\hline 4 & 2 & 1 & 5718 & 1692 & 5963 & -1 & -1 & -1 \\
\hline 5 & 3 & 1 & 6699 & 1882 & 6958 & -1 & -1 & -1 \\
\hline 6 & 3 & 1 & 7620 & 2058 & 7893 & -1 & -1 & -1 \\
\hline 7 & 2 & 1 & 11192 & 2545 & 11478 & -1 & -1 & -1 \\
\hline 8 & 3 & 1 & 12752 & 2811 & 13059 & -1 & -1 & -2 \\
\hline 9 & 2 & 1 & 9564 & 2769 & 9956 & -1 & -1 & -1 \\
\hline 10 & 3 & 1 & 4220 & 878 & 4310 & -1 & -1 & -1 \\
\hline 11 & 2 & 1 & 3034 & 887 & 3161 & -1 & -1 & -1 \\
\hline 12 & 3 & 1 & 3614 & 976 & 3744 & -1 & -1 & -1 \\
\hline 13 & 2 & 1 & 8099 & 1642 & 8264 & -1 & -1 & -1 \\
\hline 14 & 3 & 1 & 9346 & 1810 & 9519 & -1 & -1 & -2 \\
\hline 15 & 2 & 1 & 6751 & 1797 & 6986 & -1 & -1 & -1 \\
\hline 16 & 2 & 1 & 15560 & 2415 & 15746 & -2 & -2 & -2 \\
\hline 17 & 1 & 1 & 11342 & 2373 & 11587 & -1 & -1 & -1 \\
\hline 18 & 2 & 1 & 13462 & 2651 & 13721 & -1 & -1 & -1 \\
\hline
\end{tabular}

\subsection{Discussions}

\subsection{Simulation of N-IF Cases}

The fact that Kim and Mudawar as well as Kandlikar correlations' pressuredrop and heat-flux values are very different - except for order of magnitude - than the experiments in Table 8, is understandable. This is because the experiments are primarily in annular (close to suppressed nucleation) regime whereas correlations try to fit data covering all the regimes (from inlet to dry-out in Figure 1a).

\subsubsection{Case 4}

\subsubsection{Pressure}

As presented in Table 8, the predicted pressures are not numerically equal to the experimental measurements. Although, it may be adequate enough to say that the predictions are within the order of 10 to the zeroth power. Therefore when an experimental team member is looking at sizing 
additional pressure components, they can use an order of magnitude estimation a guide to specify transducers, so in this case I would suggest the design or choice of components be around $10 \mathrm{kPa}$.

\subsubsection{Heat Flux}

The local heat flux, seen in Table 8 , predicted via the nucleate boiling component of both HTC correlations provide even a closer estimate, around $20 \%$ difference, although the Kandlikar HTC correlation seems to provide a "better" estimate.

Another prediction made with the simulation tool can be seen in Figures 18 $\& 19$, with a prediction of local heat flux along the length of the test section. One thing to take note of with these Figures is that the experimental results seem to follow fairly closely with the nucleate curve.

\subsubsection{Mass Flow Rates}

At this point there is no available experimental data of exit mass flow rates for either liquid or vapor. Although it is apparent in Figures 10 and 11 that the results of predicted flow quality vary between which of the two correlations is referenced. There will be continued experimentation with additional equipment that will assist in determining experimental exit mass flow rates which will assist in determining the correct HTC correlation.

\subsubsection{Case 6}

\subsubsection{Pressure}

As presented in Table 8, the predicted pressures are again not numerically equal to the experimental measurements. Although, the results for case 6 seem be of the order 10 to the zeroth power, which is similar to the experimental measures. The NIST pressure correlation with the Kim and Mudawar HTC correlation is the only prediction that provides a similar result to case 4 .

\subsubsection{Heat Flux}

The local heat flux, seen in Table 8 , predicted via the nucleate boiling component of both $\mathrm{HTC}$ correlations provides an overestimate, greater than $100 \%$ difference, although with this case the Kim and Mudavar HTC correlation seems to provide a "better" estimate.

Another prediction made with the simulation tool can be seen in Figures 20 $\& 21$, with a prediction of local heat flux along the length of the test section. One thing to take note of with these Figures is that the experimental results seem to be well below the nucleate curve.

\subsubsection{Mass Flow Rate}

At this point there is no available experimental data of exit mass flow rates for either liquid or vapor. Although it is apparent in Figures 12 and 13 that 
the results of predicted flow quality vary between which of the two correlations is referenced. There will be continued experimentation with additional equipment that will assist in determining experimental exit mass flow rates which will assist in determining the correct HTC correlation.

\subsection{Test Matrix}

The results of the test matrix is used to determine which inputs had more of an effect on the outputs. A method of programmatic fitting was used with a simple linear regression mathematical model shown in Equation 31 below. The resulting line of best fit coefficients are used to shed light on which inputs may drive a particular output of interest. Further evaluation is required with both experimental data sets and possibly a more diverse investigation of linear regression models. In the following analysis only the power of the coefficients is used to assist with possible correlations to use in the future.

$$
\begin{aligned}
& y=a_{0}+a_{1} x_{1}+a_{2} x_{2}+a_{3} x_{3}+a_{4} x_{4} \\
& x_{1}=\dot{M}_{T}, x_{2}=X_{i n}, x_{3}=\Delta T, x_{4}=P_{i n}
\end{aligned}
$$




\subsubsection{Kandlikar HTC Correlation}

Table 12, below, presents the different regression coefficients, rounded to the nearest 0.001 , for 6 different chosen outputs, the 3 heat flux predictions and the 3 different pressure drop predictions solved under the Kandlikar HTC correlation assumptions.

Table 12: Linear Regression model coefficients for various parameters from the Kandlikar HTC correlation

\begin{tabular}{|c|c|c|c|c|c|}
\hline Output (y) & $a_{0}$ & $a_{1}$ & $a_{2}$ & $a_{3}$ & $a_{4}$ \\
\hline$q^{\prime \prime}{ }_{c b}$ & $-1.49 \mathrm{E}+03$ & $1.08 \mathrm{E}+06$ & $-2.92 \mathrm{E}+02$ & $6.10 \mathrm{E}+02$ & $-2.02 \mathrm{E}+01$ \\
\hline$q^{\prime \prime}{ }_{c b}$ & $1.06 \mathrm{E}+03$ & $2.63 \mathrm{E}+05$ & $-5.98 \mathrm{E}+03$ & $2.22 \mathrm{E}+02$ & $1.10 \mathrm{E}+00$ \\
\hline$q^{\prime \prime}{ }_{c b}$ & $-1.49 \mathrm{E}+03$ & $1.08 \mathrm{E}+06$ & $-2.92 \mathrm{E}+02$ & $6.10 \mathrm{E}+02$ & $-2.02 \mathrm{E}+01$ \\
\hline$\Delta P_{\text {Froude }}$ & $3.37 \mathrm{E}-01$ & $-2.33 \mathrm{E}+02$ & $-1.14 \mathrm{E}+00$ & $-3.00 \mathrm{E}-03$ & $4.00 \mathrm{E}-03$ \\
\hline$\Delta P_{L \& M}$ & $3.05 \mathrm{E}-01$ & $-2.20 \mathrm{E}+02$ & $1.51 \mathrm{E}+00$ & $-5.00 \mathrm{E}-03$ & $4.00 \mathrm{E}-03$ \\
\hline$\Delta P_{N I S T}$ & $1.96 \mathrm{E}-01$ & $-1.44 \mathrm{E}+02$ & $-1.10 \mathrm{E}+00$ & $-1.20 \mathrm{E}-02$ & $4.00 \mathrm{E}-03$ \\
\hline
\end{tabular}




\subsubsection{Kim and Mudawar HTC Correlation}

Table 13, below, presents the different regression coefficients, rounded to the nearest 0.001 , for 6 different chosen outputs, the 3 heat flux predictions and the 3 different pressure drop predictions solved under the Kim and Mudawar HTC correlation assumptions.

Table 13: Linear Regression model coefficients for various parameters from the Kim and Mudawar HTC correlation

\begin{tabular}{|c|c|c|c|c|c|}
\hline Output (y) & $a_{0}$ & $a_{1}$ & $a_{2}$ & $a_{3}$ & $a_{4}$ \\
\hline$q^{\prime \prime}{ }_{c b}$ & $-8.83 \mathrm{E}+03$ & $1.16 \mathrm{E}+06$ & $1.43 \mathrm{E}+04$ & $9.01 \mathrm{E}+02$ & $-1.62 \mathrm{E}+01$ \\
\hline$q^{\prime \prime}{ }_{c b}$ & $-5.52 \mathrm{E}+02$ & $5.30 \mathrm{E}+04$ & $-1.37 \mathrm{E}+03$ & $1.65 \mathrm{E}+02$ & $7.01 \mathrm{E}+00$ \\
\hline$q^{\prime \prime}{ }_{c b}$ & $-8.71 \mathrm{E}+03$ & $1.15 \mathrm{E}+06$ & $1.37 \mathrm{E}+04$ & $9.15 \mathrm{E}+02$ & $-1.44 \mathrm{E}+01$ \\
\hline$\Delta P_{\text {Froude }}$ & $4.19 \mathrm{E}-01$ & $-2.61 \mathrm{E}+02$ & $-1.28 \mathrm{E}+00$ & $-9.00 \mathrm{E}-03$ & $5.00 \mathrm{E}-03$ \\
\hline$\Delta P_{\text {L\&M }}$ & $4.14 \mathrm{E}-01$ & $-2.57 \mathrm{E}+02$ & $1.47 \mathrm{E}+00$ & $-1.10 \mathrm{E}-02$ & $5.00 \mathrm{E}-03$ \\
\hline$\Delta P_{\text {NIST }}$ & $5.69 \mathrm{E}-01$ & $-2.75 \mathrm{E}+02$ & $-1.81 \mathrm{E}+00$ & $-3.80 \mathrm{E}-02$ & $7.00 \mathrm{E}-03$ \\
\hline
\end{tabular}

\subsubsection{Regression Model comparison}

The regression models demonstrate that the input with seemingly the most influential is related to coefficient a_1 due to the order of magnitude dissimilarity. This would indicate that the total inlet mass flow rate has the highest influence on the system's response - as far as controlling achievable heat flux and system pressure drop (across the test section) is concerned.

\subsection{Future Work}

Continuation of this research will be conducted with a different working fluid (i.e. water and other refrigerants) to bring the proposed high heat flux enhancements to practical industry practice/usage.

Patcharapol Gorgitrattanagul (PG) is to run future experiments that could be used to help assess the effectiveness of this simulation tool. 


\subsection{Conclusions}

Based on the comparison from past experimental data and the results of the developed MATLAB tool, the following things should be considered:

- The tool, as of now can be used to provide rough order of magnitude estimations of pressure drop and local heat transfer rates. Although the two HTC correlations has been used to provide a better gauge of the estimated magnitude, better HTC correlations can be used.

- More work should be done on finding or developing HTC correlations that may have better modeling of the influence of mass flux - this recommendation is based on this modeling being most critical and also due to the fact that significant differences are seen in the predictions for cases $4 \& 6$ of Table 8 . 


\section{References}

[1] T. L. Bergman and F. P. Incropera, Fundamentals of heat and mass transfer, 7th ed. Hoboken, NJ: Wiley, 2011.

[2] M. T. Kivisalu, P. Gorgitrattanagul, and A. Narain, "Results for high heat-flux flow realizations in innovative operations of millimeter scale condensers and boilers," International Journal of Heat and Mass Transfer, vol. 75, pp. 381-398, Aug 2014.

[3] S.-M. Kim and I. Mudawar, "Review of databases and predictive methods for heat transfer in condensing and boiling mini/microchannel flows," International Journal of Heat and Mass Transfer, vol. 77, pp. 627-652, 10// 2014.

[4] S. G. Kandlikar, "Heat transfer mechanisms during flow boiling in microchannels," in ASME 2003 1st International Conference on Microchannels and Minichannels, 2003, pp. 33-46.

[5] S. G. Kandlikar, "A General Correlation for Saturated Two-Phase Flow Boiling Heat Transfer Inside Horizontal and Vertical Tubes," Journal of Heat Transfer, vol. 112, pp. 219-228, 1990.

[6] S.-M. Kim and I. Mudawar, "Universal approach to predicting two-phase frictional pressure drop for adiabatic and condensing mini/micro-channel flows," International Journal of Heat and Mass Transfer, vol. 55, pp. 3246-3261, 5// 2012.

[7] D. Chisholm, "A theoretical basis for the Lockhart-Martinelli correlation for two-phase flow," International Journal of Heat and Mass Transfer, vol. 10, pp. 1767-1778, 1967.

[8] R. Lockhart and R. Martinelli, "Proposed correlation of data for isothermal two-phase, two-component flow in pipes," Chem. Eng. Prog, vol. 45, pp. 39-48, 1949.

[9] L. Friedel, "Improved friction pressure drop correlations for horizontal and vertical two-phase pipe flow," in European twophase flow group meeting, Paper E, 1979, p. 1979.

[10] S.-M. Kim and I. Mudawar, "Universal approach to predicting two-phase frictional pressure drop for mini/micro-channel saturated flow boiling," International Journal of Heat and Mass Transfer, vol. 58, pp. 718-734, 2013.

[11] Y. Xu, X. Fang, X. Su, Z. Zhou, and W. Chen, "Evaluation of frictional pressure drop correlations for two-phase flow in pipes," Nuclear Engineering and Design, vol. 253, pp. 86-97, 2012. 
[12] J.-Y. Choi, M. A. Kedzierski, and P. Domanski, A generalized pressure drop correlation for evaporation and condensation of alternative refrigerants in smooth and micro-fin tubes, 1999.

[13] M. T. Kivisalu, "Experimental Investigation of Internal Condensing Flows, Their Sensitivity to Pressure Fluctuations and Heat Transfer Enhancements," Ph. D., Mechanical Engineering, Michigan Technological University, 2015. 
Appendix 


\section{Appendix A - Flow Quality Differential Equation Derivation}

mass balace: $\dot{M}_{f}+\dot{M}_{g}=\dot{M}_{\text {in }}$

$$
\frac{d \dot{M}_{g}}{d z}=-\frac{d \dot{M}_{f}}{d z}
$$

Energy Balance: $\dot{E}_{\text {in }}-\dot{E}_{\text {out }}+\dot{E}_{g}=\frac{d E_{\text {sys }}}{d t}$

$$
\begin{aligned}
& \dot{E}_{\text {in }}=\left[\dot{M}_{f_{\text {in }}} h_{f}+\dot{M}_{g_{\text {in }}} h_{g}\right]+\dot{q}_{\text {in }} \\
& \dot{E}_{\text {out }}=\left[\dot{M}_{f_{\text {out }}} h_{f}+\dot{M}_{g_{\text {out }}} h_{g}\right] \\
& \dot{E}_{g}=0 \\
& \frac{d E_{\text {sys }}}{d t}=0 \\
& \dot{q}_{\text {in }}=\left[\dot{M}_{f_{\text {out }}} h_{f}+\dot{M}_{g_{\text {out }}} h_{g}\right]-\left[\dot{M}_{f_{\text {in }}} h_{f}+\dot{M}_{g_{\text {in }}} h_{g}\right]
\end{aligned}
$$

Heating is from bottom, which would be $\frac{1}{4}$ of available area

Therefore: $\dot{q}_{\text {in }}=q^{\prime \prime}(z) \frac{\pi D_{h} \Delta x}{4}$

$$
\begin{aligned}
& q^{\prime \prime}(z) \frac{\pi D_{h} \Delta x}{4}=h_{f}\left[\dot{M}_{f_{\text {out }}}+\dot{M}_{f_{\text {in }}}\right]-h_{g}\left[\dot{M}_{g_{\text {out }}}+\dot{M}_{g_{\text {in }}}\right] \\
& q^{\prime \prime}(z) \frac{\pi D_{h}}{4}=h_{f}\left[\frac{\dot{M}_{f_{\text {out }}}-\dot{M}_{f_{\text {in }}}}{\Delta z}\right]+h_{g}\left[\frac{\dot{M}_{g_{\text {out }}}-\dot{M}_{g_{\text {in }}}}{\Delta z}\right]
\end{aligned}
$$

apply the mass balance $\rightarrow \frac{q^{\prime \prime}(z) w}{4}=h_{f}\left[\frac{d M_{L}}{d z}\right]+h_{g}\left[\frac{d M_{V}}{d z}\right]$

$$
\frac{q^{\prime \prime}(z) \pi D_{h}}{4}=\left[\frac{d M_{V}}{d z}\right]\left(h_{g}-h_{f}\right)=\left[\frac{d M_{V}}{d z}\right] h_{f g}
$$

suggest that $\dot{M}_{g}(z)=X(z) \dot{M}_{\text {Total }}$

$$
q^{\prime \prime}(z) \pi D_{h}=\left[\frac{d X(z)}{d z}\right] 4 \dot{M}_{\text {Total }} h_{f g}
$$




$$
h_{x} \Delta T \pi D_{h}=\left[\frac{d X(z)}{d z}\right] 4 \dot{M}_{\text {Total }} h_{f g}
$$

introduce non - dimensional length: $\hat{z}={ }^{z} / D_{h} \rightarrow d \hat{x}=d z / D_{h}$ introduce nusselt number: $N u_{z}=\frac{h_{z} D_{h}}{k_{f}}$

$$
\begin{aligned}
& \frac{N u_{z} k_{f}}{D_{h}} \Delta T \pi D_{h}=\left[\frac{d X(z)}{d x}\right] 4 \dot{M}_{\text {Total }} h_{f g} \\
& {\left[\frac{d X(z)}{d z}\right]=\frac{N u_{z} k_{f}}{4 \dot{M}_{\text {Total }} h_{f g}} \Delta T \pi} \\
& {\left[\frac{d X(\hat{z})}{d \hat{z}}\right]=\frac{N u_{z} k_{f}}{4 \dot{M}_{\text {Total }} h_{f g}} \Delta T \pi D_{h}}
\end{aligned}
$$

multiply right hand side by: $\frac{c_{p_{f}}}{c_{p_{f}}}, \frac{\mu_{f}}{\mu_{f}}, \frac{\mu_{g}}{\mu_{g}}$ and group some terms

$$
\left[\frac{d X(\hat{z})}{d \hat{z}}\right]=N u_{z} \times \frac{c_{p_{f}} \Delta T}{h_{f g}} \times \frac{k_{f}}{\mu_{f} c_{p_{f}}} \times \frac{\mu_{f}}{\mu_{g}} \times \frac{\pi D_{h} \mu_{g}}{4 \dot{M}_{\text {Total }}}
$$

Introduce: $J a_{f}=\frac{c_{p_{f}} \Delta T}{h_{f g}}, P r_{f}=\frac{\mu_{f} c_{P_{f}}}{k_{f}}, R e_{G O}=\frac{4 \dot{M}_{\text {Total }}}{\pi D_{h} \mu_{g}}$

Final Equation: $\left[\frac{d X(\hat{z})}{d \hat{z}}\right]=N u_{z} \frac{J a_{f}}{P r_{f}} \frac{\mu_{f}}{\mu_{g}} \frac{1}{R e_{G O}}$ 


\section{Appendix B - MATLAB Dashboard}

Section 1 - Start up

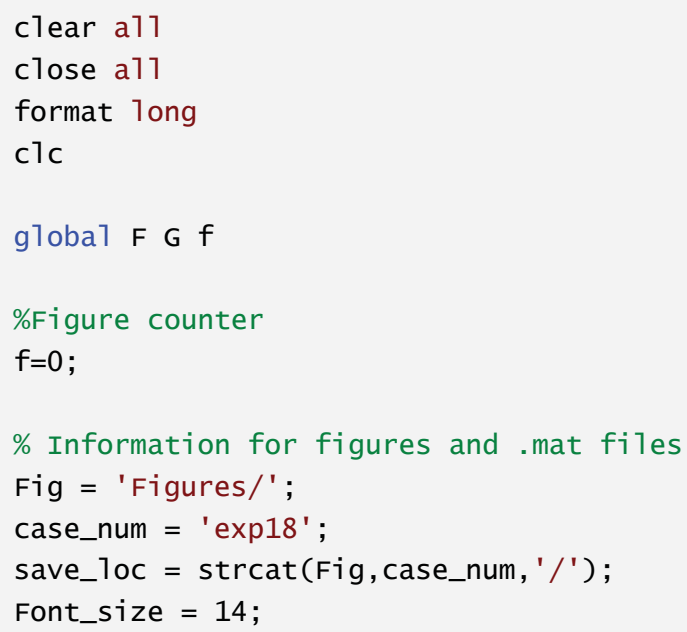

Dashboard

This dashboard is to be used to run the any correlation script of your choice/making. The purpose of this dashboard is to provide a modular design to our groups coding process. This modulation should help with the ease of knowledge transfer.

\section{Section 2 - Define Geometric Properties}

This section is used to define the geometric parameters or dimensions of the channel or tube that will be investigated with the simulation

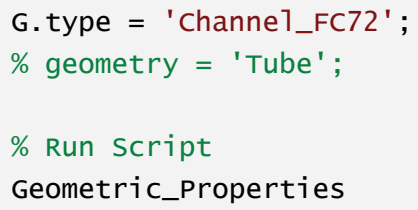

\section{Section 3 - Run Set-up}

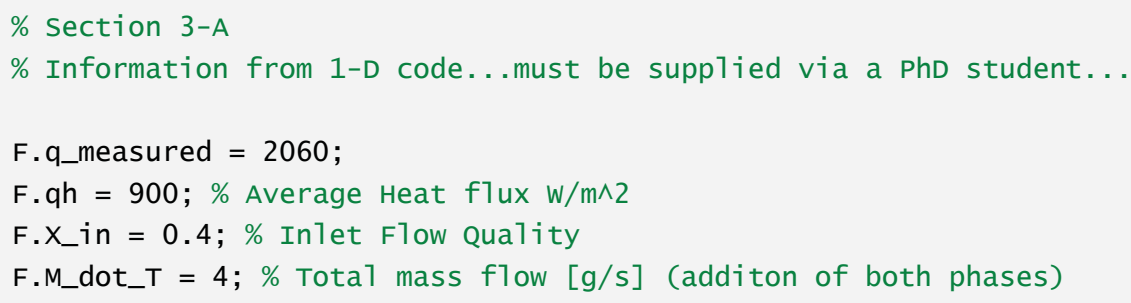




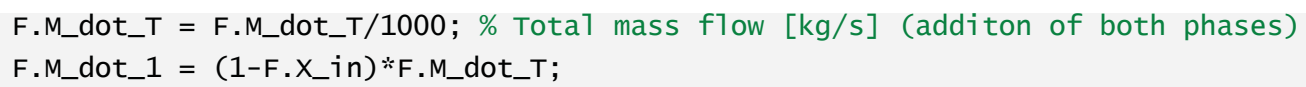

\section{Section 4 -Define Fluid Properties}

Choose a fluid from the current options below Water, FC-72,R-133,.... Follow a command such as the following to pull properties from the fluid properties script $/ . \mathrm{m}$ file fluid $=$ 'Water' 
F.fluid $=$ 'FC72';

\% Ca11 Fluid Properties Script

Fluid_Properties

\section{Section 5 - Correlation Solver}

Call the correlation script of choice

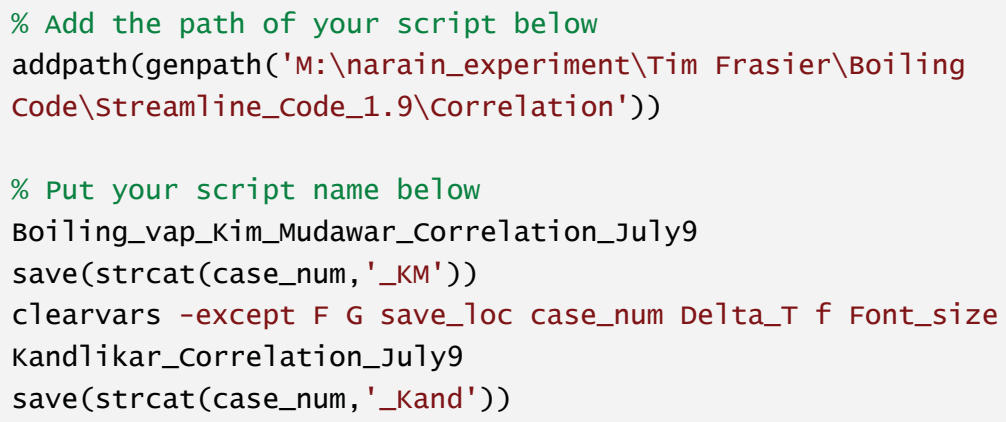

\section{Section 6 - Mechanical Work}

This section is not saved and will need to be re-run on the saved mat file Finds the mechanical work provided through steam generation

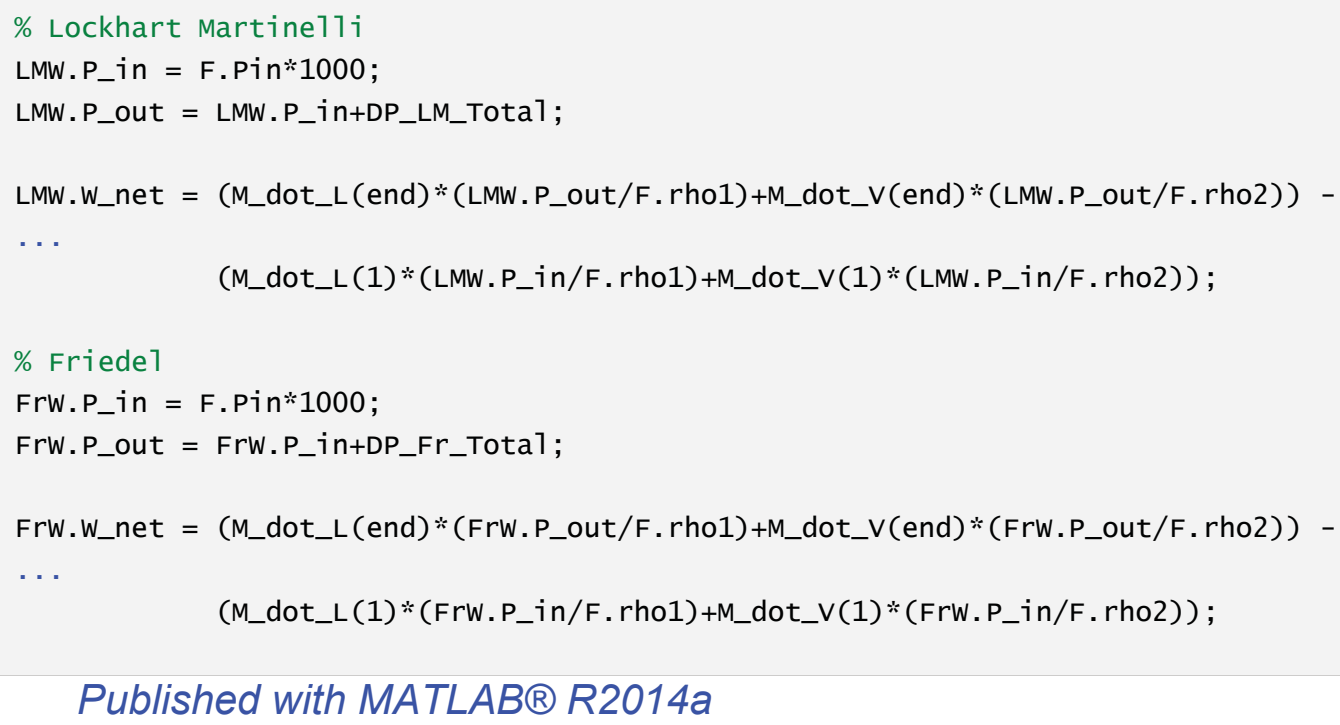




\section{Appendix C - MATLAB Geometric Properties}

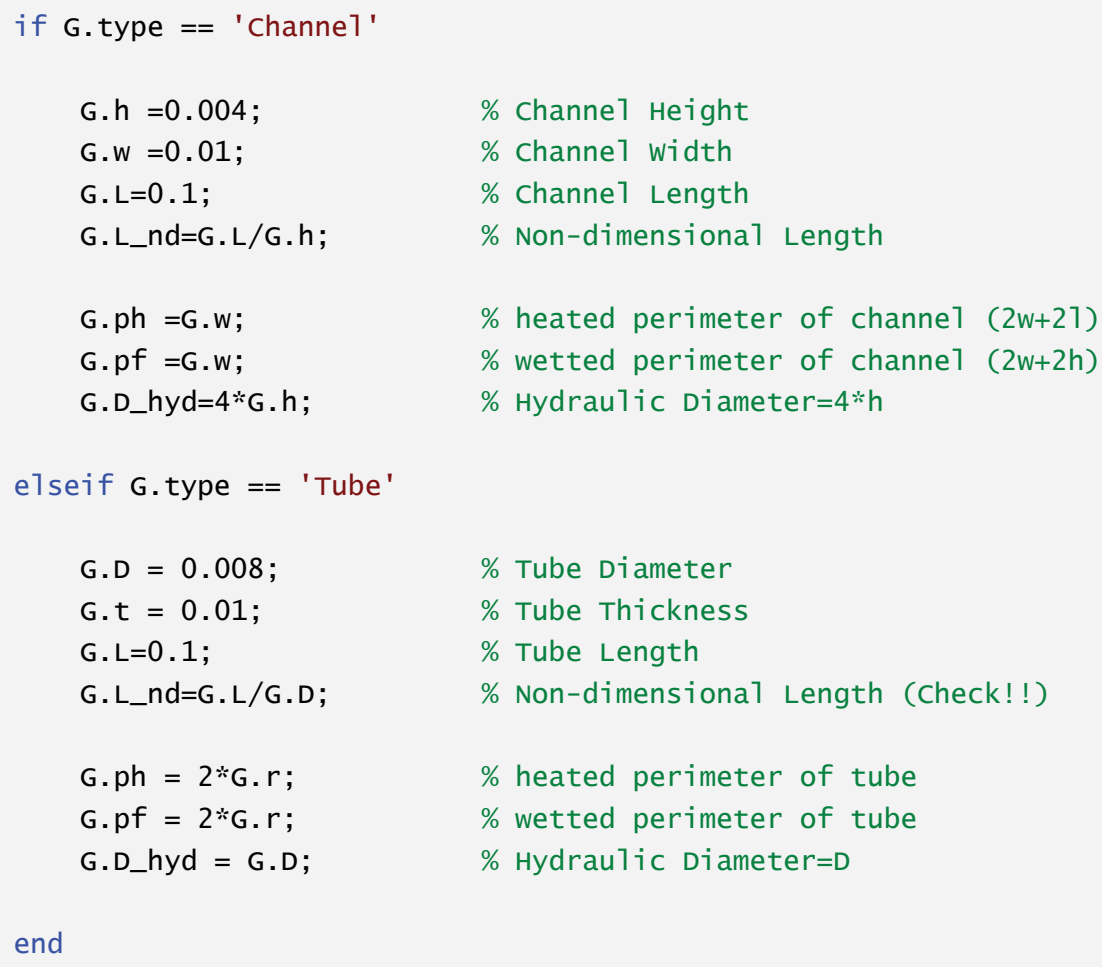

Published with MATLAB® R2014a 


\section{Appendix D - MATLAB Fluid Properties}

\section{Fluid Properties}

Please either chose one of the predefine fluids or make another section with your specific Properties. You make your choice by un-commenting the appropriate fluid properties and having all other properties commented.

if F.fluid == 'Water'

Water

Properties are define at $\mathrm{P}$ [bar] with the use of XSteam function

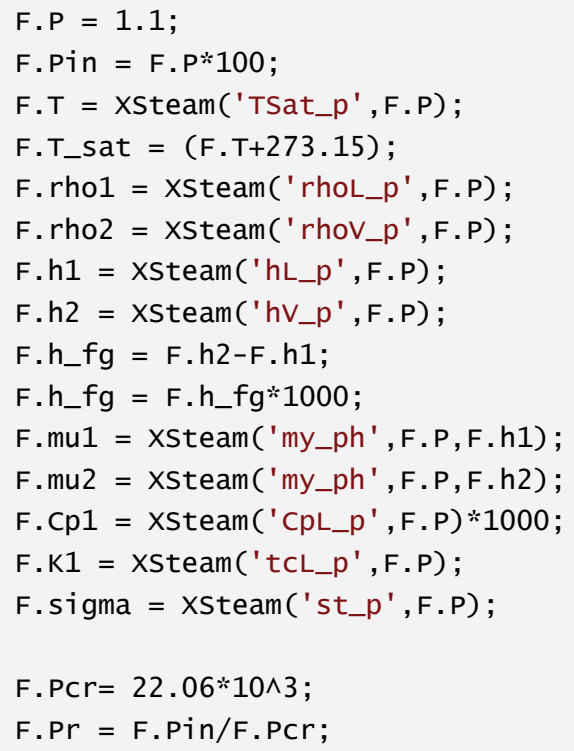

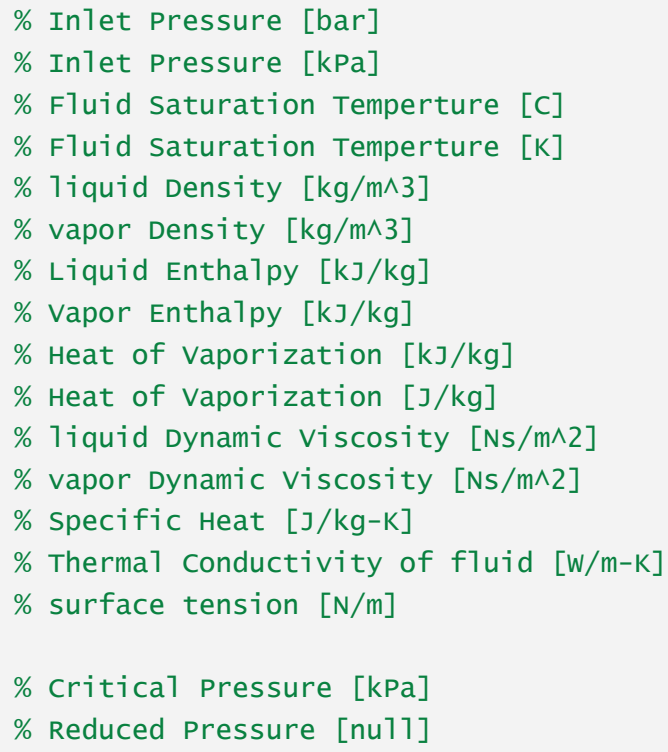

FC-72

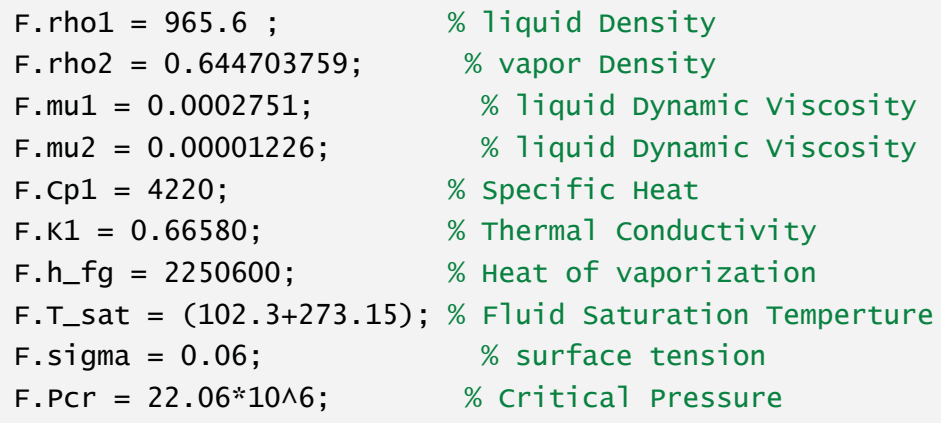


elseif F.fluid $==$ ' $R-113^{\prime}$

\section{Basic Definitions and Fluid property - R 113}

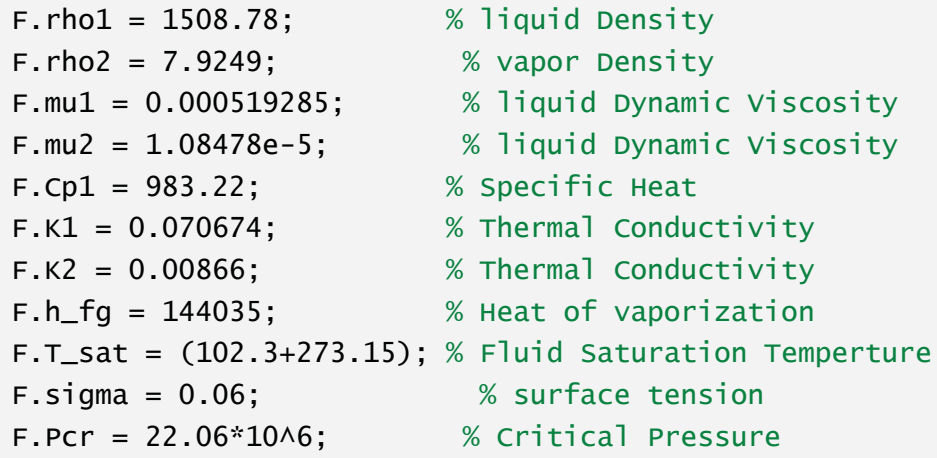

\section{Derived Fluid Properties (Non-dimensional)}

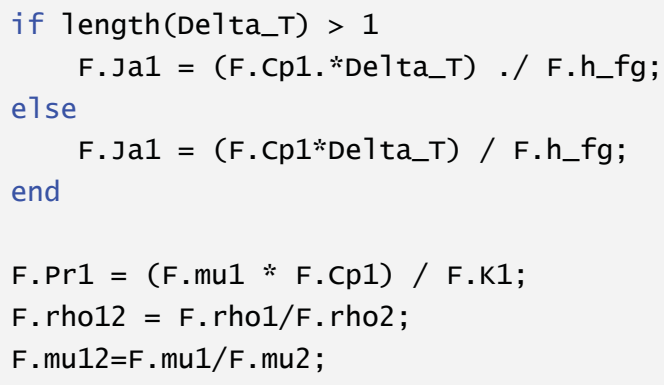

Published with MATLAB® R2014a 


\section{Appendix E - MATLAB Kandlikar Correlation Script}

\section{Correlation Code Setup}

clc

format 1ong;

global F G

num_points = 100 ;

\section{Kandlikar Correlation}

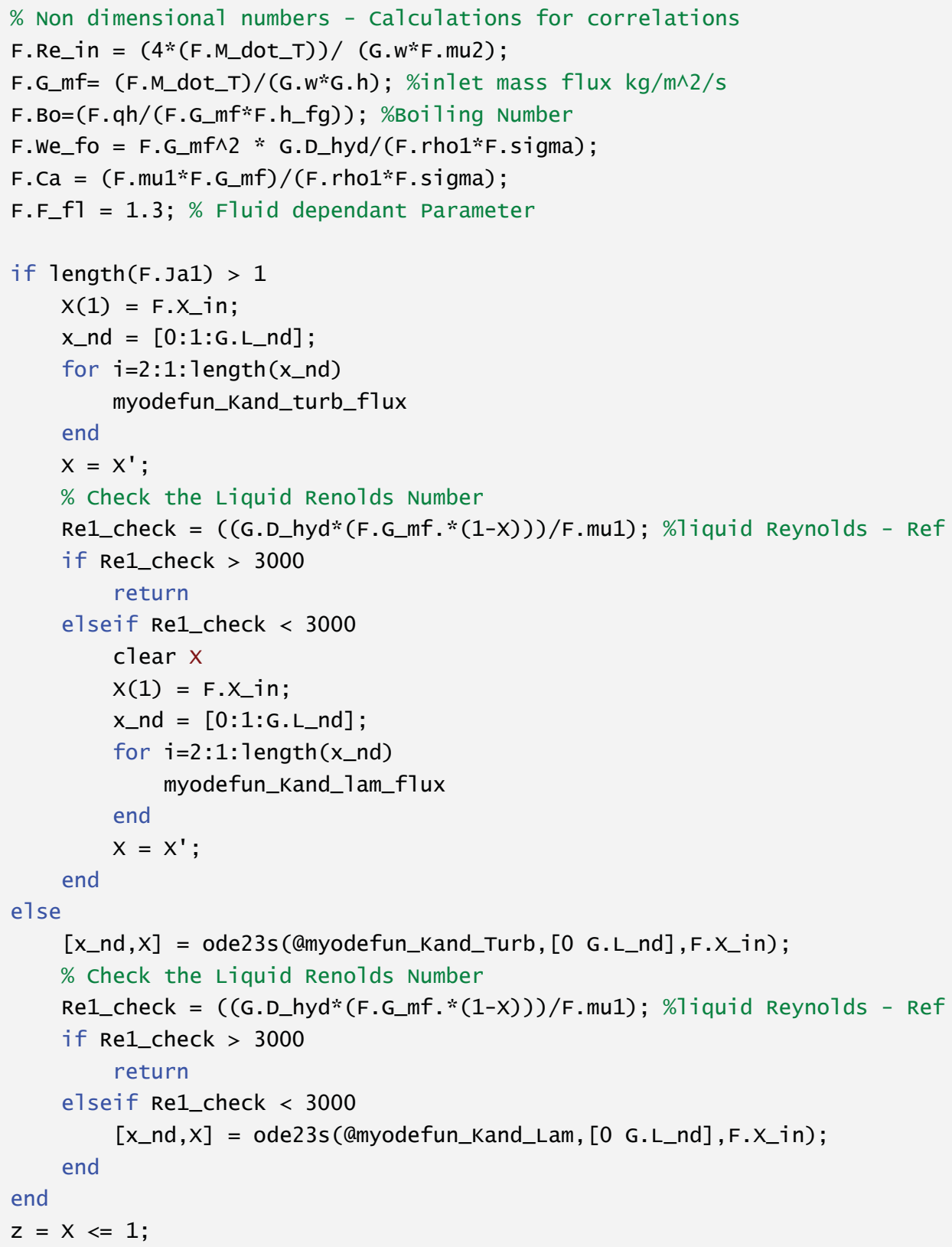




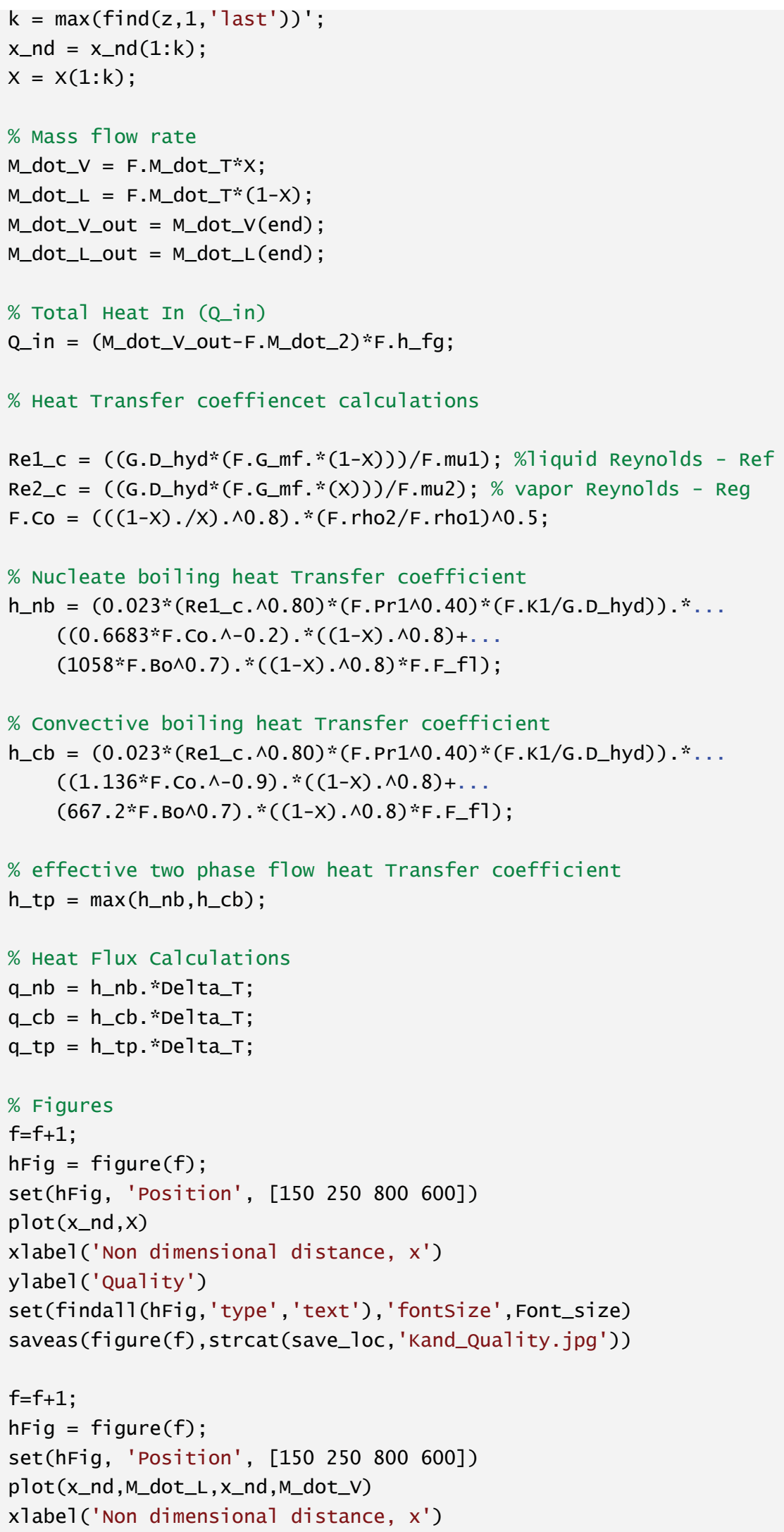




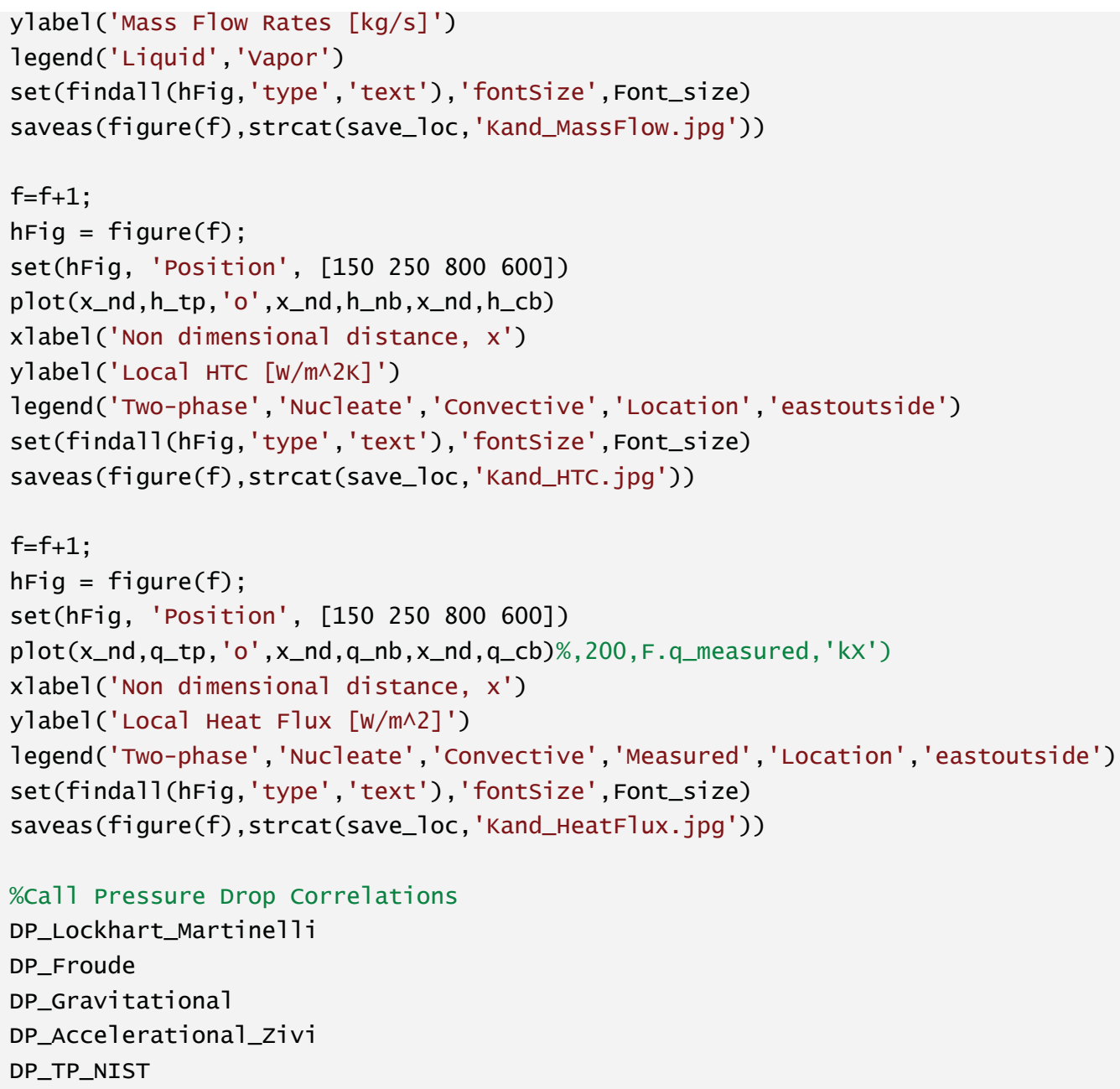

\section{Total Two phase Pressure Drop}

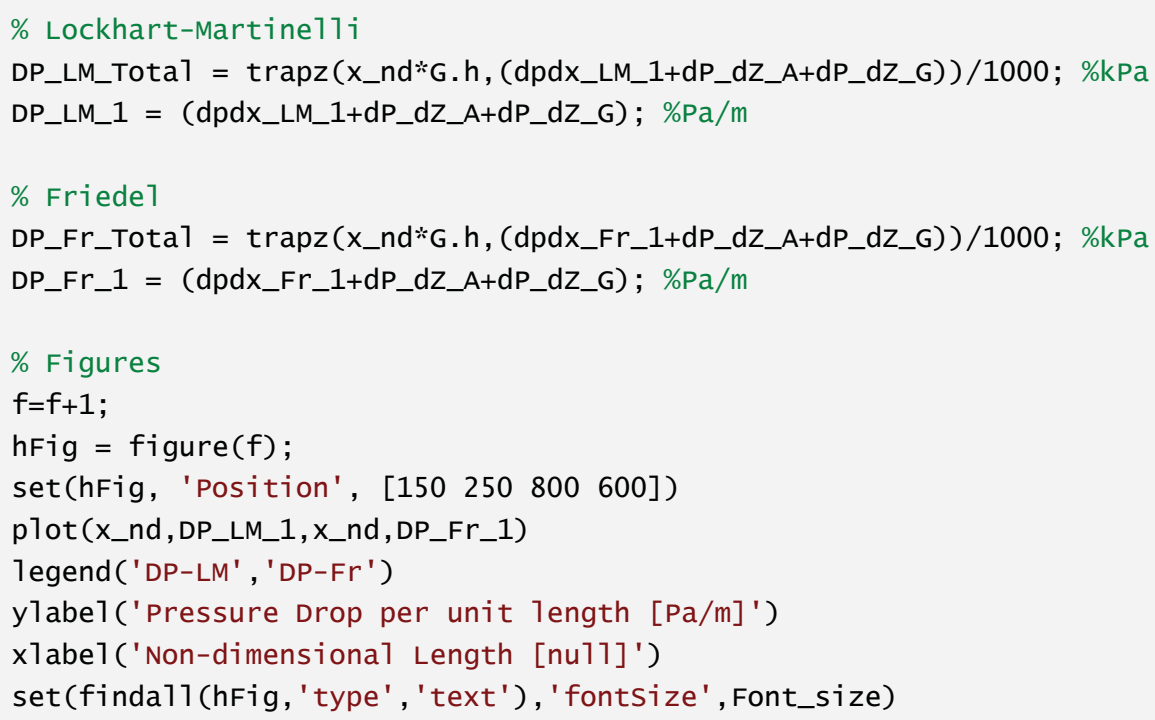


saveas(figure(f), strcat(save_1oc, 'Kand_DP_nd.jpg'))

$f=f+1$;

hFig = figure(f);

set(hFig, 'Position', [ [150 250800 600])

plot (x_nd*G.h,DP_LM_1, x_nd*G.h,DP_Fr_1)

legend ('DP-LM', 'DP-Fr')

ylabel('Pressure Drop per unit length $[\mathrm{Pa} / \mathrm{m}]$ ')

xlabel ('Dimensional Length $[\mathrm{m}]$ ')

set(finda11 (hFig, 'type', ' text'), 'fontSize', Font_size)

saveas (figure(f), strcat(save_loc, 'Kand_DP.jpg'))

Published with MATLAB® R2014a 


\title{
Appendix F - MATLAB Kim \& Mudawar Correlation Script
}

\section{Correlation Code Setup}

\author{
clc \\ format 1ong; \\ g7obal F G
}

\section{Kim and Mudawar Boiling Correlation (2013)}

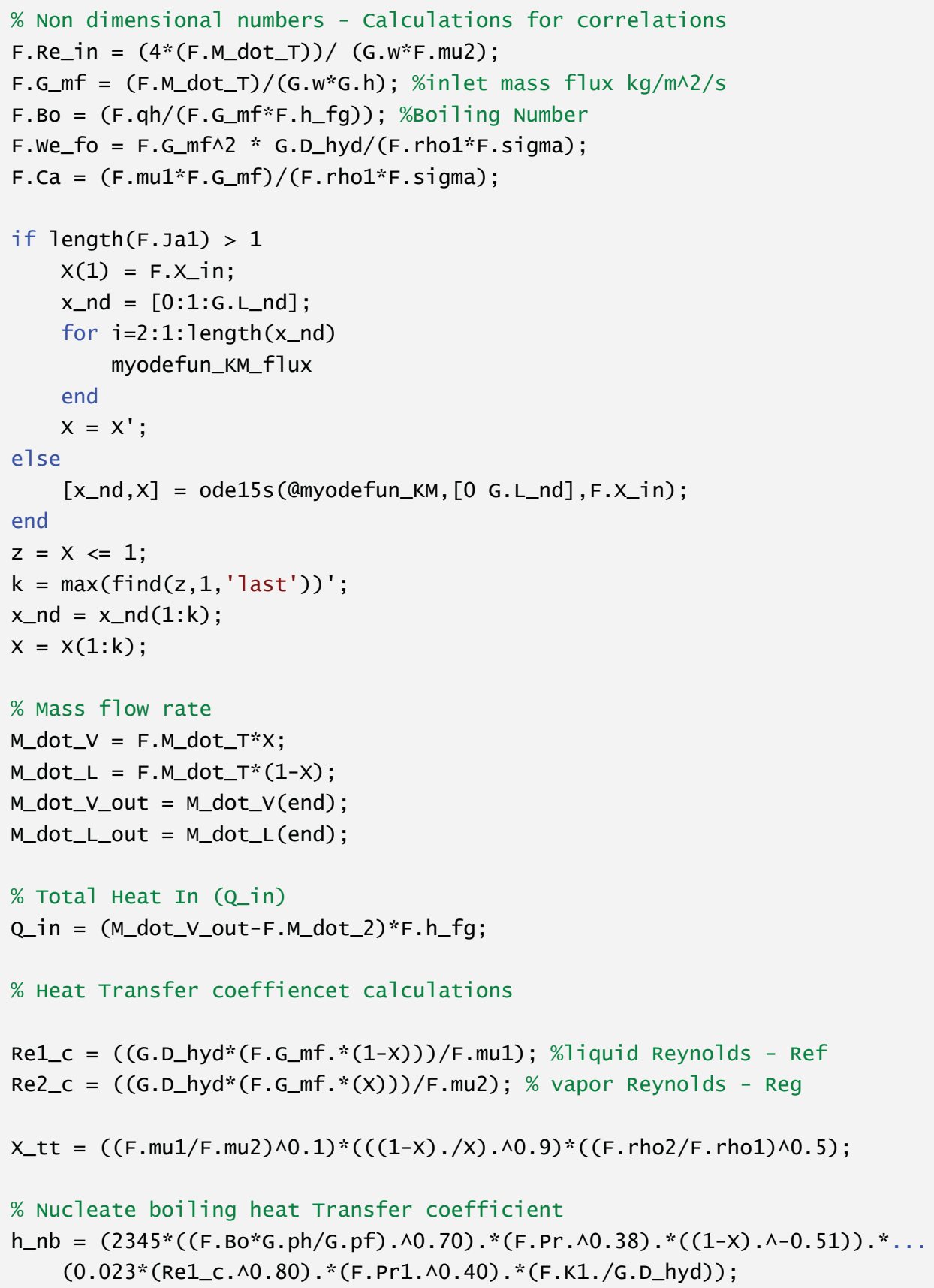




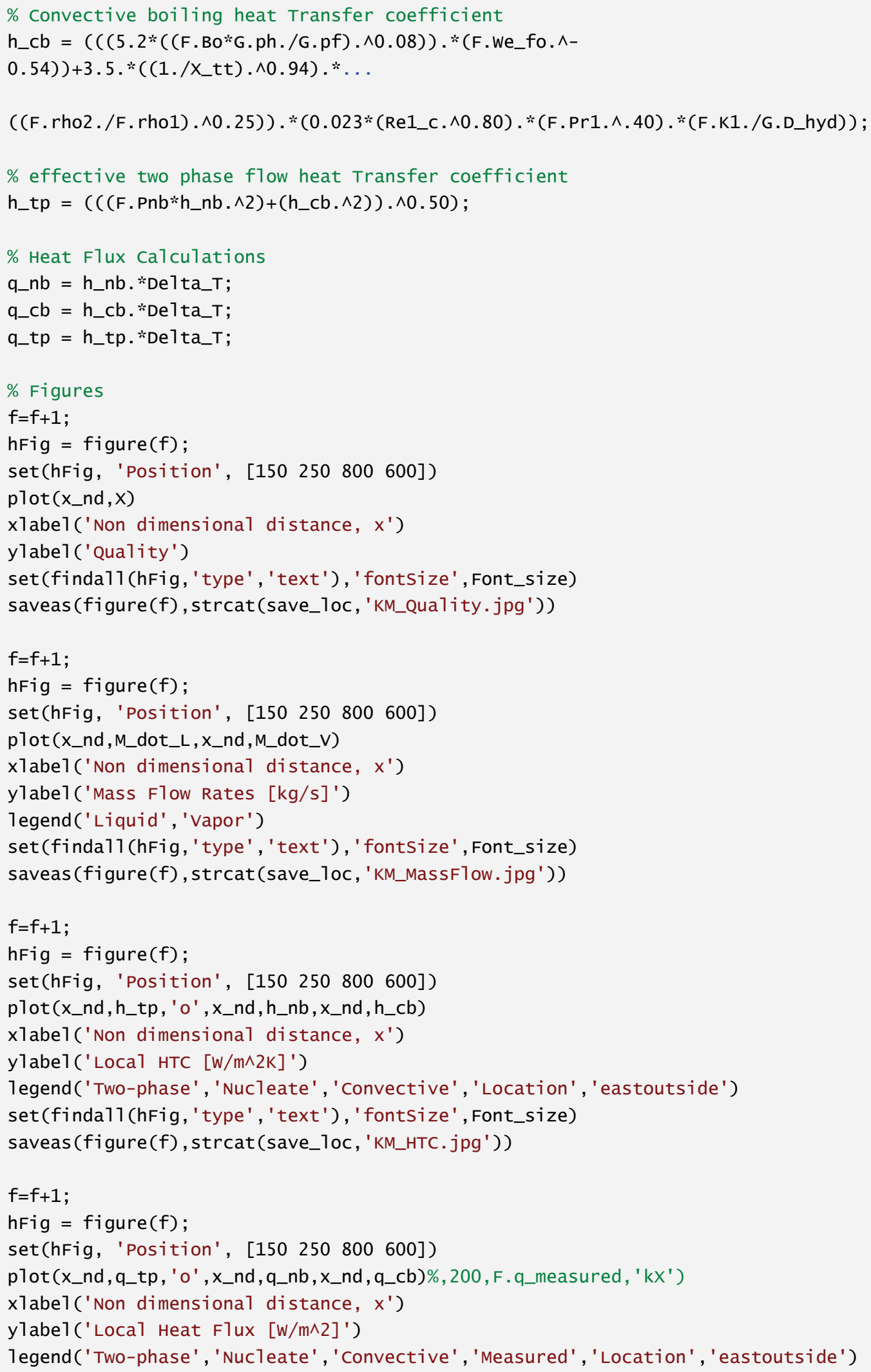


set (finda11 (hFig, 'type' , 'text'), ' fontsize', Font_size)

saveas (figure(f), strcat(save_loc, 'KM_HeatFlux.jpg'))

\%Ca11 Pressure Drop Correlations

DP_Lockhart_Martine11i

DP_Froude

DP_Gravitational

DP_Accelerationa1_zivi

DP_TP_NIST

\section{Total Two phase Pressure Drop}

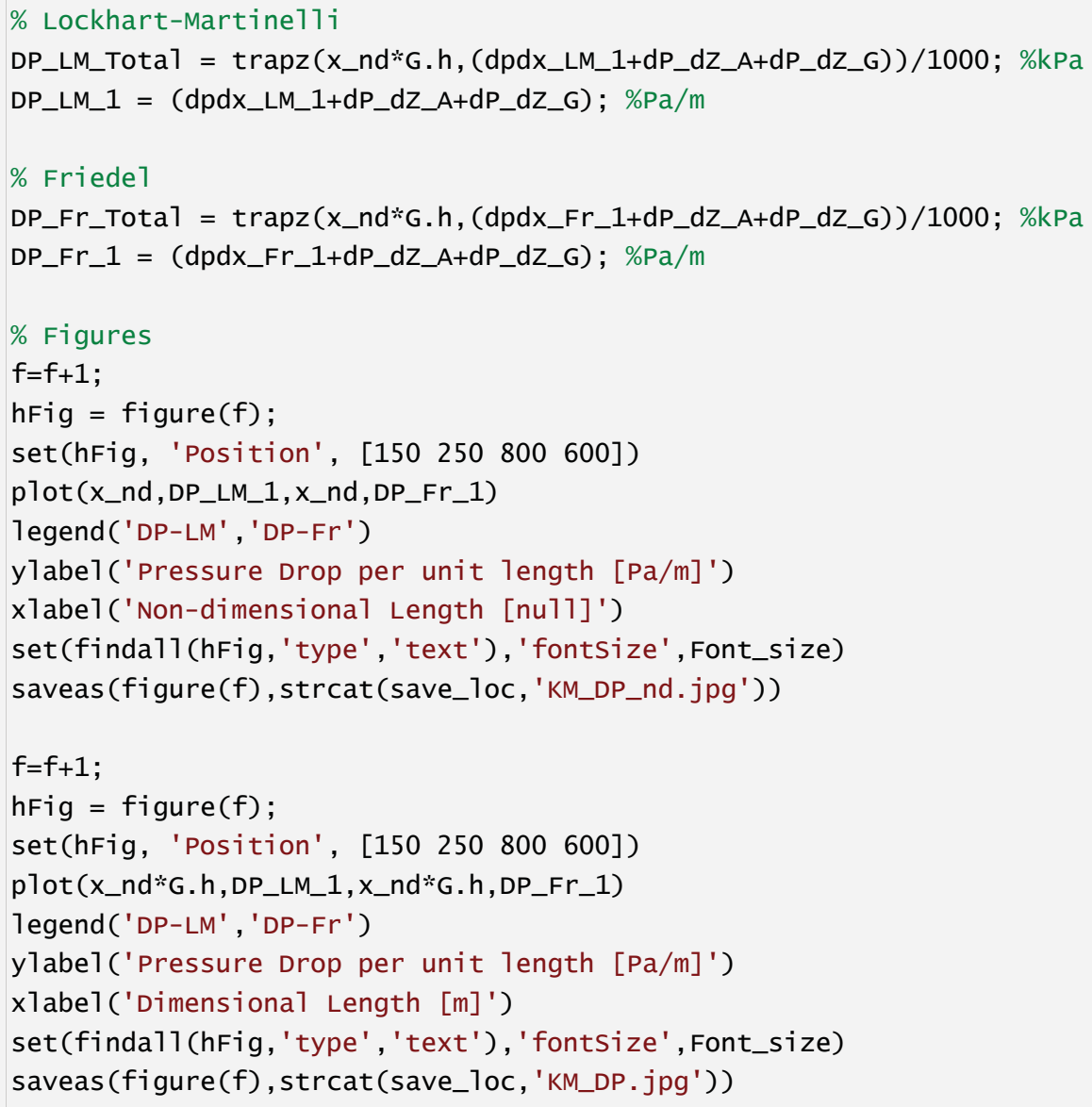

Published with MATLAB® R2014a 


\section{Appendix G - MATLAB Kandlikar myodefun for Laminar Reynolds Number}

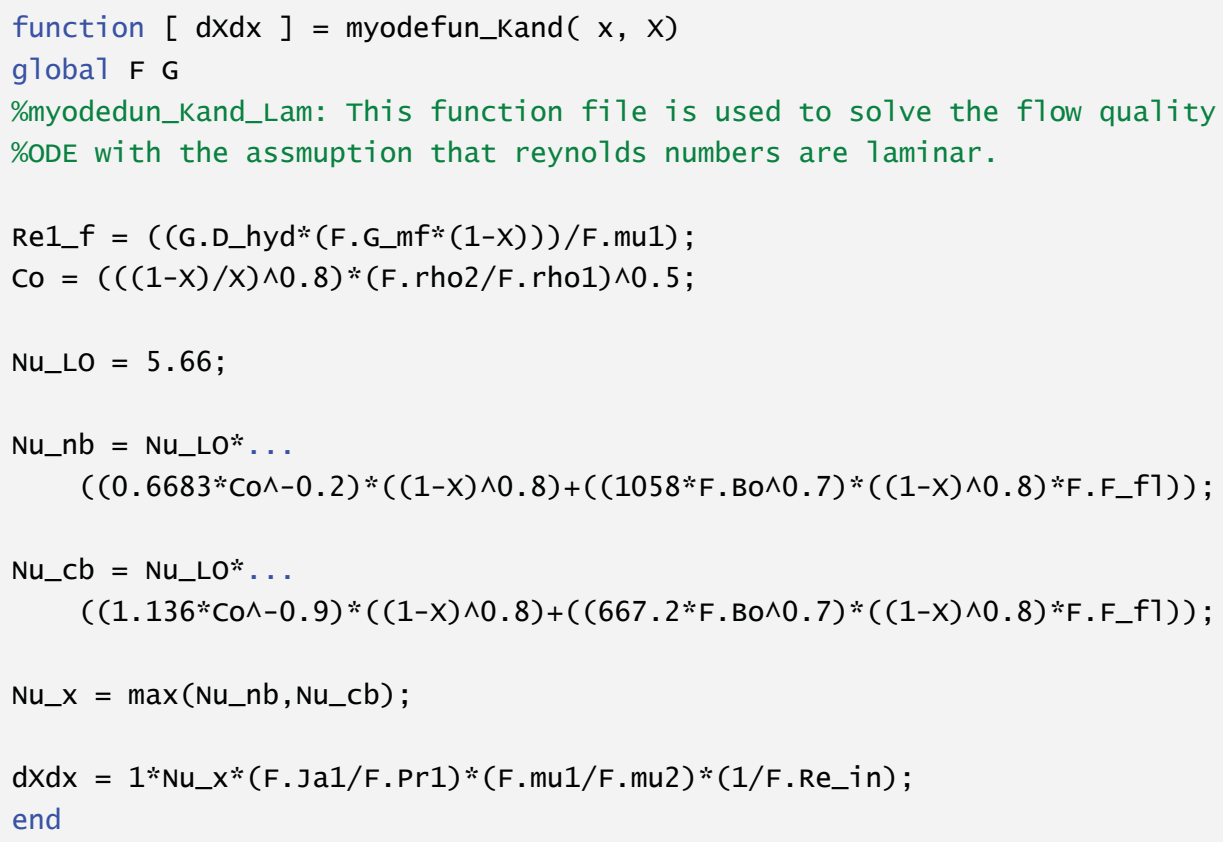

Published with MATLAB® R2014a

\section{Appendix H - MATLAB Kandlikar myodefun for Turbulent Reynolds number}

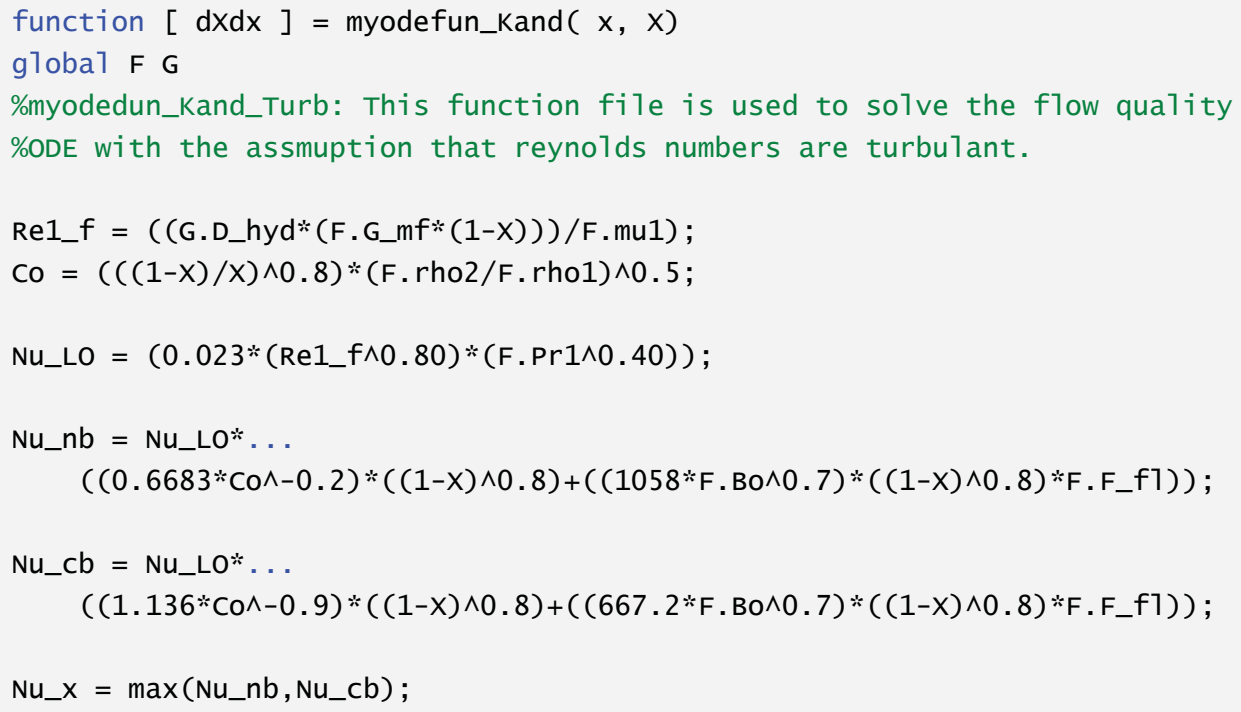




\section{Appendix I - MATLAB Kim \& Mudawar myodefun}

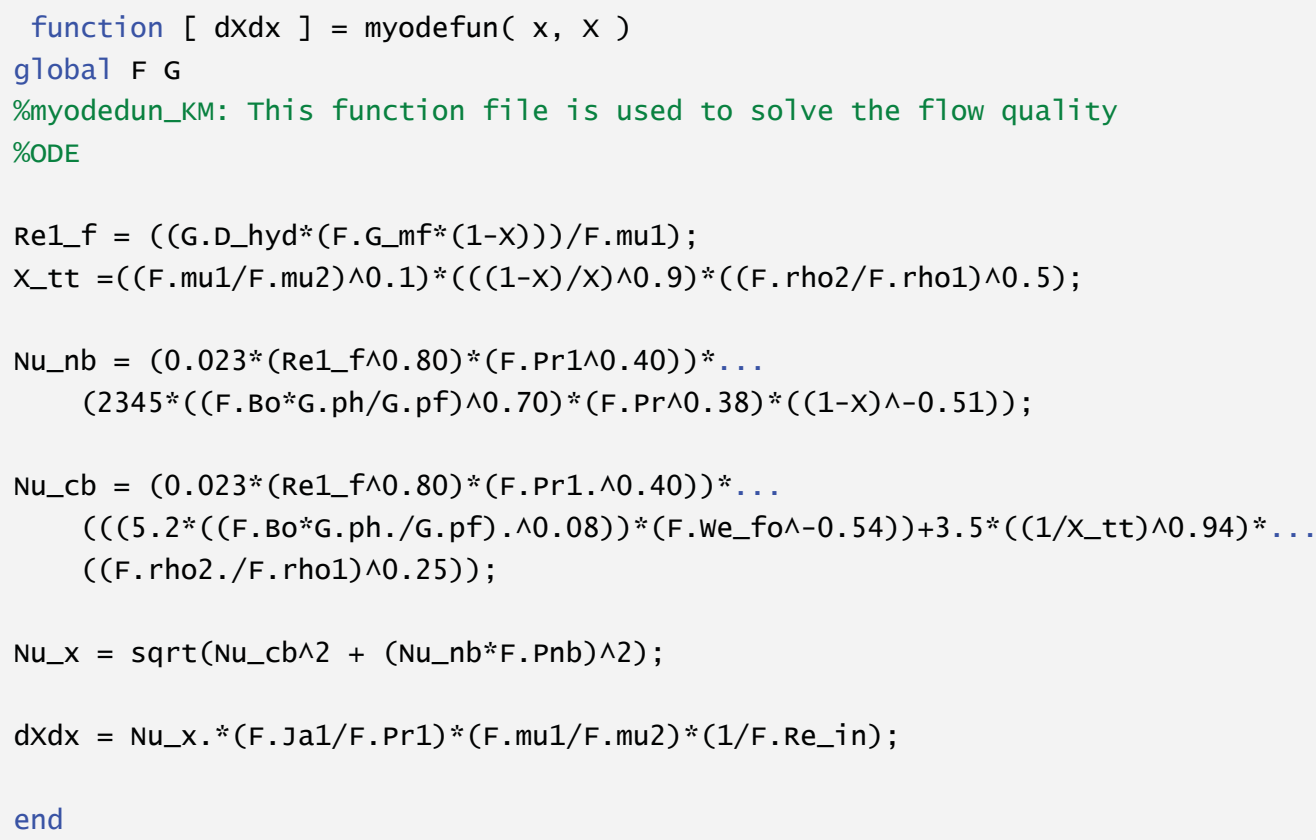

Published with MATLAB® R2014a 


\section{Appendix J - MATLAB Lockhart-Martinelli Pressure Drop}

\section{Pressure Drop Lockhart Martinelli}

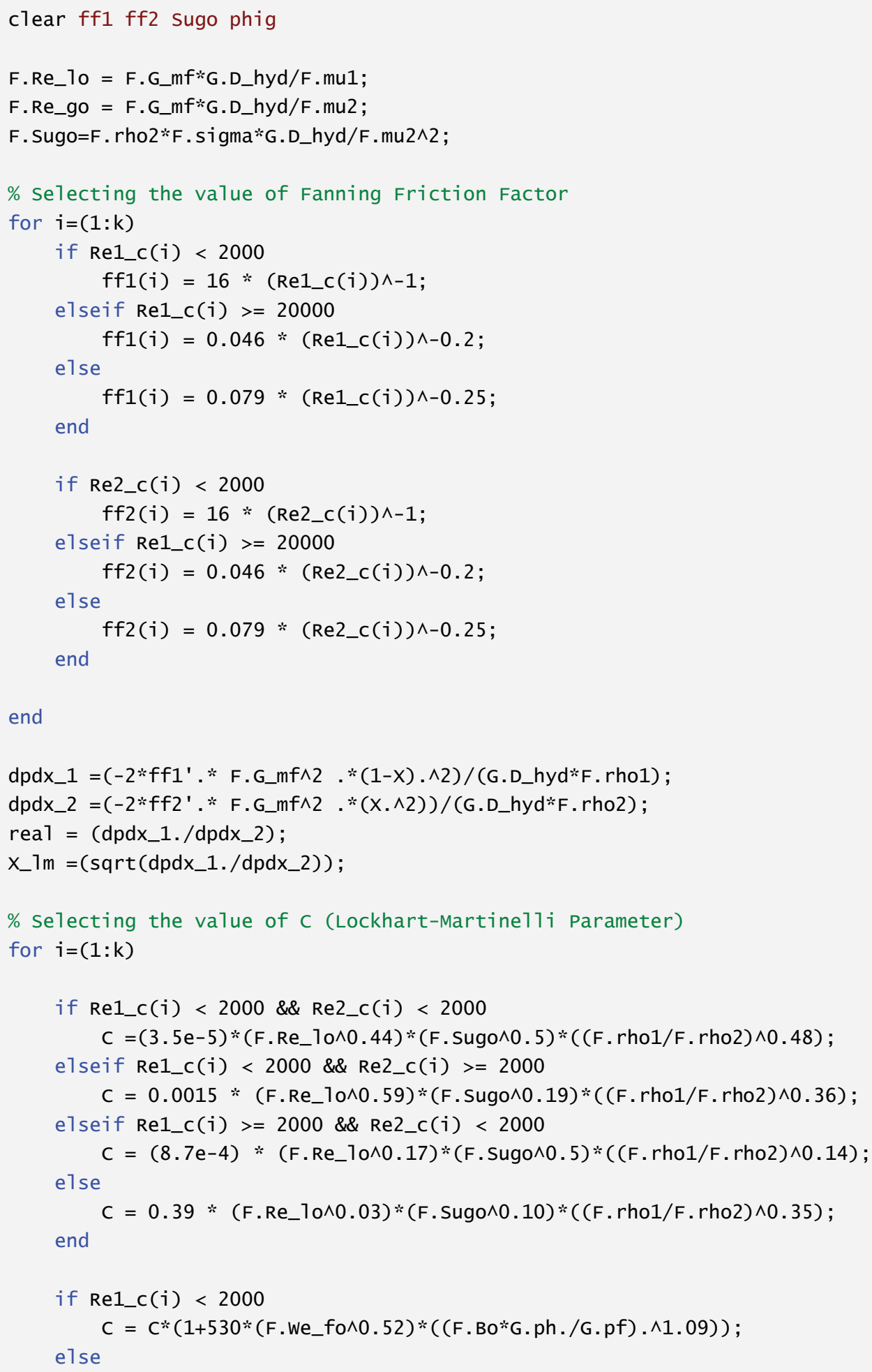




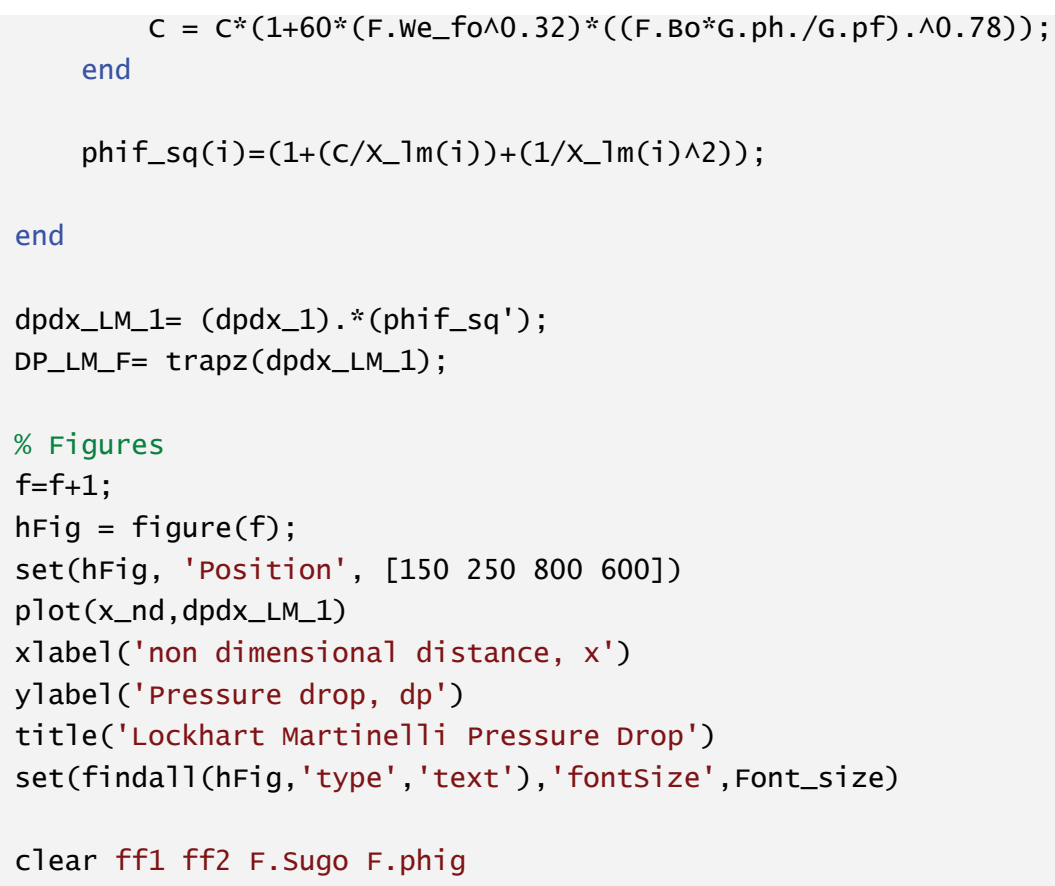

Published with MATLAB® R2014a 


\section{Appendix K - MATLAB Friedel Pressure Drop}

\section{Pressure Drop Friedel}

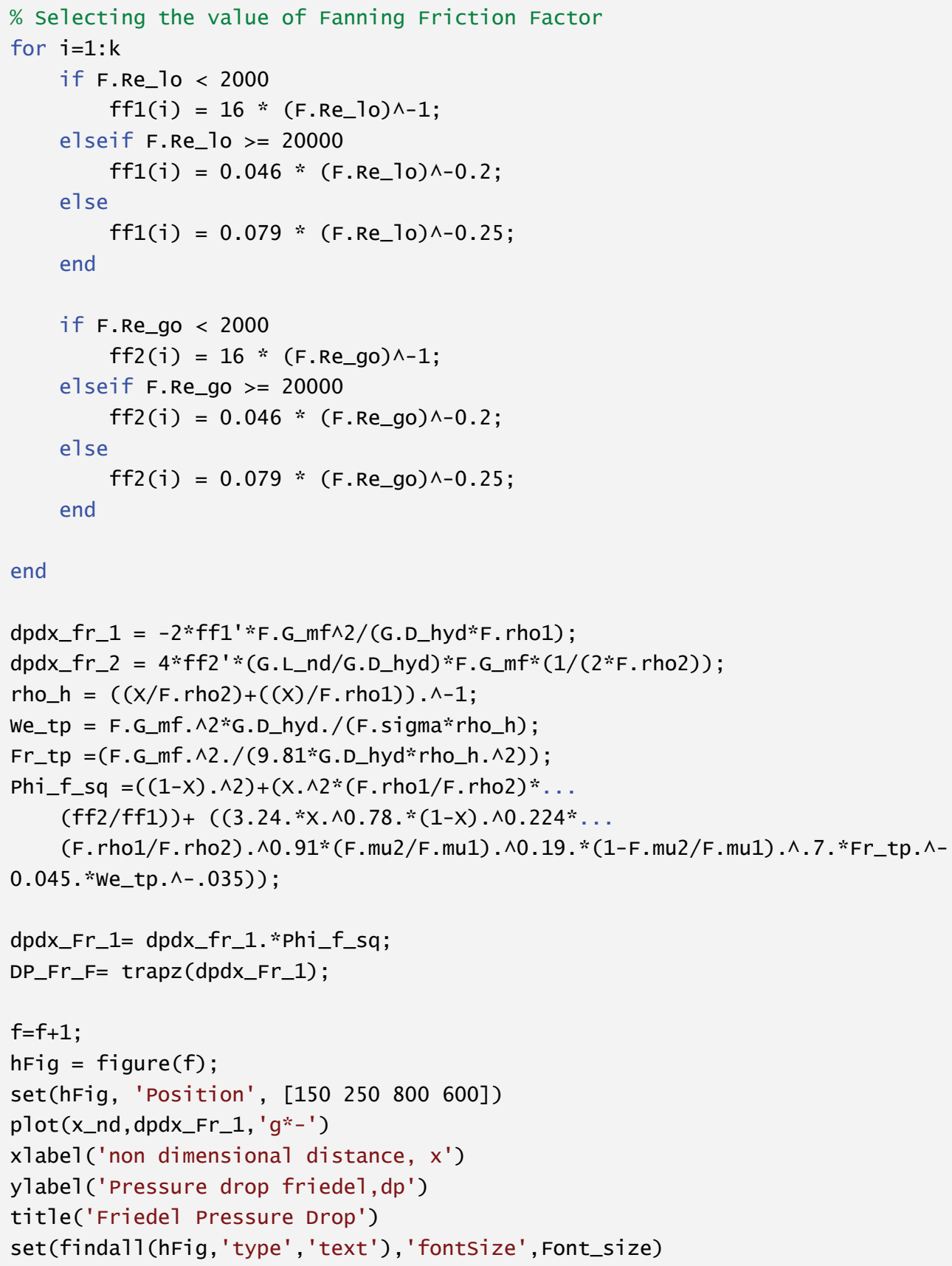

Published with MATLAB® R2014a 


\section{Appendix L - MATLAB NIST Pressure Drop}

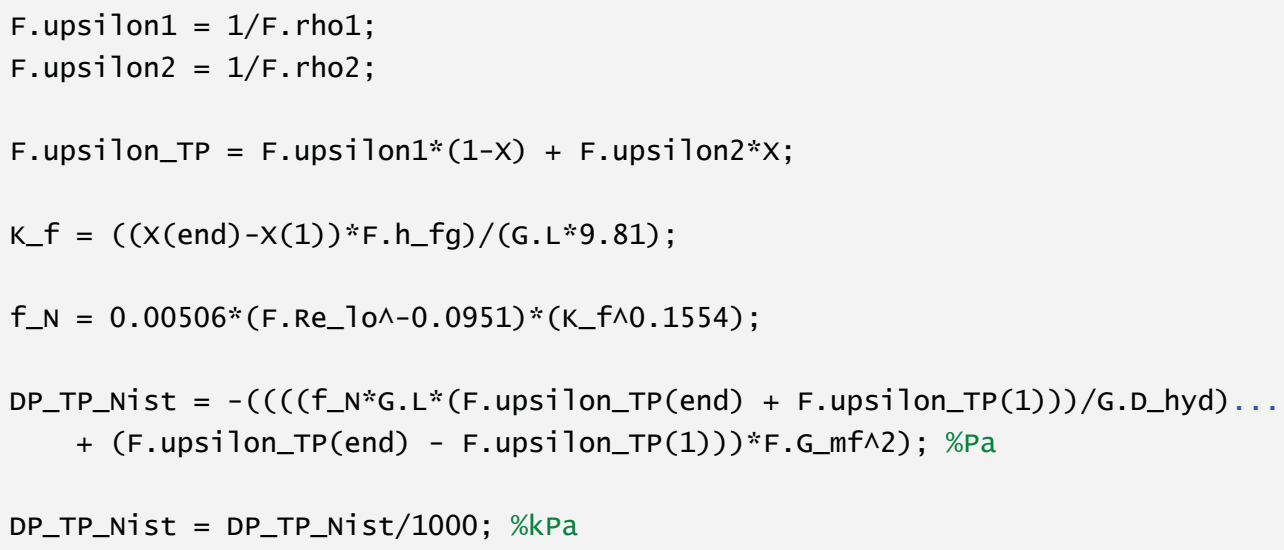

Published with MATLAB® R2014a

\section{Appendix M - MATLAB Accelerational Pressure Drop}

Accelerational Pressure - Zivi

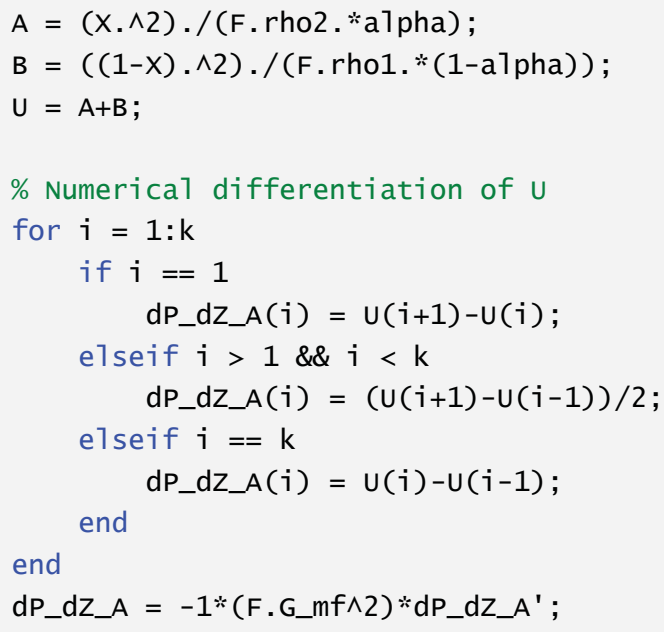

Published with MATLAB® R2014a 


\section{Appendix N - MATLAB Gravitational Pressure Drop}

Gravitational Pressure

alpha $=(1+((1-X) \cdot / X) *(F \cdot r h o 2 / F \cdot r h o 1) \wedge(2 / 3)) \cdot \wedge-1 ;$

dP_dz_G = -1.*(alpha.*F.rho2 + (1-alpha).*F.rho1)*F.gx;

Published with MATLAB® R2014a

\section{Appendix O - Simulation of Experimental comparisons for H-IF cases}

Table of Values

Table 14: Simulation Predictions for the new experimental runs with the shorter test section

\begin{tabular}{|c|c|c|c|c|c|c|c|c|}
\hline \multirow{3}{*}{ Case } & $\dot{M}_{L_{i n}}[\mathbf{g} / \mathbf{s}]$ & $\dot{M}_{V_{i n}}[\mathrm{~kg} / \mathrm{s}]$ & \multicolumn{3}{|c|}{$q_{40}^{\prime \prime}\left[\mathrm{W} / \mathrm{m}^{\wedge} 2\right]$} & \multicolumn{3}{|c|}{ DP_total [kPa] } \\
\hline & \multirow{2}{*}{ Kand } & \multirow{2}{*}{ Kand } & \multicolumn{3}{|c|}{ Kand } & \multicolumn{3}{|c|}{ Kand } \\
\hline & & & cb & nb & tp & $\mathrm{Fr}$ & LM & NIST \\
\hline 3 & 3 & 1 & 6543 & 2139 & 6543 & -2 & -2 & -2 \\
\hline 5 & 2 & 1 & 5237 & 2213 & 5237 & -1 & -1 & -1 \\
\hline \multirow{3}{*}{ Case } & $\dot{M}_{L_{i n}}[\mathrm{~g} / \mathrm{s}]$ & $\dot{M}_{V_{i n}}[\mathrm{~kg} / \mathrm{s}]$ & & ${ }_{0}[\mathrm{~W} / \mathrm{n}$ & & & total & \\
\hline & \multirow{2}{*}{ KM } & \multirow{2}{*}{ KM } & \multicolumn{3}{|c|}{ KM } & \multicolumn{3}{|c|}{ KM } \\
\hline & & & cb & $\mathrm{nb}$ & tp & $\mathrm{Fr}$ & LM & NIST \\
\hline 3 & 1 & 1 & 8426 & 1652 & 8587 & -2 & -2 & -3 \\
\hline 5 & 1 & 1 & 6076 & 1661 & 6299 & -1 & -1 & -2 \\
\hline \multirow{2}{*}{ Case } & $\dot{M}_{L_{\text {in }}}[\mathrm{g} / \mathrm{s}]$ & $\dot{M}_{V_{i n}}[\mathrm{~kg} / \mathrm{s}]$ & \multicolumn{3}{|c|}{$q^{\prime \prime}{ }_{40}\left[W / m^{\wedge} 2\right]$} & \multicolumn{3}{|c|}{ DP_total [kPa] } \\
\hline & \multicolumn{8}{|c|}{ Experimental Values } \\
\hline 3 & $\mathrm{~N} / \mathrm{A}$ & $\mathrm{N} / \mathrm{A}$ & \multicolumn{3}{|c|}{4890} & \multicolumn{3}{|c|}{6.38} \\
\hline 5 & $\mathrm{~N} / \mathrm{A}$ & N/A & \multicolumn{3}{|c|}{1560} & \multicolumn{3}{|c|}{4.15} \\
\hline
\end{tabular}




\section{Charts}

\section{Quality}

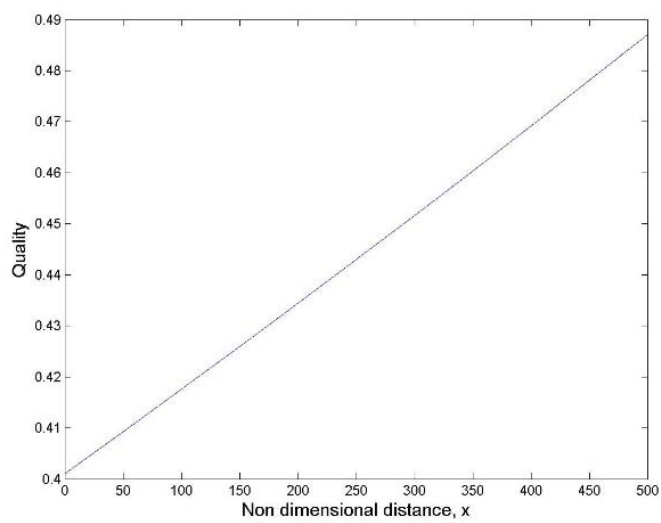

Figure 46: Case 3 Kandlikar

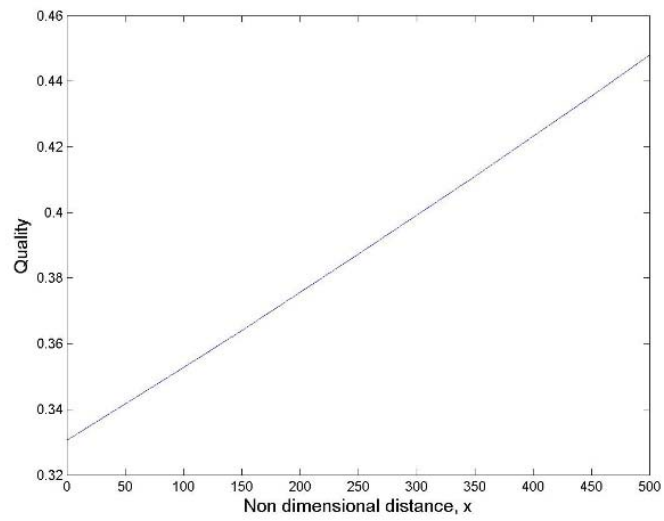

Figure 48: Case 5 Kandlikar

\section{Mass Flow Rate}

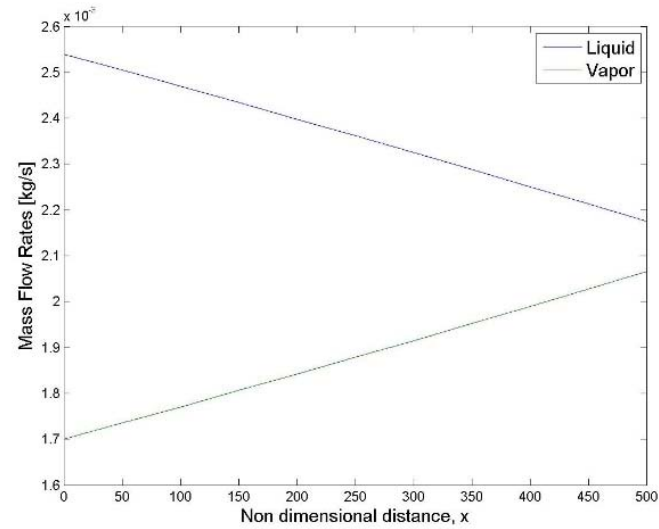

Figure 50: Case 3 Kandlikar

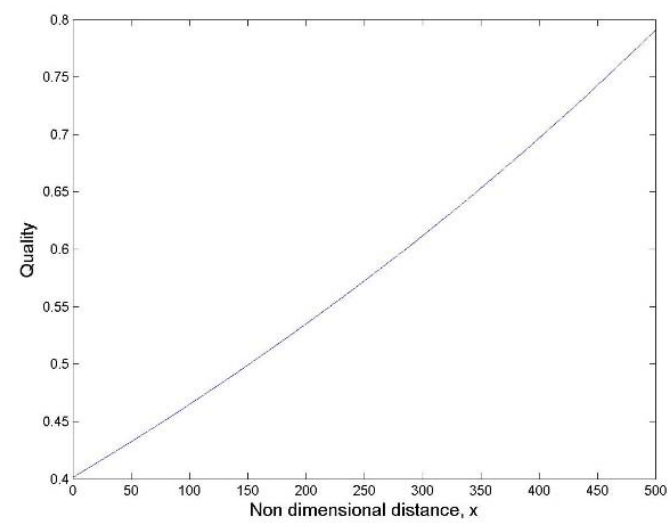

Figure 47: Case 3 Kim \& Mudawar

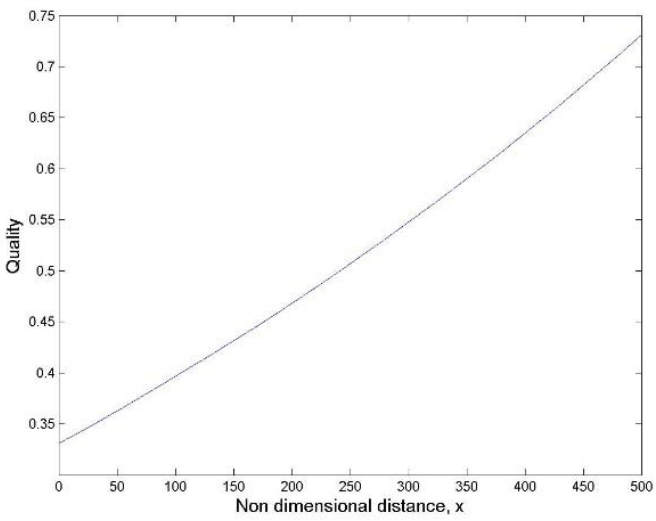

Figure 49: Case 5 Kim \& Mudawar

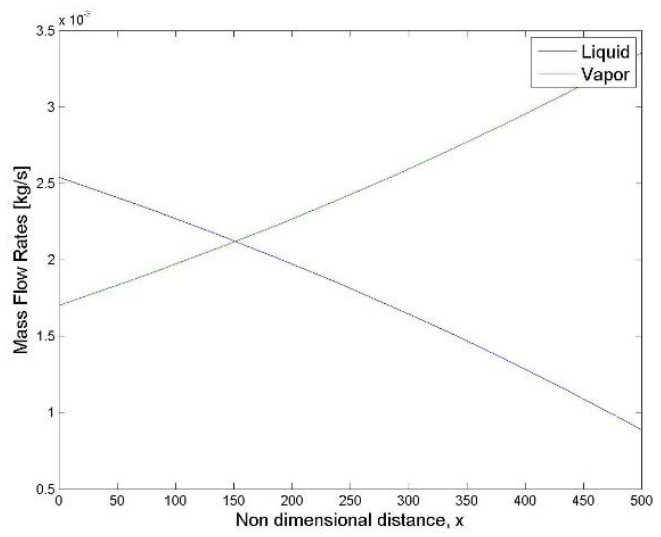

Figure 51: Case $3 \mathrm{Kim} \&$ Mudawar 


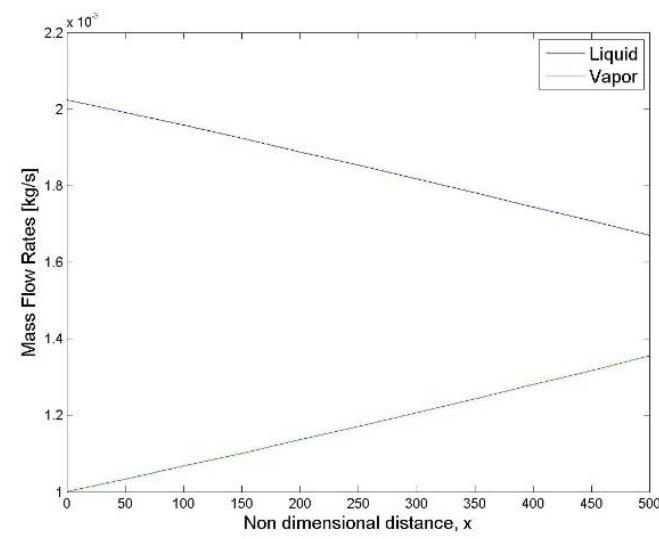

Figure 52: Case 5 Kandlikar

\section{$\underline{\mathrm{HTC}}$}

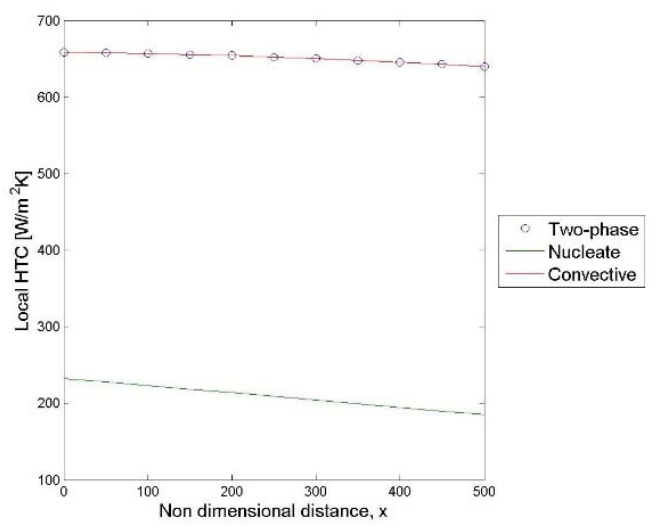

Figure 54: Case 3 Kandlikar

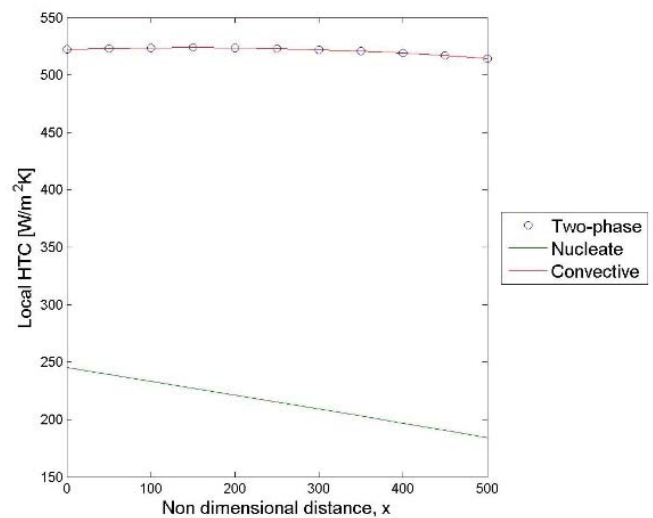

Figure 56: Case 5 Kandlikar

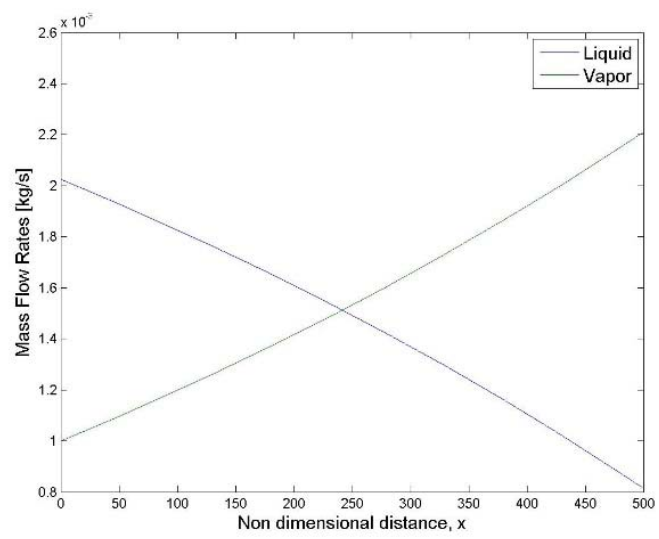

Figure 53: Case $5 \mathrm{Kim}$ and Mudawar

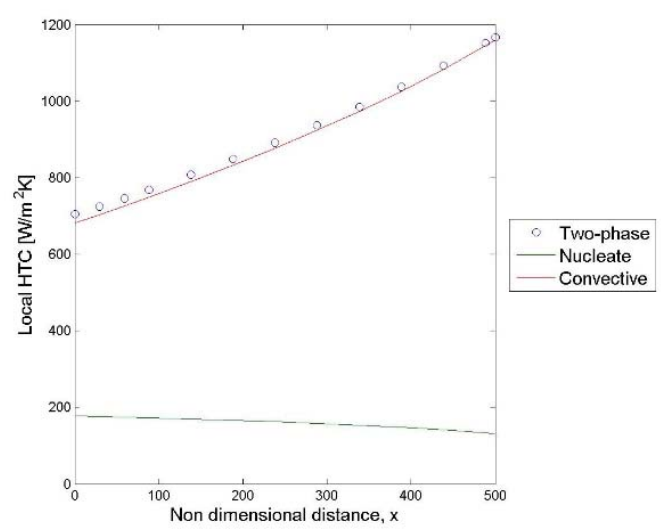

Figure 55: Case $3 \mathrm{Kim} \&$ Mudawar

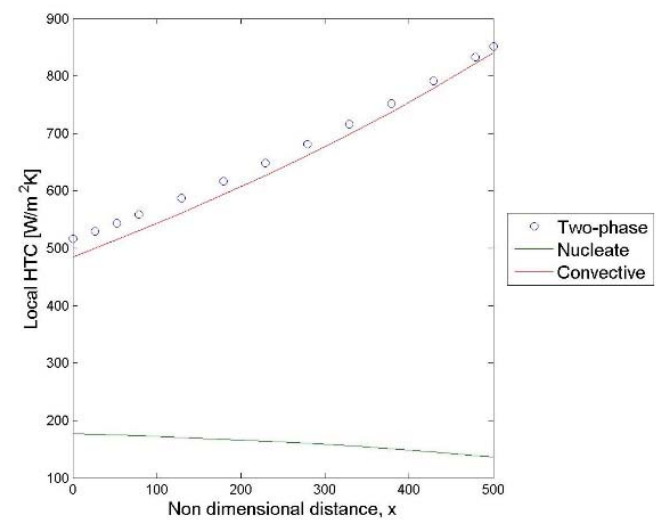

Figure 57: Case 5 Kim \& Mudawar 


\section{$\underline{\text { Heat Flux }}$}

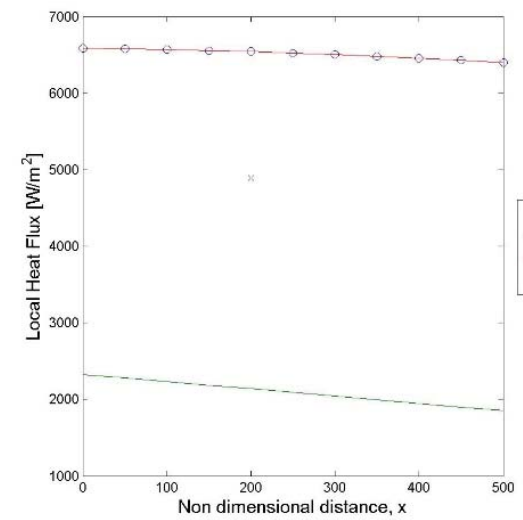

Figure 58: Case 3 Kandlikar

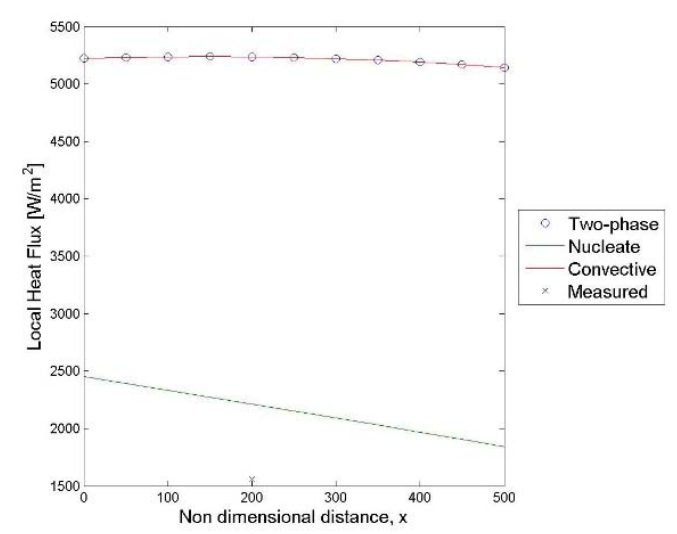

Figure 60: Case 5 Kandlikar

\section{Test Section Pressure Drop}

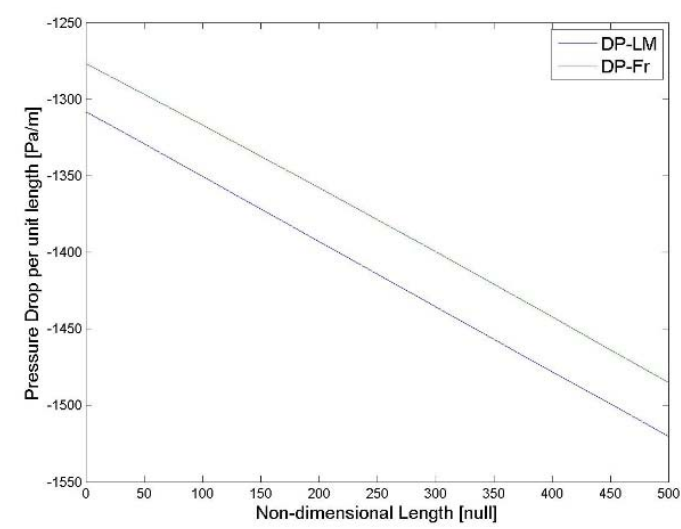

Figure 62: Case 3 Kandlikar

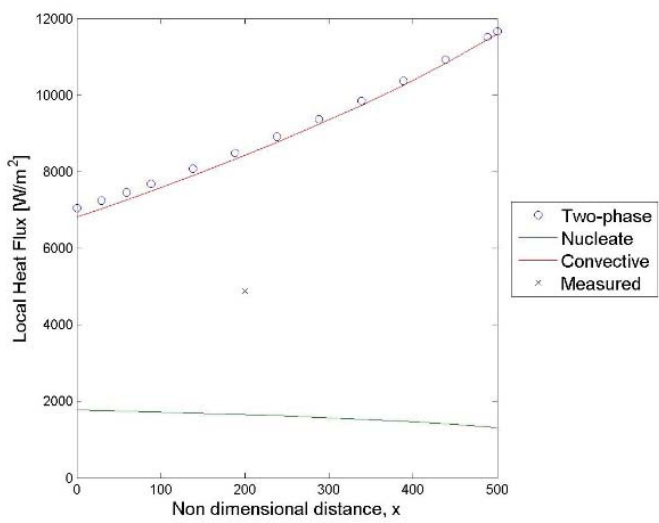

Figure 59: Case $3 \mathrm{Kim}$ and Mudawar

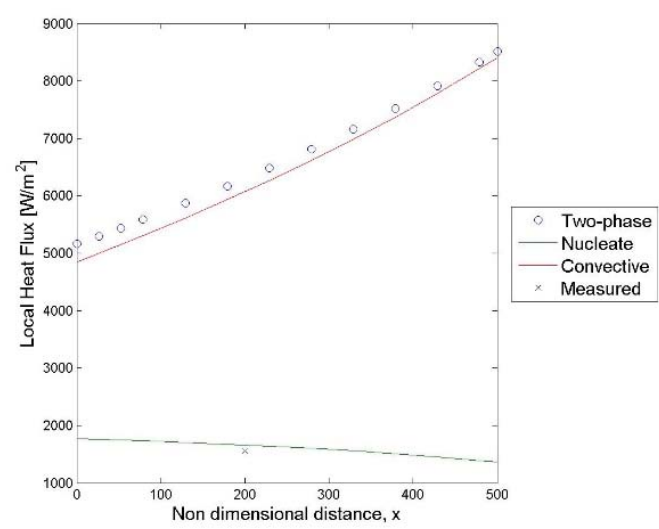

Figure 61: Case $5 \mathrm{Kim}$ and Mudawar

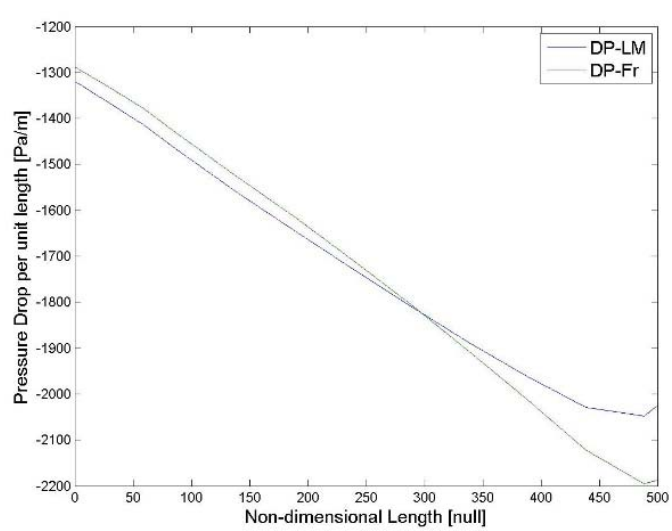

Figure 63: Case $3 \mathrm{Kim}$ and Mudawar 


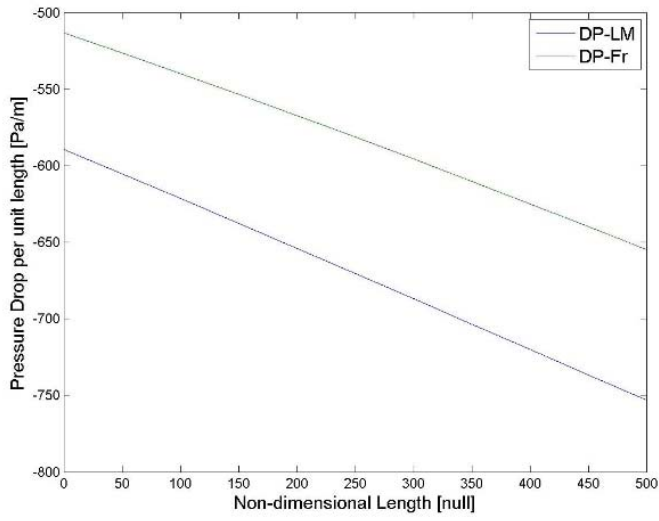

Figure 64: Case 5 Kandlikar

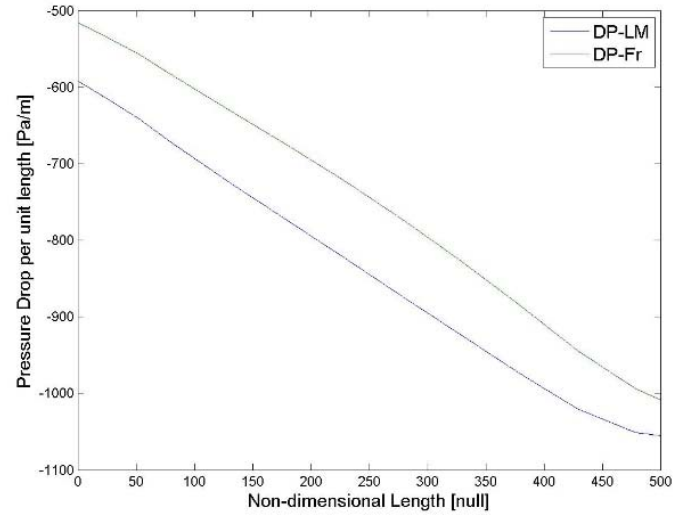

Figure 65: Case 5 Kim \& Mudawar 


\section{Appendix P}

\section{Test Matrix Extra information}

\section{Charts}

\section{Flow Quality}
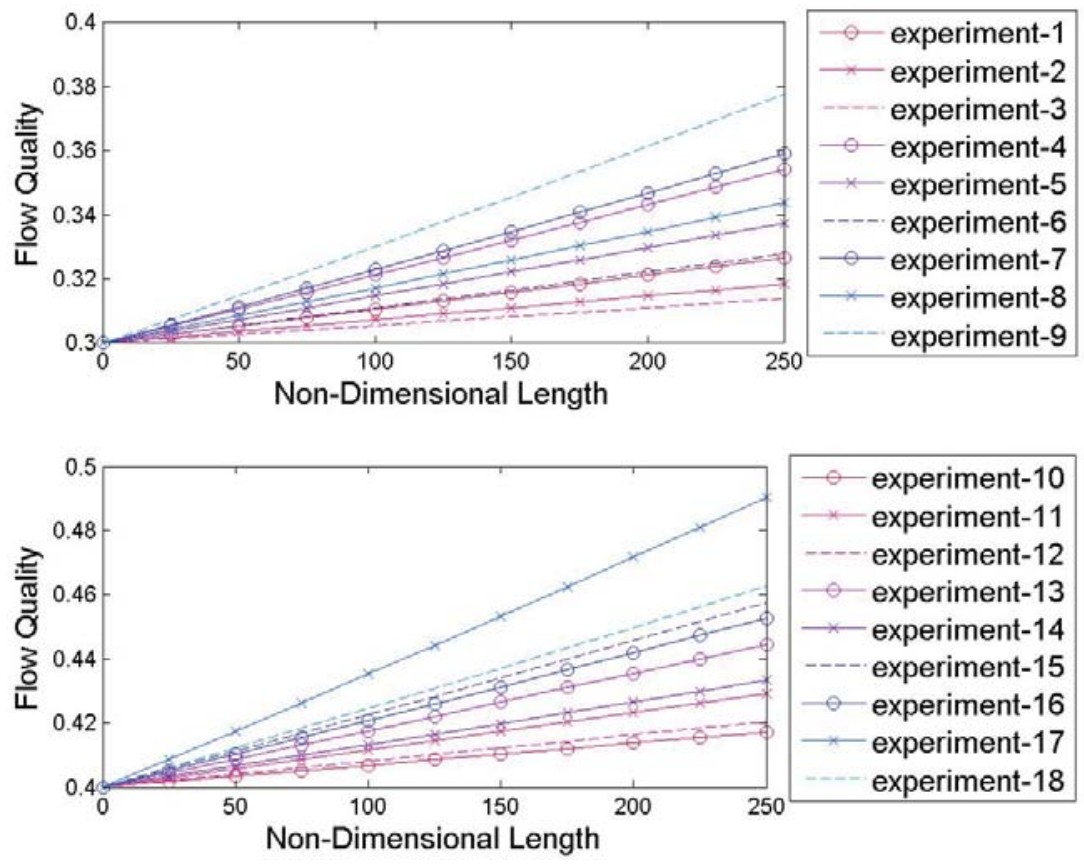

Figure 66: Flow Quality using Kandlikar 

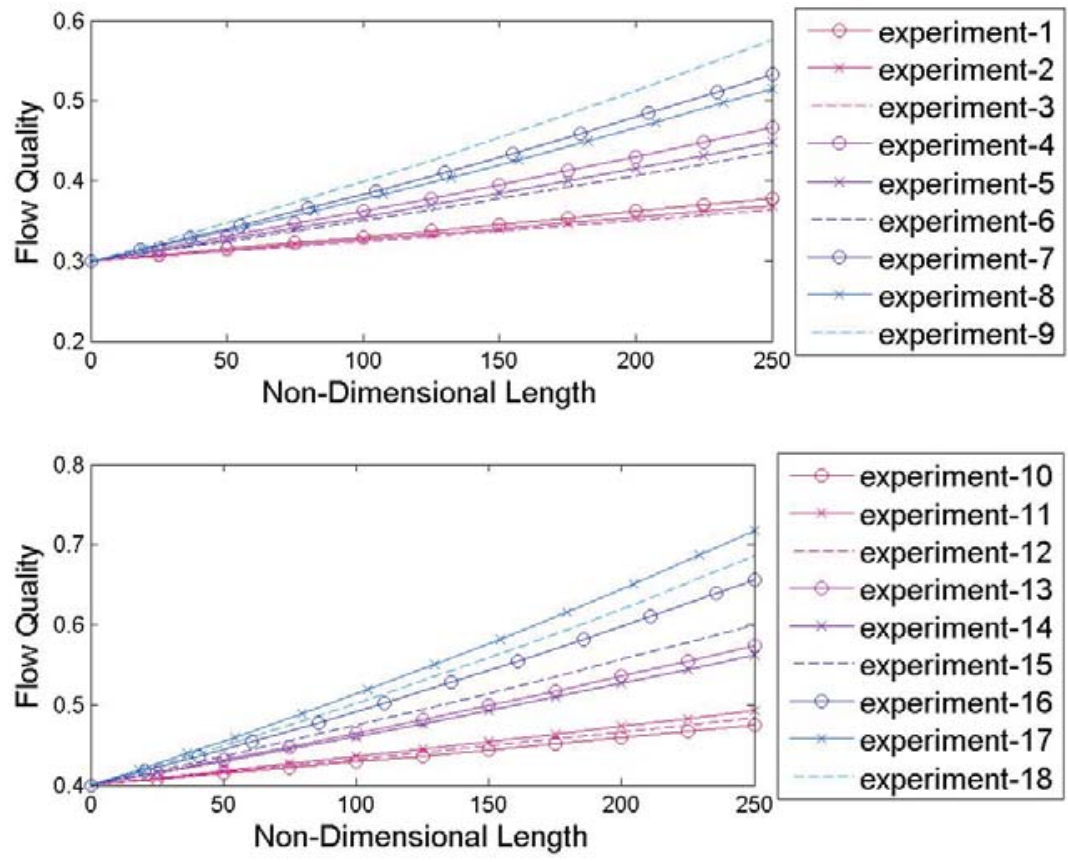

Figure 67: Flow Quality using Kim \& Mudawar

\section{Mass Flow Rate}
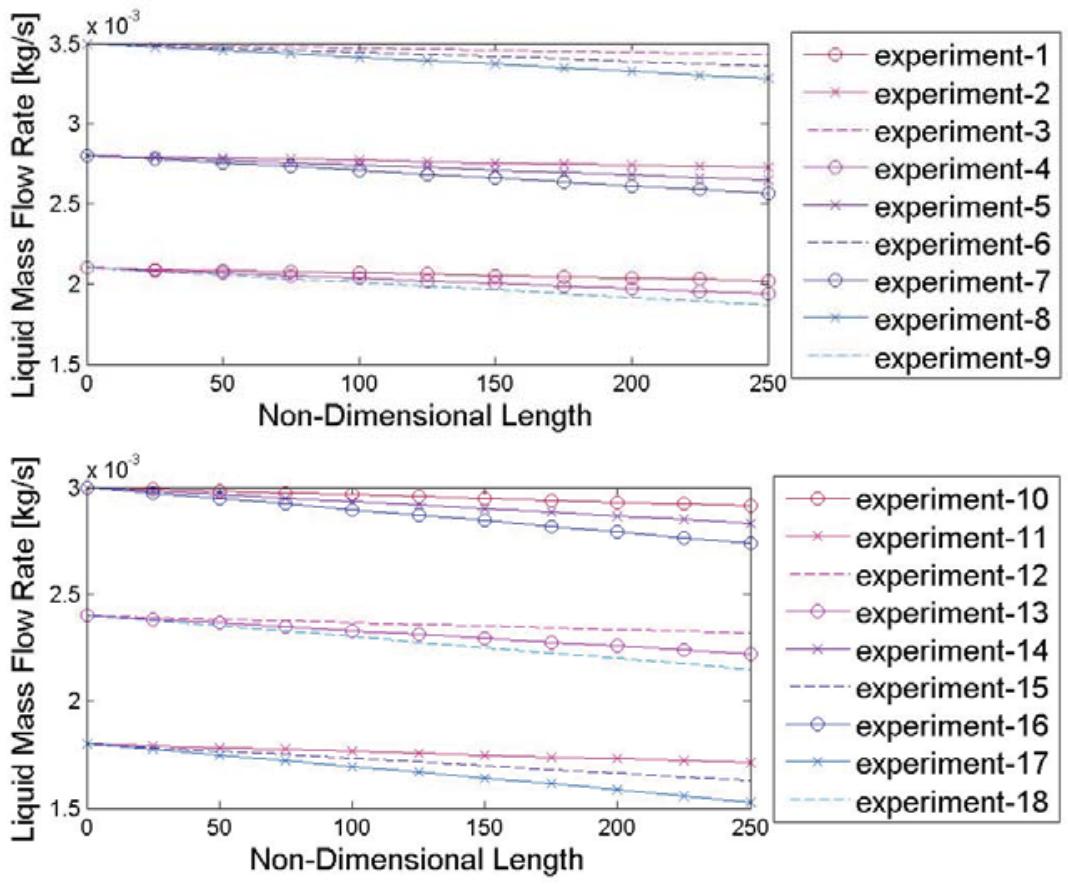

Figure 68: Liquid Mass Flow Rate using Kandlikar 

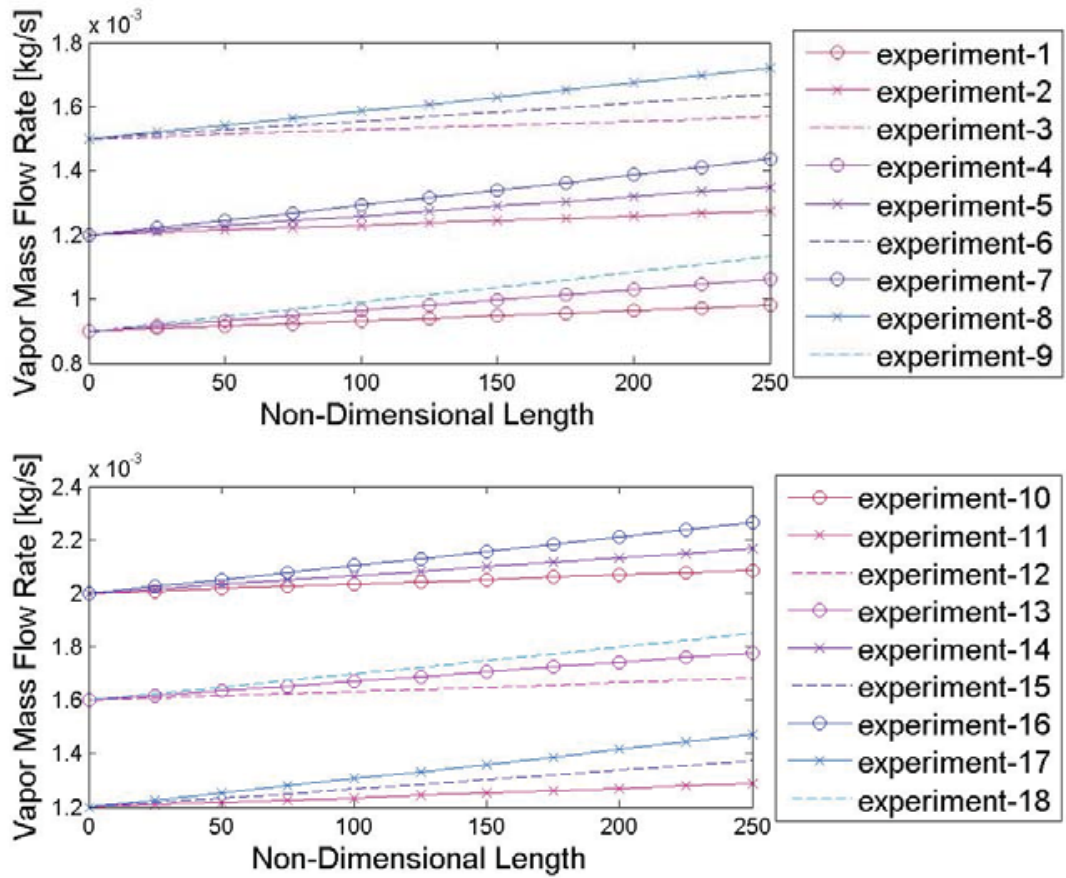

Figure 69: Vapor Mass Flow Rate using Kandlikar
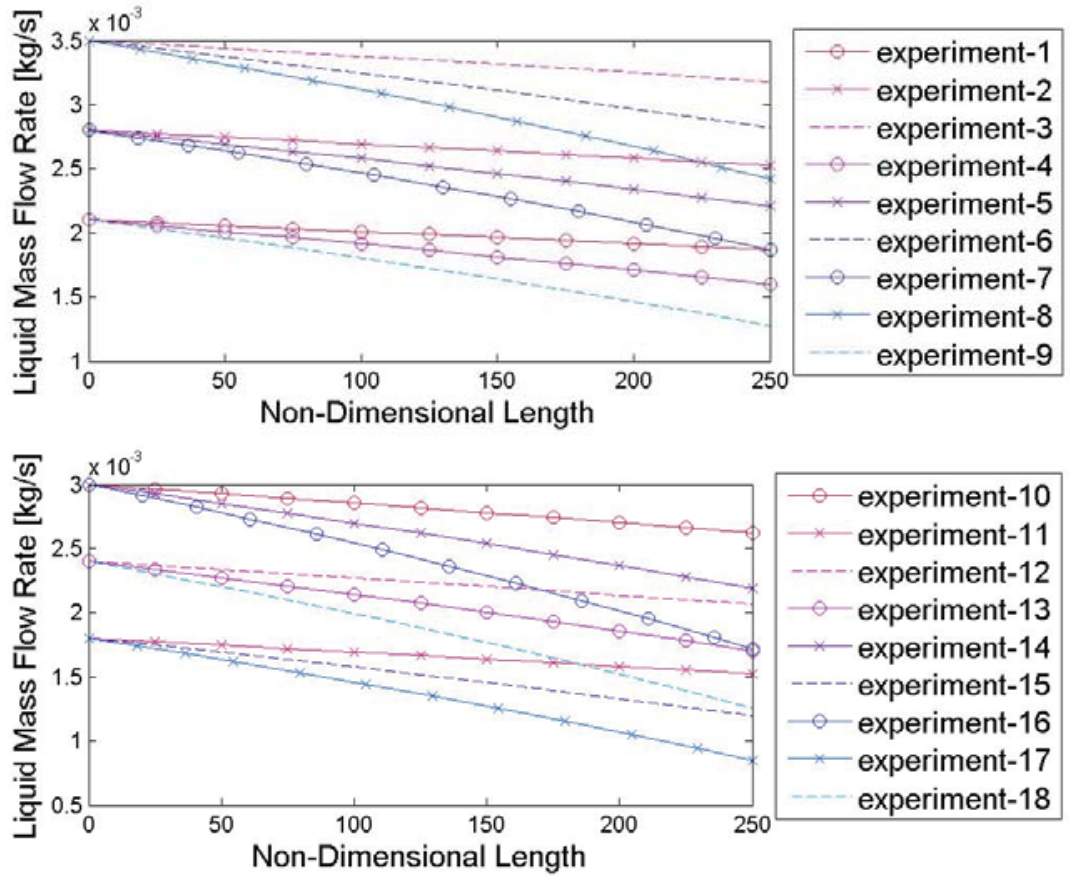

Figure 70: Liquid Mass Flow Rate using Kim \& Mudawar 

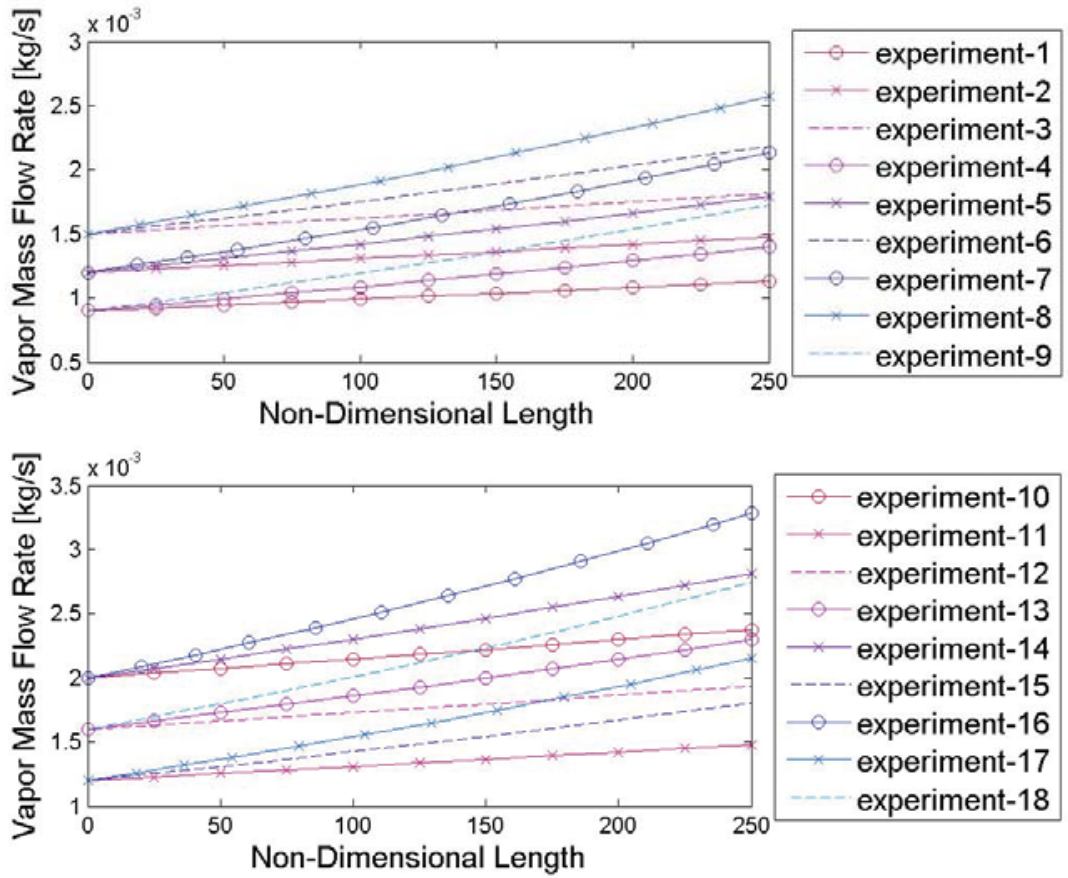

Figure 71: Vapor Mass Flow Rate using Kim \& Mudawar

\section{HTC}
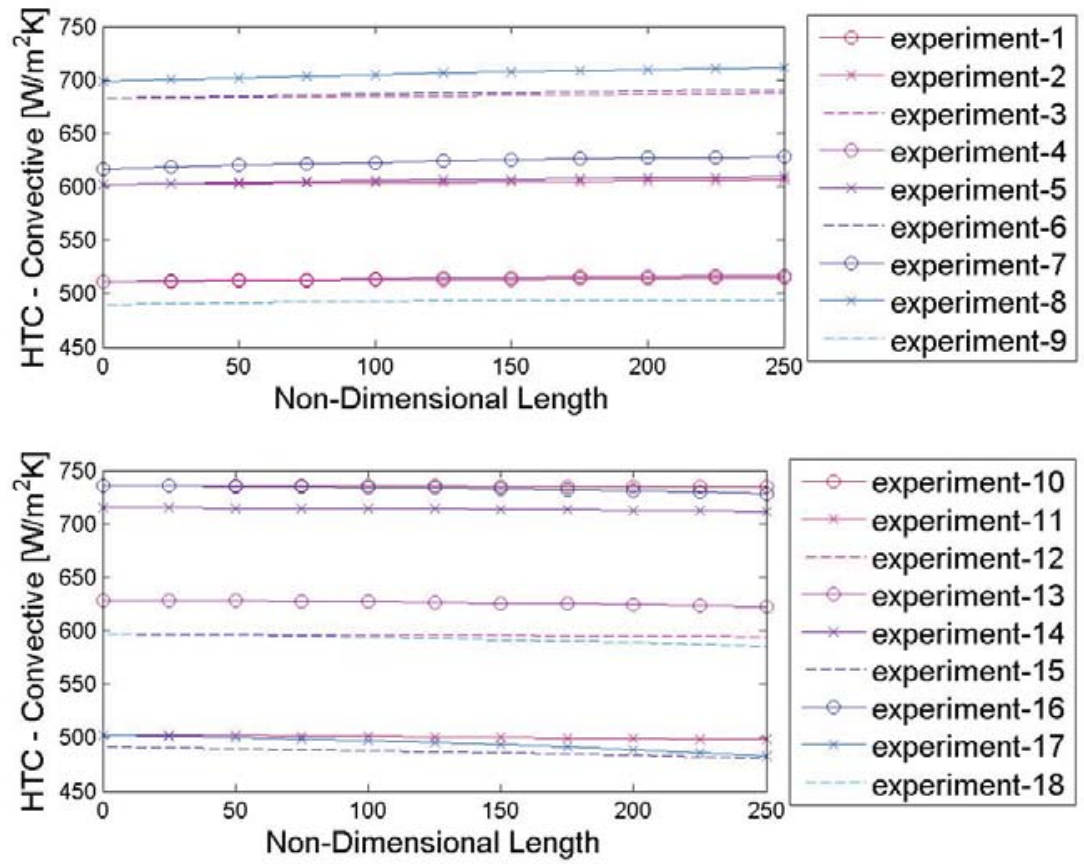

Figure 72: Convective HTC using Kandlikar 

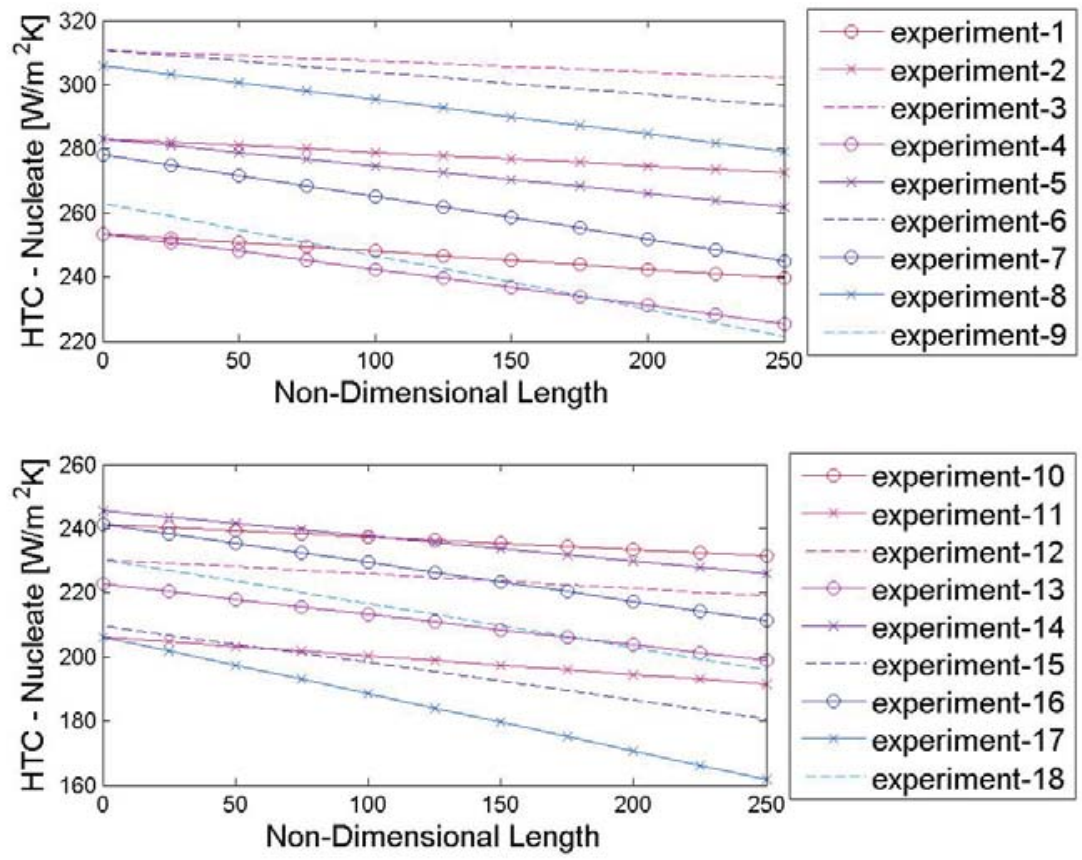

Figure 73: Nucleate HTC using Kandlikar
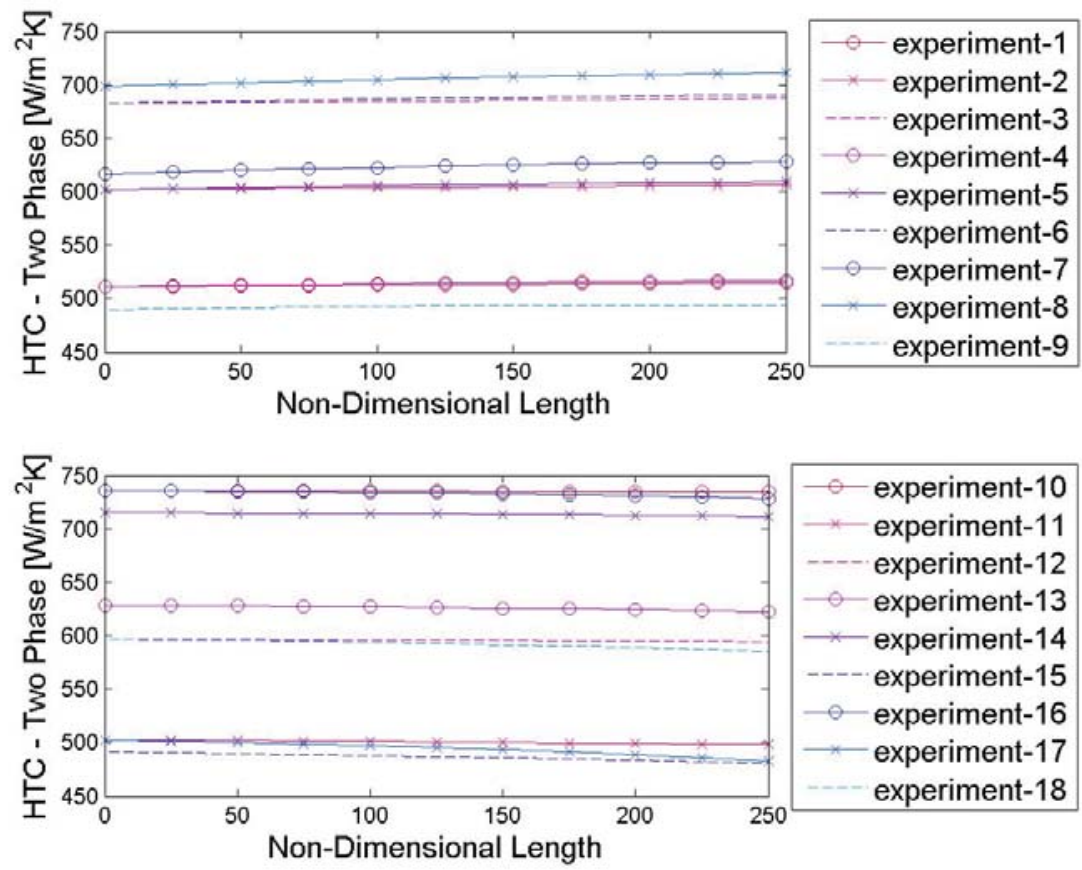

Figure 74: Two-Phase HTC using Kandlikar 

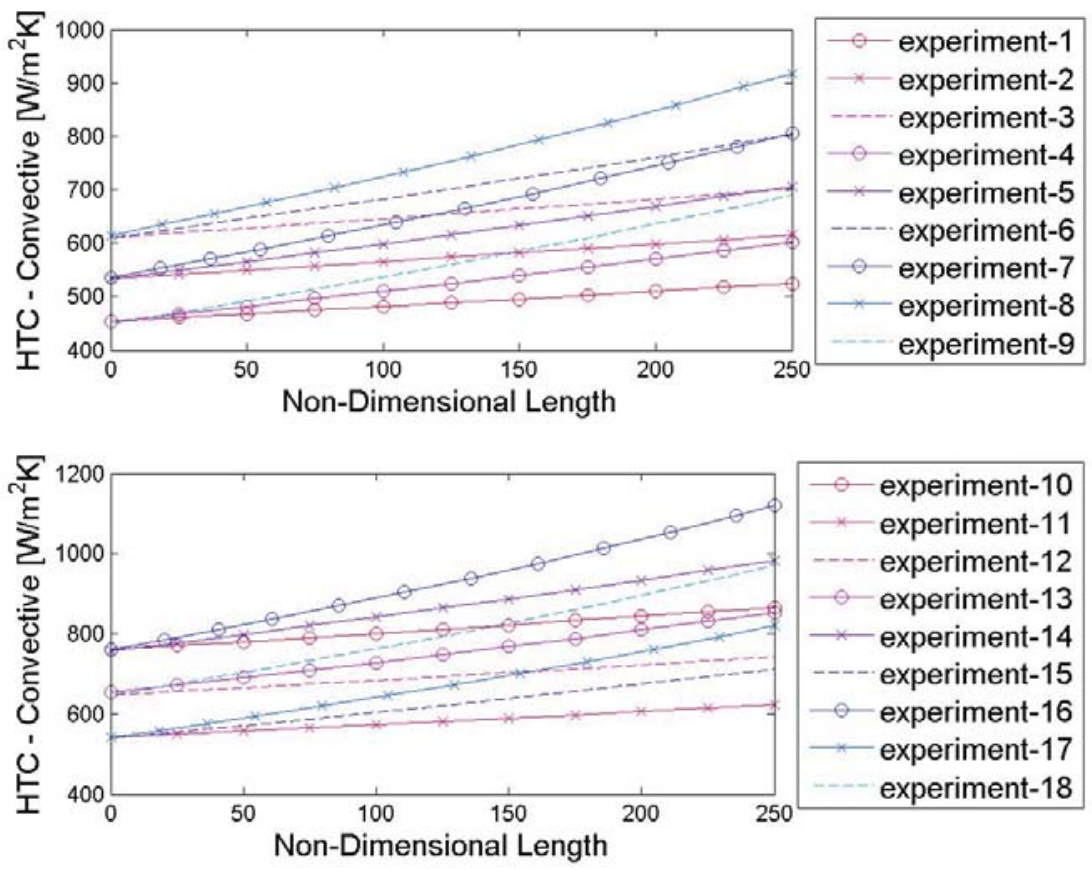

Figure 75: Convective HTC using Kim \& Mudawar
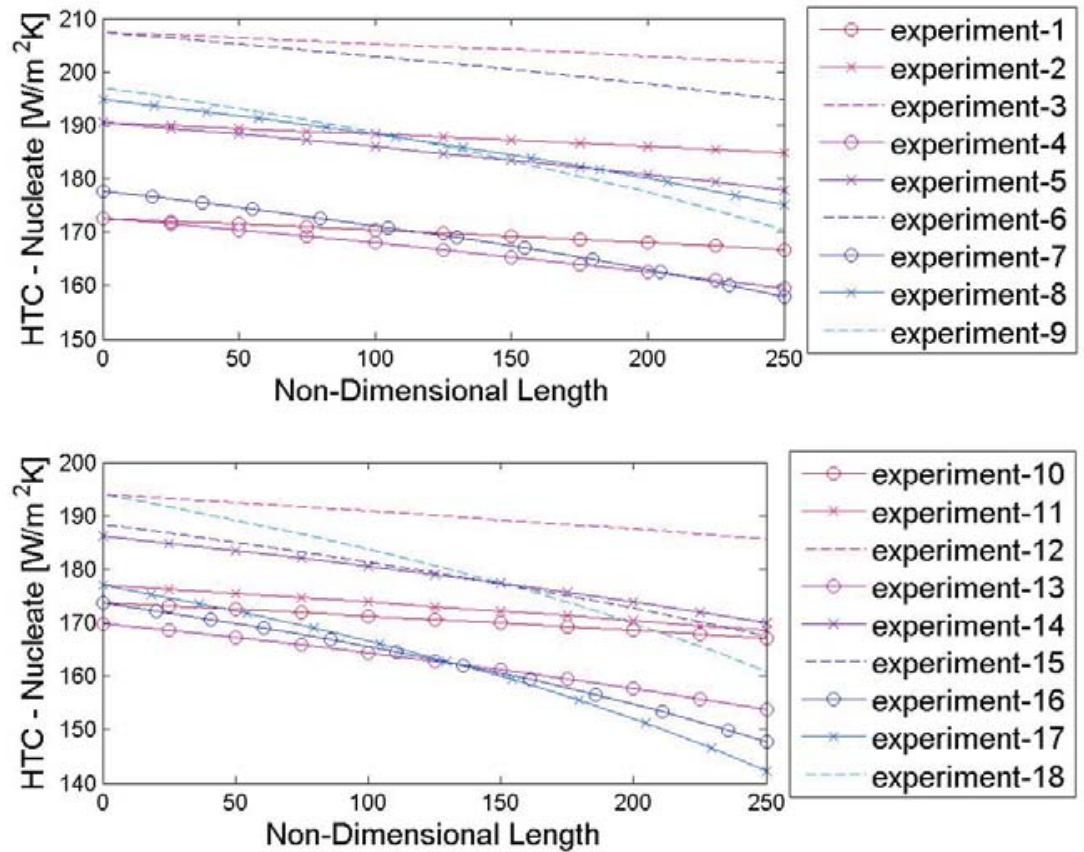

Figure 76: Nucleate HTC using Kim \& Mudawar 

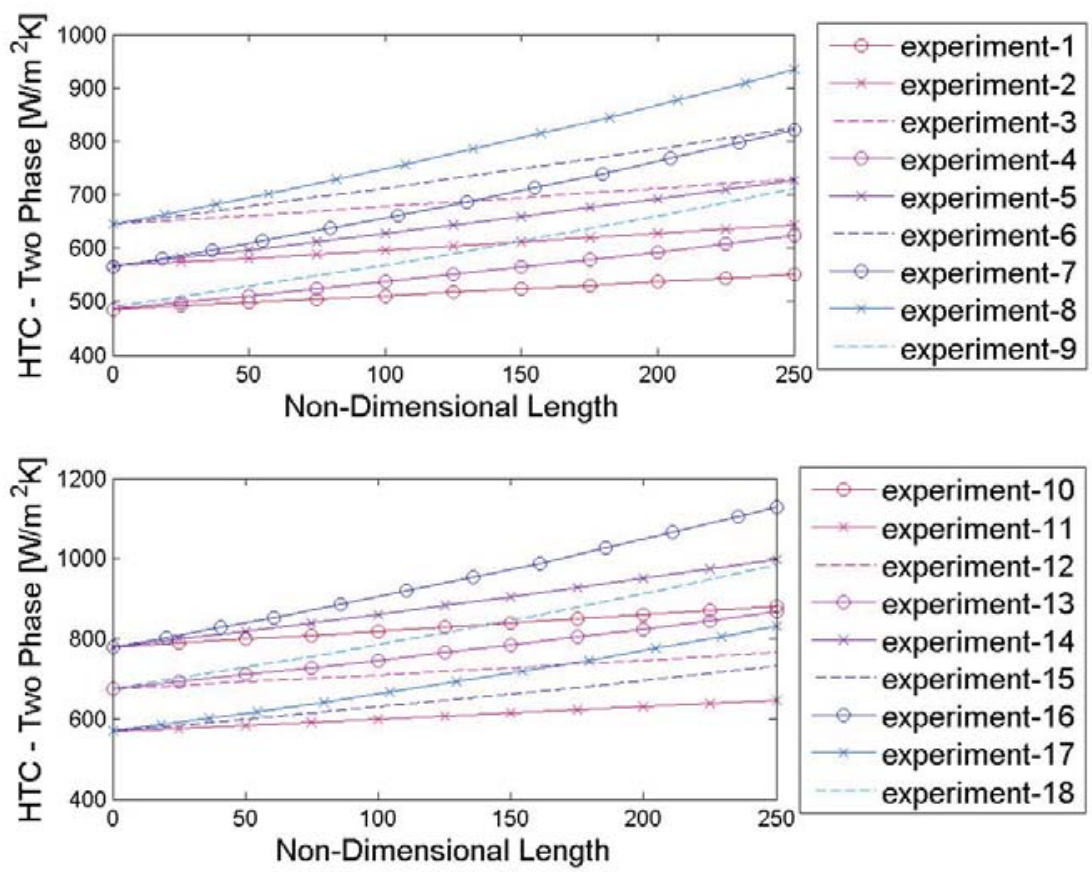

Figure 77: Two-Phase HTC using Kim \& Mudawar

\section{$\underline{\text { Heat Flux }}$}
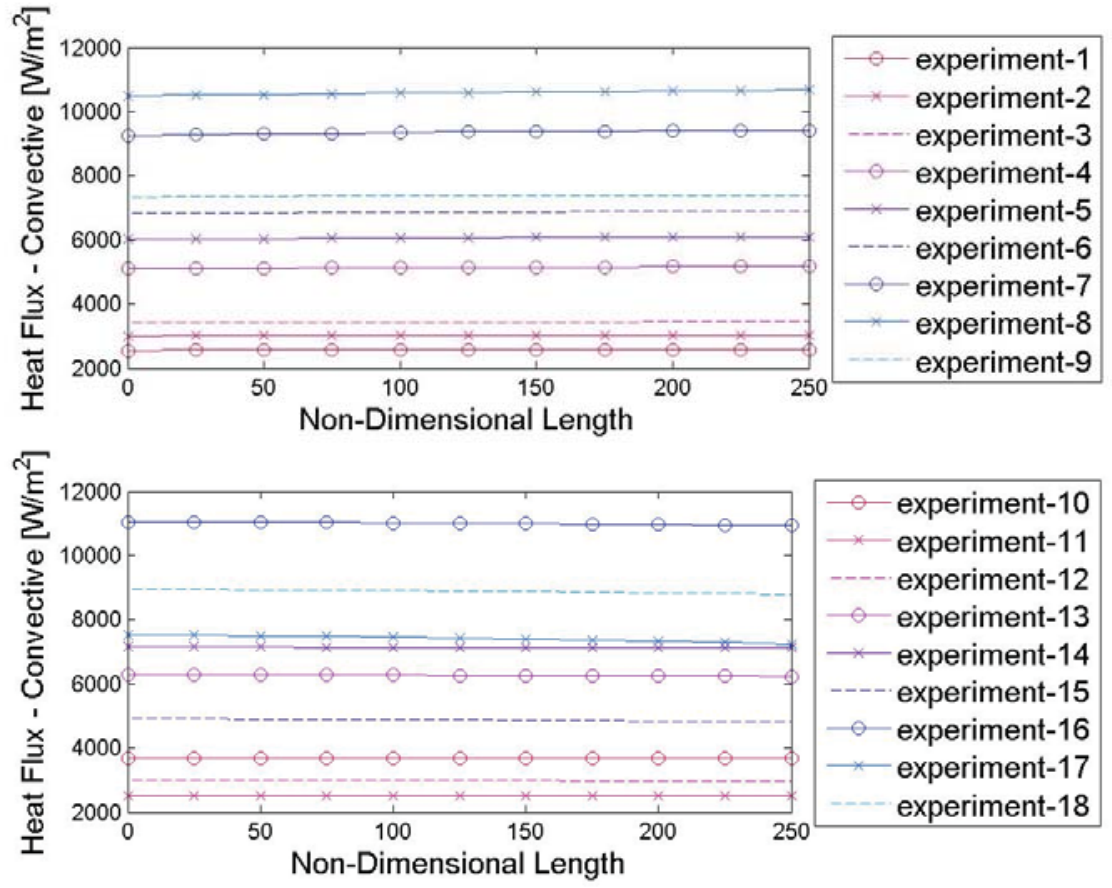

Figure 78: Convective Heat Flux using Kandlikar 

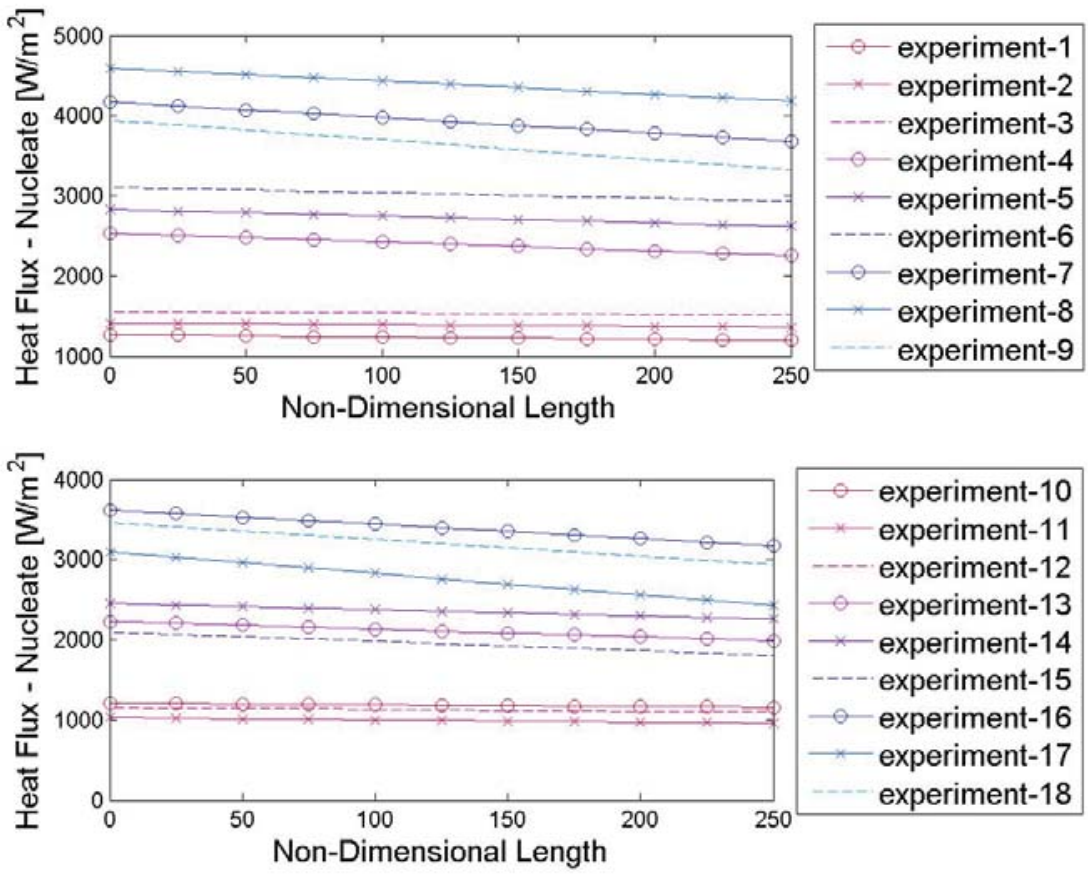

Figure 79: Nucleate Heat Flux using Kandlikar

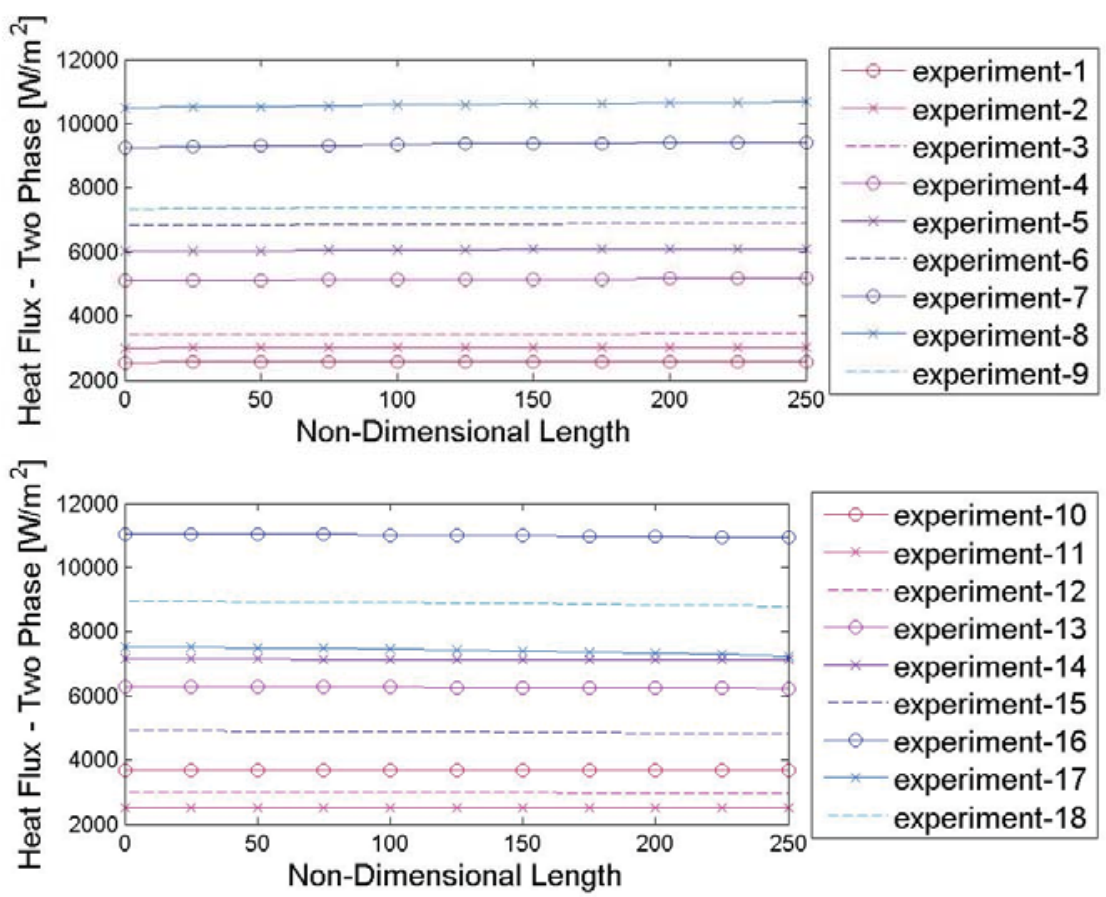

Figure 80: Two-Phase Heat flux using Kandlikar 

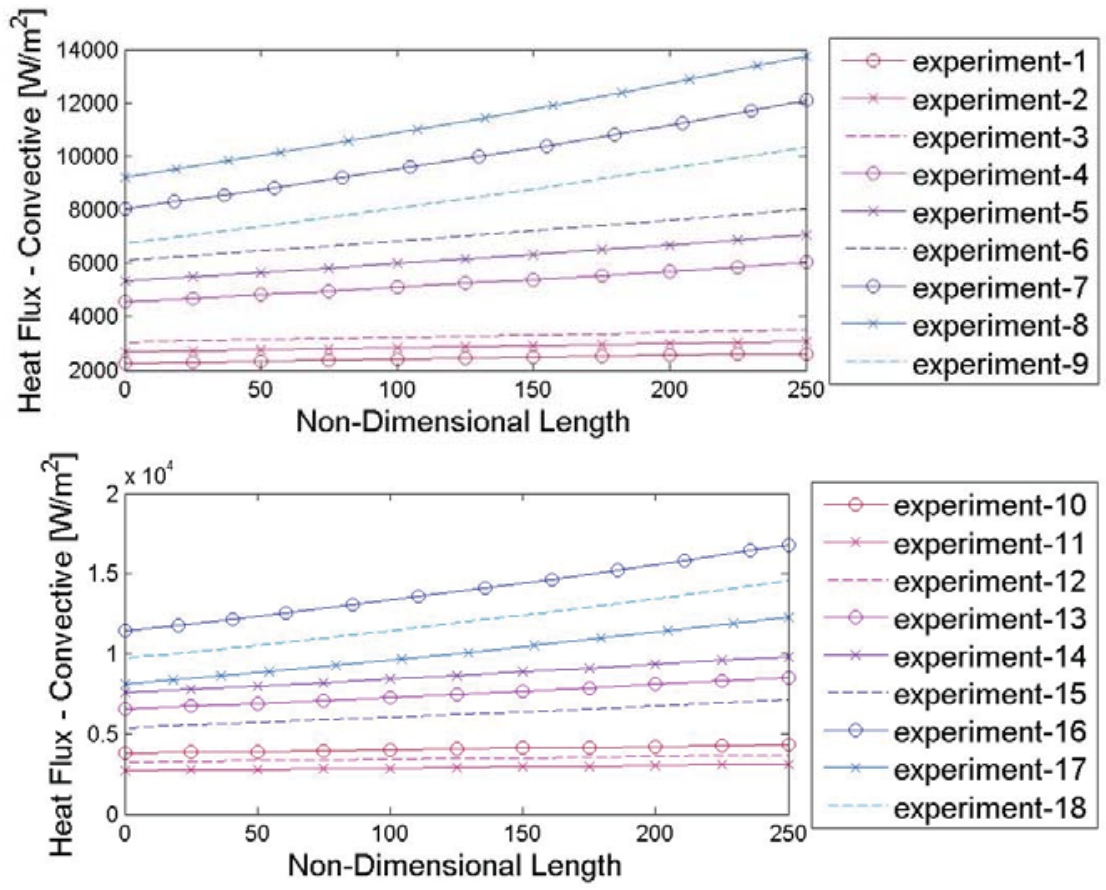

Figure 81: Convective Heat Flux using Kim \& Mudawar
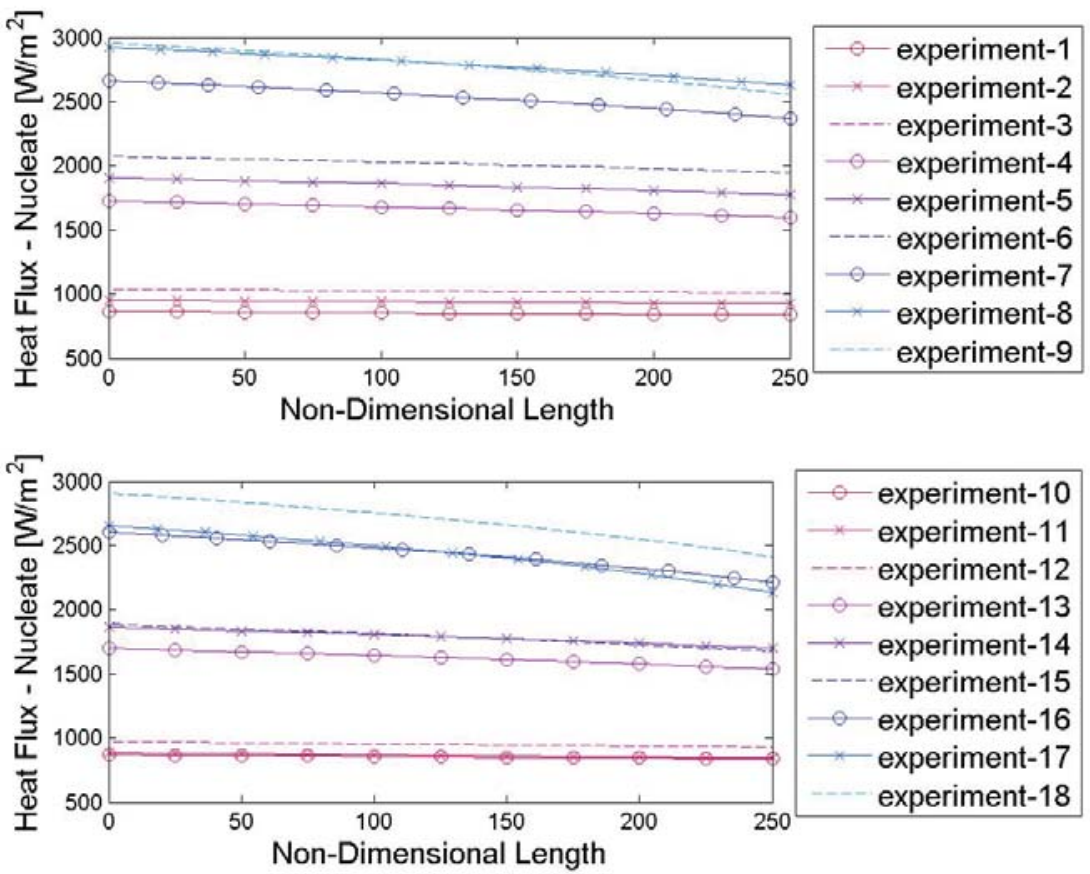

Figure 82: Nucleate Heat Flux using Kim \& Mudawar 

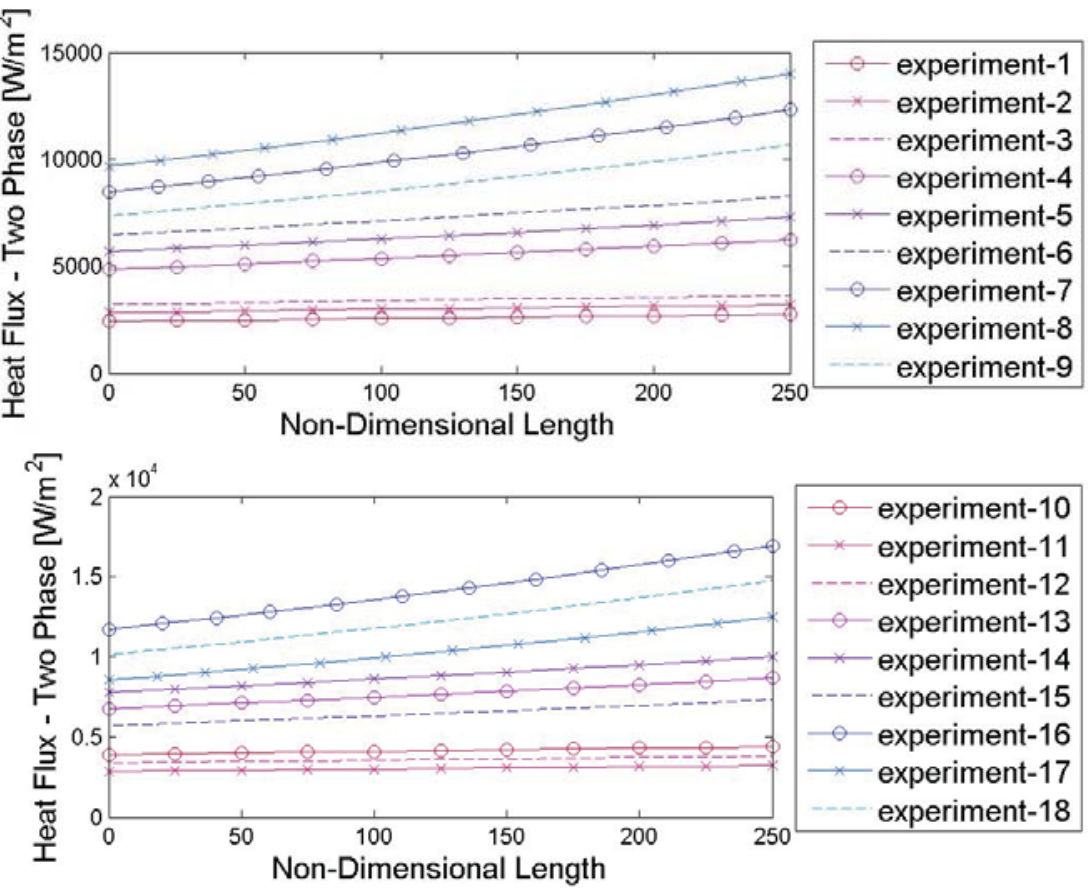

Figure 83: Two-Phase Heat Flux using Kim \& Mudawar

\section{Test Section Pressure Drop}
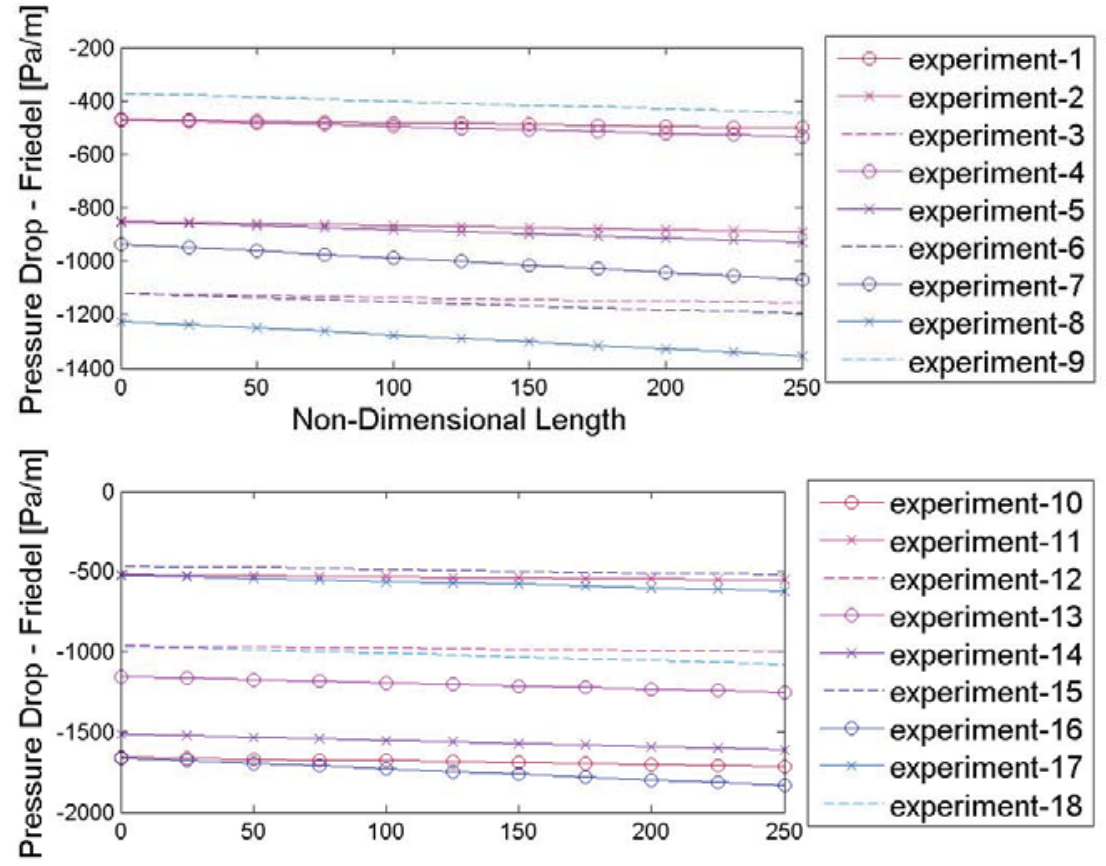

Figure 84: Friedel Pressure Drop using Kandlikar 

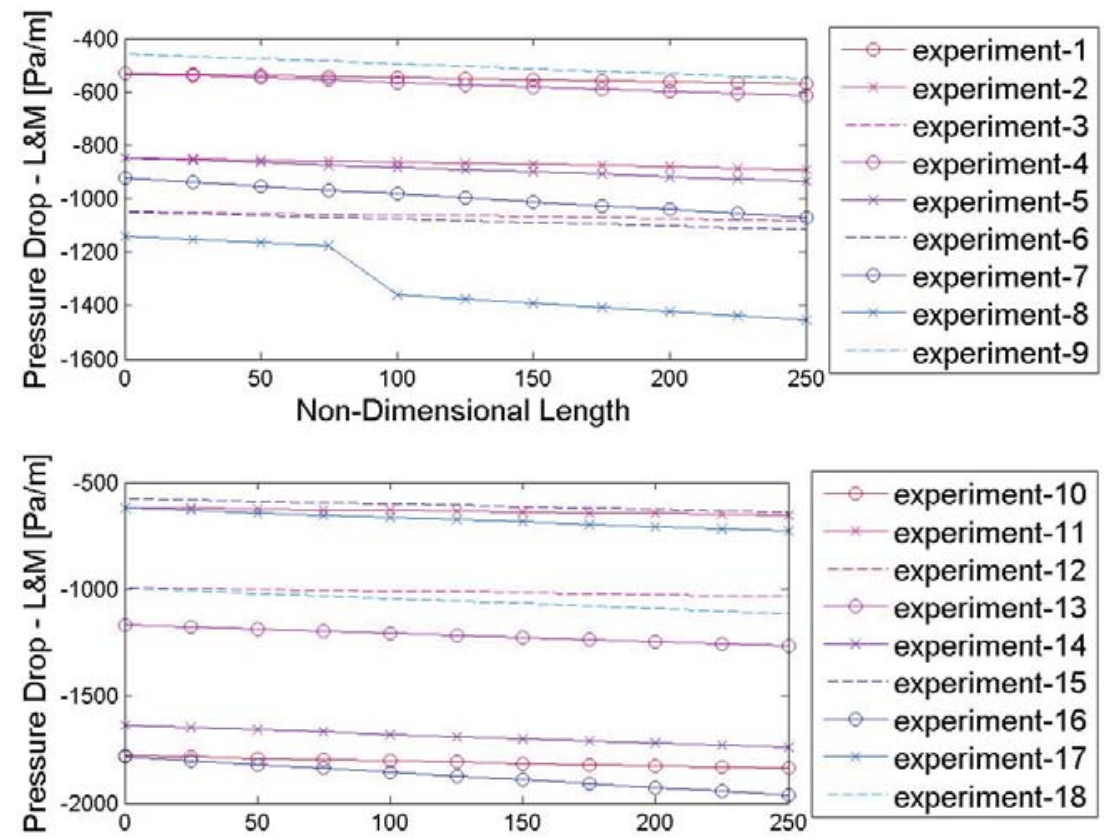

Figure 85: Lockhart \& Martinelli Pressure Drop using Kandlikar

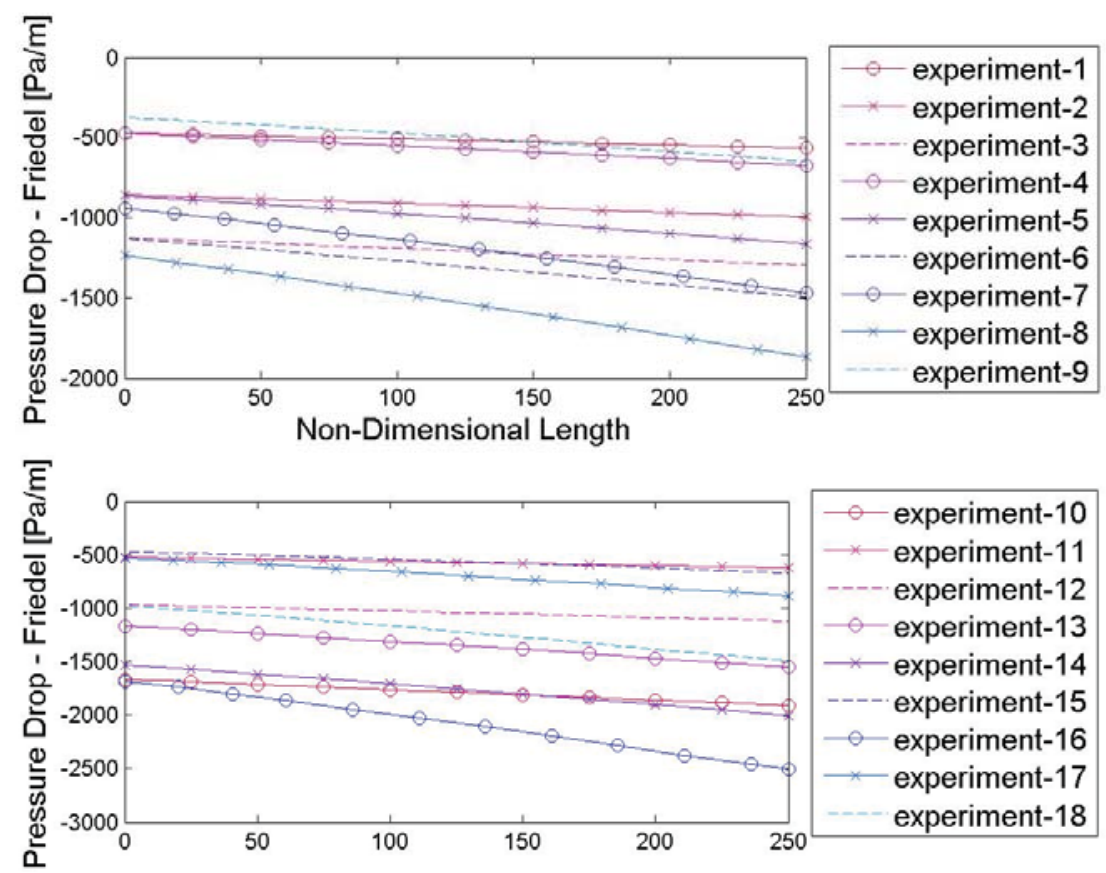

Figure 86: Friedel Pressure Drop using Kim \& Mudawar 

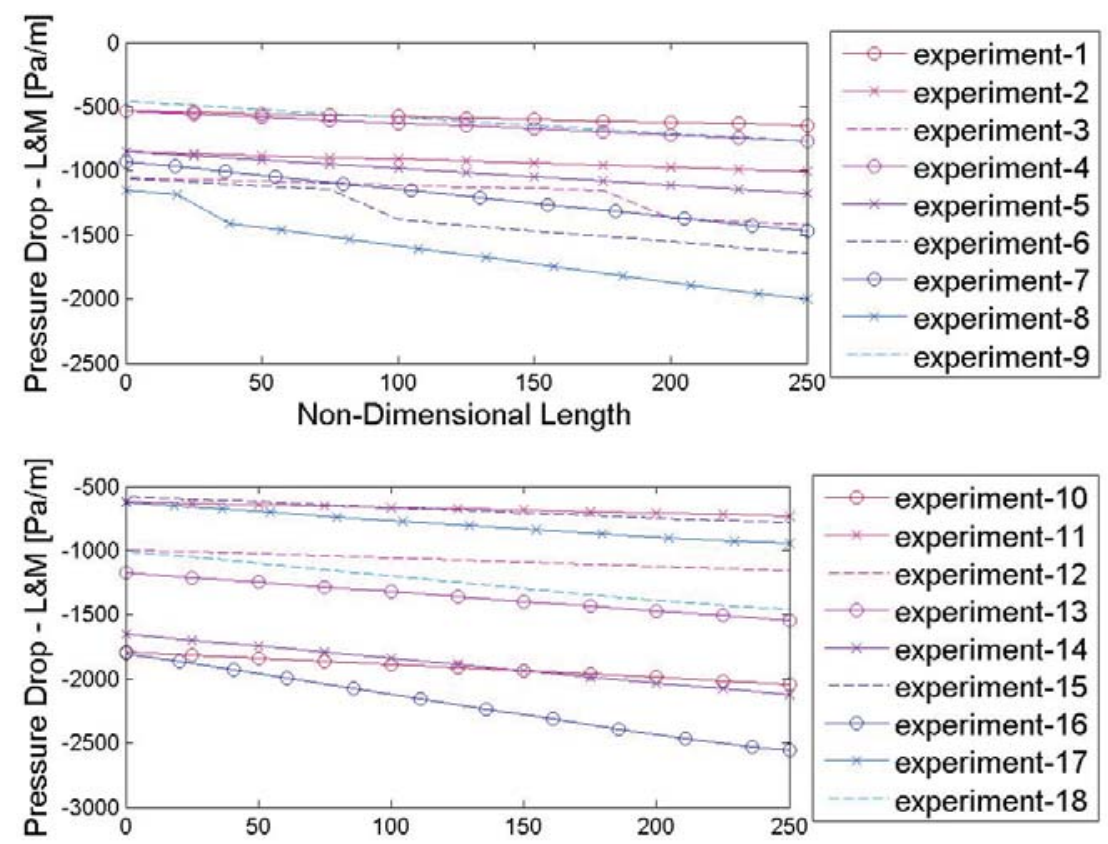

Figure 87: Lockhart \& Martinelli Pressure Drop using Kim \& Mudawar 